\title{
A multicentre randomised controlled trial assessing the costs and benefits of using structured information and analysis of women's preferences in the management of menorrhagia
}
ADM Kennedy
MJ Sculpher
A Coulter
N Dwyer
$M$ Rees
SIlorsley
D Cowley
C Kidson
C Kirwin
C Naish
$\mathrm{K}$ Bidgood
J Cullimore
R Kerr-Wilson
KR Abrams
G Stirrat

Health Technology Assessment NHS R\&D HTA Programme 


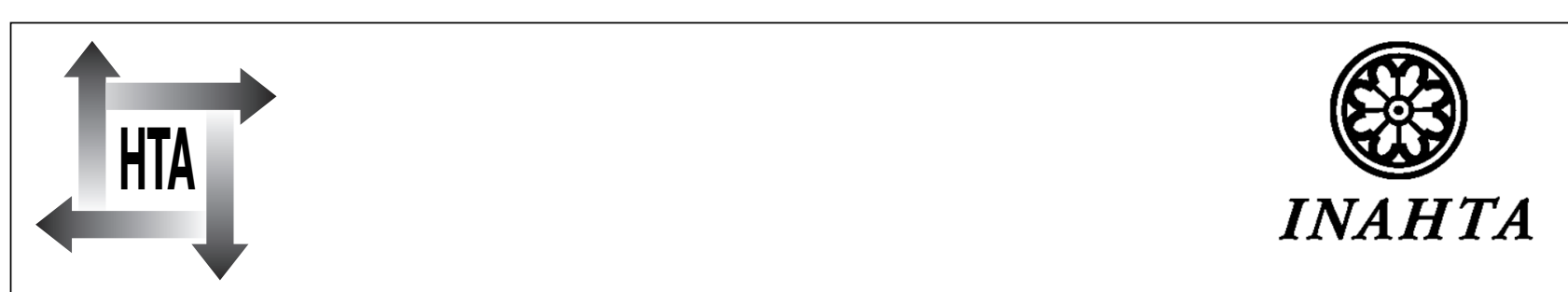

How to obtain copies of this and other HTA Programme reports.

An electronic version of this publication, in Adobe Acrobat format, is available for downloading free of charge for personal use from the HTA website (http://www.hta.ac.uk). A fully searchable CD-ROM is also available (see below).

Printed copies of HTA monographs cost $£ 20$ each (post and packing free in the UK) to both public and private sector purchasers from our Despatch Agents.

Non-UK purchasers will have to pay a small fee for post and packing. For European countries the cost is $£ 2$ per monograph and for the rest of the world $£ 3$ per monograph.

You can order HTA monographs from our Despatch Agents:

- fax (with credit card or official purchase order)

- post (with credit card or official purchase order or cheque)

- phone during office hours (credit card only).

Additionally the HTA website allows you either to pay securely by credit card or to print out your order and then post or fax it.

Contact details are as follows:

HTA Despatch

c/o Direct Mail Works Ltd

4 Oakwood Business Centre

Downley, HAVANT PO9 2NP, UK

Email: orders@hta.ac.uk

Tel: 02392492000

Fax: 02392478555

Fax from outside the UK: +442392478555

NHS libraries can subscribe free of charge. Public libraries can subscribe at a very reduced cost of $£ 100$ for each volume (normally comprising 30-40 titles). The commercial subscription rate is $£ 300$ per volume. Please see our website for details. Subscriptions can only be purchased for the current or forthcoming volume.

\section{Payment methods}

Paying by cheque

If you pay by cheque, the cheque must be in pounds sterling, made payable to Direct Mail Works Ltd and drawn on a bank with a UK address.

Paying by credit card

The following cards are accepted by phone, fax, post or via the website ordering pages: Delta, Eurocard, Mastercard, Solo, Switch and Visa. We advise against sending credit card details in a plain email.

Paying by official purchase order

You can post or fax these, but they must be from public bodies (i.e. NHS or universities) within the UK. We cannot at present accept purchase orders from commercial companies or from outside the UK.

\section{How do I get a copy of HTA on CD?}

Please use the form on the HTA website (www.hta.ac.uk/htacd.htm). Or contact Direct Mail Works (see contact details above) by email, post, fax or phone. HTA on CD is currently free of charge worldwide.

The website also provides information about the HTA Programme and lists the membership of the various committees. 


\section{A multicentre randomised controlled trial assessing the costs and benefits of using structured information and analysis of women's preferences in the management of menorrhagia}
ADM Kennedy ${ }^{1 *}$ S Horsley ${ }^{6}$
K Bidgood ${ }^{8}$
MJ Sculpher ${ }^{2}$
D Cowley ${ }^{7}$
J Cullimore ${ }^{6}$
A Coulter ${ }^{3}$
N Dwyer ${ }^{4}$
$M$ Rees $^{5}$
C Kidson ${ }^{8}$
R Kerr-Wilson?
C Kirwin
KR Abrams ${ }^{10}$
C Naish ${ }^{5}$
$\mathrm{G} \mathrm{Stirrat}^{7}$

1 Health Economics Research Group, Brunel University, Uxbridge, UK

2 Centre for Health Economics, University of York, UK

3 Picker Institute Europe, Oxford, UK

4 Weston General Hospital,Weston-super-Mare, UK

5 John Radcliffe Hospital, Oxford, UK

6 Princess Margaret Hospital, Swindon, UK

7 St Michael's Hospital, Bristol, UK

8 Taunton and Somerset Hospital, Taunton, UK

9 St Paul's Hospital, Cheltenham, UK

${ }^{10}$ Department of Epidemiology \& Public Health, University of Leicester, UK

* Corresponding author

Declared competing interests of the authors: none

Published February 2003

This report should be referenced as follows:

Kennedy ADM, Sculpher MJ, Coulter A, Dwyer N, Rees M, Horsley S, et al. A multicentre randomised controlled trial assessing the costs and benefits of using structured information and analysis of women's preferences in the management of menorrhagia. Health Technol Assess 2003;7(8).

Health Technology Assessment is indexed in Index Medicus/MEDLINE and Excerpta Medical EMBASE. Copies of the Executive Summaries are available from the NCCHTA website (see opposite).

Related publication:

Kennedy ADM, Sculpher MJ, Coulter A, Dwyer N, Rees M, Abrams KR, et al. Effects of decision aids for menorrhagia on treatment choices, health outcomes, and costs. JAMA 2002;288:2701-8. 


\section{NHS R\&D HTA Programme}

$\mathrm{T}$ he NHS R\&D Health Technology Assessment (HTA) Programme was set up in 1993 to ensure that high-quality research information on the costs, effectiveness and broader impact of health technologies is produced in the most efficient way for those who use, manage and provide care in the NHS.

Initially, six HTA panels (pharmaceuticals, acute sector, primary and community care, diagnostics and imaging, population screening, methodology) helped to set the research priorities for the HTA Programme. However, during the past few years there have been a number of changes in and around NHS R\&D, such as the establishment of the National Institute for Clinical Excellence (NICE) and the creation of three new research programmes: Service Delivery and Organisation (SDO); New and Emerging Applications of Technology (NEAT); and the Methodology Programme.

This has meant that the HTA panels can now focus more explicitly on health technologies ('health technologies' are broadly defined to include all interventions used to promote health, prevent and treat disease, and improve rehabilitation and long-term care) rather than settings of care. Therefore the panel structure has been redefined and replaced by three new panels: Pharmaceuticals; Therapeutic Procedures (including devices and operations); and Diagnostic Technologies and Screening.

The HTA Programme continues to commission both primary and secondary research. The HTA Commissioning Board, supported by the National Coordinating Centre for Health Technology Assessment (NCCHTA), will consider and advise the Programme Director on the best research projects to pursue in order to address the research priorities identified by the three HTA panels.

The research reported in this monograph was funded as project number 93/18/12.

The views expressed in this publication are those of the authors and not necessarily those of the HTA Programme or the Department of Health. The editors wish to emphasise that funding and publication of this research by the NHS should not be taken as implicit support for any recommendations made by the authors.

\section{Criteria for inclusion in the HTA monograph series}

Reports are published in the HTA monograph series if (1) they have resulted from work commissioned for the HTA Programme, and (2) they are of a sufficiently high scientific quality as assessed by the referees and editors.

Reviews in Health Technology Assessment are termed 'systematic' when the account of the search, appraisal and synthesis methods (to minimise biases and random errors) would, in theory, permit the replication of the review by others.

HTA Programme Director: Series Editors:

Managing Editors:

\section{Professor Kent Woods}

Professor Andrew Stevens, Dr Ken Stein, Professor John Gabbay, Dr Ruairidh Milne and Dr Chris Hyde Sally Bailey and Sarah Llewellyn Lloyd

The editors and publisher have tried to ensure the accuracy of this report but do not accept liability for damages or losses arising from material published in this report. They would like to thank the referees for their constructive comments on the draft document.

ISSN 1366-5278

(C) Queen's Printer and Controller of HMSO 2003

This monograph may be freely reproduced for the purposes of private research and study and may be included in professional journals provided that suitable acknowledgement is made and the reproduction is not associated with any form of advertising.

Applications for commercial reproduction should be addressed to The National Coordinating Centre for Health Technology Assessment, Mailpoint 728, Boldrewood, University of Southampton, Southampton, SO16 7PX, UK. 


\section{Contents}

\section{List of abbreviations}

\section{Executive summary}

\section{Background}

Menorrhagia

Information and preferences

in menorrhagia

\section{Development of the interventions:}

phase I

Introduction

Focus groups

Menorrhagia

Interventions

\section{Methods for phase II.}

Aims

Participants

Design

Protocol

Data collection

Outcomes

Covariates

Statistical methods

Sample size

4 Economic evaluation methods

Introduction

Cost analysis

Outcomes

Analysis

5 Results: baseline to post-consultation

Recruitment.

Baseline characteristics

Use of interventions

Satisfaction with the interventions

Post-consultation preferences

Change in preferences

Women's perceived knowledge

and satisfaction

6 Results: short-term follow-up

Response to follow-up.

Health status

Treatment undergone

Agreement between preferences and

treatments undergone

Satisfaction

7 Results: long-term follow-up

Response to follow-up.
Health status ............................................... 25

Treatments undergone ............................... 25

Agreement between preferences and

treatments undergone ................................ 27

Satisfaction ................................................... 27

8 Economic evaluation ................................ 29

Data availability ......................................... 29

Resource use ........................................ $\quad 29$

Costs ................................................. 29

Health outcomes.......................................... 32

Cost-effectiveness .................................... 32

Sensitivity analysis ........................................ 32

9 Discussion ................................................... 37

Conclusions .......................................... $\quad 38$

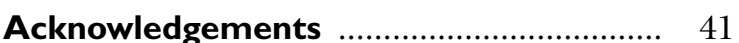

References ........................................ 43

Appendix 1 Expert advisory group for phase I

Appendix 2 The Bleeding Nuisance booklet and video

Appendix 3 Interview schedule ................ 51

Appendix 4 Interview Summary Form ..... 57

Appendix 5 Baseline questionnaire........... 59

Appendix 6 Fixed effect covariate pool for each analysis

Appendix 7 Fixed effect covariates included in each analysis

Appendix 8 Details of the multiple imputation procedures used to handle missing data in the economic evaluation ....

\section{Health Technology Assessment reports} published to date

Health Technology Assessment

Programme 



\section{List of abbreviations}

\begin{tabular}{ll|ll} 
ANOVA & analysis of variance & MI & multiple imputation \\
BCA & bias corrected and accelerated & OCP & oral contraceptive pill \\
CI & confidence interval & OR & odds ratio \\
D\&C & dilation and curettage & QALY & quality-adjusted life-year \\
EQ-5D & EuroQol-5 dimensions & RRR & relative risk ratio \\
IPMEN & information and preferences & SD & standard deviation \\
& in menorrhagia & SF-36 & Short Form with 36 items \\
IUCD & intrauterine contraceptive device & VAS & visual analogue scale
\end{tabular}

All abbreviations that have been used in this report are listed here unless the abbreviation is well known (e.g. NHS), or it has been used only once, or it is a non-standard abbreviation used only in figures/tables/appendices in which case the abbreviation is defined in the figure legend or at the end of the table. 



\section{. \\ Executive summary}

\section{Objectives}

To develop decision aids to provide evidence-based information and formal preference elicitation for women with menorrhagia; and to evaluate their effects on patient outcomes, patient management and cost-effectiveness.

\section{Design}

The development of the interventions was based on a series of activities including a systematic review of published literature on available treatments, their effectiveness and their impact on quality of life; surveys of treatment patterns and women's treatment-related preferences; and focus groups with women experiencing menorrhagia or who had undergone treatment for the condition.

The interventions were evaluated using a pragmatic, parallel group, multicentre, randomised controlled trial with 2 years of follow-up. Women were randomised to one of three arms:

- control (usual practice)

- information only

- interview plus information.

\section{Setting}

Six hospitals in south-west England.

\section{Participants}

A total of 894 of 1301 women referred to one of 28 consultant gynaecologists with a new episode of uncomplicated menorrhagia.

\section{Interventions}

The interventions consisted of an information pack, including a booklet and complementary video, and a preference elicitation interview with a research nurse. Women randomised to the information and interview groups were sent the information pack 6 weeks prior to their initial outpatient appointment. The interview group also underwent a structured interview with a research nurse immediately prior to the initial consultation with their gynaecologist. The control group received standard practice.

\section{Main outcome measures}

The primary outcome was health status, measured using the 36-item short-form general health survey (SF-36) instrument. Secondary outcomes included women's treatment preferences, treatments undergone and satisfaction. In the economic analyses, health outcomes were measured in terms of qualityadjusted life-years (QALYs) based on women's responses to the EQ-5D (EuroQol-5 dimensions) instrument.

\section{Results}

\section{Health status}

The interventions had no consistent effect on health status compared with controls.

\section{Preference formation}

In comparison with the control group, women were more likely to hold a treatment preference in both the information (adjusted odds ratio (OR) $1.87 ; 95 \%$ confidence interval (CI), 1.25 to 2.80 ) and interview (adjusted OR 2.51; 95\% CI, 1.66 to 3.79 ) groups post-consultation. The interview also influenced preferences towards individual treatments, where women were less likely than controls to want hysterectomy (adjusted OR 0.54; $95 \%$ CI, 0.35 to 0.85 ) or drug therapy (adjusted OR $0.44 ; 95 \%$ CI, 0.24 to 0.82 ).

\section{Treatments undergone}

After 2 years of follow-up, women in the interview group were less likely to have undergone hysterectomy than controls (adjusted OR 0.60; 95\% CI, 0.38 to 0.96 ) and women who were only given information (adjusted OR 0.52; 95\% CI, 0.33 to 0.82 ).

\section{Satisfaction}

The results of the satisfaction analyses were mixed. At short-term follow-up, the information group was significantly more satisfied than controls with the 
opportunities that they had been given to be involved in treatment decision-making (adjusted OR 1.39; $95 \%$ CI, 1.04 to 1.86). At long-term follow-up the interview group rated both these opportunities (adjusted OR 1.49; 95\% CI, 1.11 to 2.01) and the results of their treatment (adjusted OR 1.44; $95 \%$ CI, 1.03 to 2.01) higher than women in the control group.

\section{Cost-effectiveness}

There is a high probability that information provision in conjunction with preference elicitation is cost-effective; even under a range of sensitivity analyses this result does not change. The probability that interview is the most cost-effective form of management, assuming decision-makers are willing to pay $£ 30,000$ per additional QALY, is $78 \%$, and $55 \%$ under sensitivity analysis.

\section{Conclusions}

Neither intervention had a major impact on health outcomes relative to control. Information plus interview gave major additional benefits compared with the information pack on its own. It helped women form preferences, reduced hysterectomy rates and increased long-term satisfaction. The interview also had the highest probability of being cost-effective.

\section{Implications for healthcare}

- Information alone is not sufficient: patients need help in using the information to clarify their preferences, which then need to be communicated to their clinician.

- The results of this study suggest that the use of decision aids, consisting of evidence-based information along with formal preference elicitation, can actually reduce health service costs as well as improving patients' satisfaction.

- The effects in terms of preference formation, patient management and cost-effectiveness can be generalised to the treatment of uncomplicated menorrhagia in primary care.

- The reduction in hysterectomy rate is consistent with trends observed in other studies looking at conditions where patients have a choice between conservative and radical surgical options.

\section{Recommendations for future research}

- Approaches to training clinicians in patientcentred decision-making.

- Practical methods of clarifying and eliciting a patient's treatment-related preferences and communicating them to clinicians.

- Scenarios of clinical decisions under which these methods would prove most effective and cost-effective. 


\section{Chapter 1 Background}

\section{Menorrhagia}

Menorrhagia is a significant problem for otherwise healthy women, with around a third of all menstruating women reporting heavy periods. ${ }^{1}$ It is a common reason for general practitioner (GP) consultation, ${ }^{2}$ and referral to secondary care is common with $35 \%$ of those consulting referred within a year. ${ }^{3}$ The condition is not life-threatening, but it can have a considerable effect on a woman's quality of life. ${ }^{4}$

A woman requiring treatment for menorrhagia faces a number of treatment options, including the provision of advice and reassurance, addressing possible iatrogenic causes (e.g. removing an intrauterine contraceptive device (IUCD)), a variety of drug therapies designed to reduce menstrual blood loss, or referral to a gynaecologist for advice, assessment and possible surgery. ${ }^{5}$

Traditionally, hysterectomy has been the major surgical intervention for the condition, with $20 \%$ of all women undergoing the operation by the age of $55,{ }^{6}$ the majority being for menorrhagia. ${ }^{7}$ For women referred to hospital with the condition, $60 \%$ will have a hysterectomy within 5 years. ${ }^{8}$ Hysterectomy is associated with a complication rate of around $45 \%$ and a risk of operative mortality of between 0.4 and 2 per 1000 women. ${ }^{5}$ Most women with menorrhagia who are referred to hospital have failed to have their condition adequately treated with drugs, and evidence indicates that the most frequently prescribed drugs are the least effective. ${ }^{9}$ Greater use of the more effective drugs, such as tranexamic acid, can reduce blood loss by approximately $54 \% .^{10}$

Recently, something of a revolution has occurred regarding treatment options for menorrhagia, with a range of minimal access treatments now available $^{11}$ in addition to a number of new medical therapies such as the levonorgestrel-releasing IUCD. Based on current evidence, it is not possible to identify unequivocally the optimal therapy for menorrhagia because the alternatives differ according to outcomes, risks and benefits, and clear trade-offs exist when choosing between treatments. ${ }^{12}$ For example, hysterectomy provides a permanent solution to menstrual problems, but takes women away from their usual activities for up to 3 months; ${ }^{5}$ on the other hand, minimal access surgery allows women to return to their usual activities relatively quickly, but fails to ameliorate symptoms sufficiently in a proportion of cases. Drug therapy avoids the mortality risks of surgery but is often associated with side effects and may have to be taken over many years.

\section{Information and preferences in menorrhagia}

Women are likely to have different attitudes towards the trade-offs that present themselves when choosing between these treatments. ${ }^{12}$ It is important, therefore, that women's preferences are taken into account when treatment decisions are being made. ${ }^{13-15}$ In order to share in decision-making, women need comprehensible and complete information on menorrhagia and its treatment. Evidence has shown that increased information can reduce hysterectomy rates by over $25 \% .{ }^{16}$ Outside gynaecology, studies have shown that the provision of information to patients can alter their choices about treatment ${ }^{17}$ and improve outcomes of care. ${ }^{18}$

Doctors must also be made aware of their patients' treatment preferences. Some women will be ready and able to articulate their preferences during a consultation, others will not. It may not be possible for a clinician to elicit preferences during a busy outpatient clinic, and evidence suggests that GPs are not aware of the treatment preferences of women with menorrhagia. ${ }^{3}$ When patients' preferences are systematically considered as part of the clinical decision-making process, patients' choices often differ from those of their clinician, ${ }^{19,20}$ and the outcomes of care can improve..$^{21,22}$

In the Information and Preferences in Menorrhagia (IPMEN) study, interventions were developed to help women with menorrhagia to determine and articulate their treatment preferences in the hope that this would enable them to play a more active role in decisionmaking about their care. The interventions consisted of two different patient decision aids: (1) an information pack consisting of a specially 
designed booklet and video providing information on the causes of, and treatments for, menorrhagia; and (2) a structured interview with a research nurse to elicit women's views about their condition and their preferences regarding treatment. The costs and effects of these types of intervention have not yet been adequately measured. It is crucial, therefore, to evaluate the costs and benefits of the role of structured information and the analysis of preferences in the management of menorrhagia.
This study was made up of two phases. Phase I mainly concerned the development and piloting of the information pack and preference elicitation interview. In phase II, a hospital-based randomised controlled trial (the IPMEN study) was conducted comparing the two management strategies of information provision and preference elicitation, and information alone, with standard clinical practice in terms of their effect on patient outcomes, treatment-related preferences and cost-effectiveness. 


\section{Chapter 2 \\ Development of the interventions: phase I}

\section{Introduction}

Members of the research team have participated in a wide range of research into both menorrhagia and shared clinical decision-making. This previous experience and concurrent research undertaken by the group were relied upon heavily during the development of the interventions. Sources, which were used extensively, included:

- the Effective Health Care Bulletin on menorrhagia ${ }^{5}$

- focus groups with sufferers, clinicians and non-medical experts ${ }^{23}$

- epidemiological surveys $s^{6,8,24}$

- a review of treatment in general practice. ${ }^{3}$

In addition, an expert advisory group (appendix 1) was formed to provide comment on and input to the interventions at various stages of their development.

\section{Focus groups}

The development of the interventions was greatly influenced by qualitative work conducted in collaboration with members of the advisory group. ${ }^{23}$ This work preceded the IPMEN study and we only give a brief summary of the findings here. With the aim of describing the range of experience and issues of concern for women suffering from menorrhagia, two focus groups were conducted. In addition to discussion of the condition and its treatment, these sessions also examined the attitudes and opinions of women to the use of decision aids to enhance consultations with their doctor.

A total of 13 women took part in these sessions, which were conducted at two centres in Northampton and Leeds. Participants from the target population for the interventions were chosen to take part. The groups were aged 28-48 years and were (or had recently been) in a position of thinking through the treatment options. Eight women had already undergone hysterectomy, two endometrial destruction, one drug therapy and one was waiting to undergo hysterectomy, the other had received no treatment for the condition.

Two further focus groups were conducted with clinicians and non-medical experts to gauge the full range of opinion on menorrhagia and the information needs of women with the condition. The clinicians, from Oxford, were two GPs giving the perspective from primary care, and three consultant gynaecologists representing the secondary care experience. The non-medical experts represented a hysterectomy and menopausal support group from Dunfermline, a women's health support group from London, a women's mid-life crisis centre from Birmingham and an 'agony-aunt' writing in a popular women's magazine.

\section{Menorrhagia}

The considerable impact on quality of life caused by menorrhagia was described vividly by the women in the focus groups in terms of: the practical difficulties they had coping with everyday life; the emotional effects including embarrassment, depression and low self-regard; the physical effects; the financial cost; and the effects on family life and other family members. Women's reactions to these aspects of the condition were raised as important in influencing the types of treatment that they would favour.

Further discussion within the sessions, and those conducted with clinicians and the non-medical experts, focused on two areas: information provision within and outside of the clinical encounter and what information a decision aid for the condition should contain.

All three groups (women, clinicians and nonmedical experts) agreed that patients required information about their condition and its treatment prior to any treatment decision-making process. However, major reservations were expressed about how this was currently carried out in terms of: 
- patients' communication with doctors. Women were often reluctant or embarrassed to ask questions and were intimidated by the status of their doctor.

- doctors' communication with patients. The clinician group raised the point that time constraints had an impact on the amount of information they were able to provide to women, but they also acknowledged they did not provide as much information to women as they thought they did.

- other external information sources. Sources identified by the women were family and friends, the media, nursing or other hospital staff, hospital information sheets and support groups. The clinician group also identified pharmacists, drug companies and voluntary sector health information organisations. These sources were criticised as being difficult to find, biased, directive, overtechnical, out of date, misleading or generally inaccurate or unhelpful.

Issues around the presentation and content of the information included in the decision aid were also raised. The discussions ranged over what information would be of use to women in making decisions about their care. Women felt that information on the cause of the problem would be valuable, and that reassurance and an indication that they were not alone with the problem were important. Details of the full range of different treatments available, and not just hysterectomy, should be provided, and this was highlighted as especially useful for younger women who might have concerns regarding loss of fertility. It was also felt that it was important to address both the positives and the negatives of each treatment, including any possible side effects of drugs.

In addition, detailed and practical information on hysterectomy was considered essential, such as:

- what parts of the body will be taken away during the operation?

- if left in place, how long will the ovaries continue to work?

- is it still possible to suffer from periods and premenstrual tension?

- what are the risks of surgery with respect to pain and death?

- the practicalities of going into hospital.

A number of points were raised with respect to the after-effects of the operation, the length of time women should expect to be off work, advice for the family and the need for support. Also, the physical and sexual consequences of the operation were raised as topics in need of inclusion.

The clinician and self-help focus groups also raised the issue of describing menorrhagia. However, this was not felt to be important by the women themselves.

In terms of the presentation of the information, a breadth of useful responses was expressed. The information should not be presented in a patronising manner, or be too official or intimidating in tone. The language used should be meaningful to those who would be expected to use the aid, and information from women who have 'been through it' was thought to be valuable. The women felt that diagrams, models and graphics would be useful, but that statistics should be used carefully. The aid should not be too long and should be available in a range of formats: video, audiotape and booklet. The need for foreign language versions was also raised.

\section{Interventions}

In the light of this and other work in the field, ${ }^{20,21,25}$ the advisory group proposed the development of an information pack and an interview schedule for preference elicitation to address the information needs of women with menorrhagia, and to ensure that their opinions were considered during the treatment decision-making process.

\section{Information pack}

The need for the information pack to be practical and easily accessible influenced the choice of format. A booklet and complementary video that could be sent to women, to be read and watched at home, were chosen. The starting point for the booklet was the systematic review of treatment efficacy published in the Effective Health Care series, ${ }^{5}$ with additional evidence coming from epidemiological and quality of life surveys on the condition. ${ }^{6,8,24}$ The booklet was drafted by AC in consultation with the advisory group with close reference to the results of the focus groups described on page 3 and other research into patients' information needs. ${ }^{26,27}$

The booklet (appendix 2) included an introductory section emphasising the importance of women's preferences in deciding on treatment, together with chapters describing menorrhagia and its causes, investigations, treatment options (medical and surgical), the benefits and risks of surgery, and a section entitled 'personal treatment 
plan' in which the reader was prompted to think through and write down her preferences in response to specific questions.

The video (appendix 2) complemented the information in the booklet. It was presented by a female doctor and included clips of interviews with women who had experienced different treatments for menorrhagia. It included graphical illustrations, and used colour coding to facilitate linkage of the visual material with the information in the booklet. The video, the original draft of which was written by AC, was produced in association with Boxclever Productions and won a silver medal at the 1998 British Medical Association video awards.

\section{Interview}

The structured interview also drew on material derived from patient surveys ${ }^{9,12}$ and the focus groups described on page 3 . Drafted by MJS with input from the advisory group, the interview was designed around the following scenario:

- participants would be women referred from primary to secondary care for uncomplicated menorrhagia

- interviews would be conducted by a trained research nurse immediately before the woman's first hospital appointment with her consultant

- women would already have read the booklet and watched the video, which would have been sent to them at home a fortnight previously.

The purpose of the interview was to help women clarify and articulate their preferences and to give them the chance to provide information that they might not have the opportunity or inclination to reveal to their doctor. The interview covered seven different aspects of information that women wanted their doctor to know:

- previous history

- what women wanted to achieve from the consultation

- to what extent the woman wished to be involved in the decision-making process

- clinical characteristics of treatment

- lifestyle characteristics of treatment
- questions they wished to ask their doctor and other comments

- treatment preference.

Responses to these questions were summarised on a form, which was given to the woman at the end of the interview. She was then encouraged to give it to her doctor at the beginning of the consultation. It was felt important that the woman be given ownership of this information and that she could decide not to give it to her doctor if she chose. It was planned that after the consultation the form would be added to the woman's notes.

Once a draft version of the booklet was completed, a series of pilot interviews was conducted by $\mathrm{SH}$ on women from the Princess Margaret Hospital in Swindon. Women suitable to take part in these interviews were identified by a review of GP referral letters sent to the consultants at this centre. This process identified 81 women as suitable participants and 31 agreed to take part in the interview. Prior to the interview they were given the booklet to read. These interviews helped to refine the wording and order of some questions but did not result in any major changes to the draft interview schedule. However, the pilot did identify the need for prompts to facilitate the interview and these took the form of laminated cards on which the options to answer the different questions were printed. The interview was further refined by the research nurses during their interview training programme.

The research nurses were allowed to modify the introduction to the interview schedule to enable them to build a natural rapport with the women. The interview itself was highly structured in nature with no deviation from the schedule permitted. Where women asked questions or requested additional information this was noted in the appropriate section of the summary form and the woman informed that they should direct these questions to their doctor during their subsequent consultation.

The final version of the interview schedule (appendix 3) and summary form (appendix 4) are included in this report. All questionnaires used in phase II of the study were also piloted at this stage. 



\section{Chapter 3 \\ Methods for phase II}

\begin{abstract}
Aims
Phase II of the study was a multicentre randomised controlled trial, which aimed to evaluate the information pack and interview in terms of their effects on patient outcomes, patient management and cost-effectiveness.
\end{abstract}

\section{Participants}

Women consulting one of 28 consultant gynaecologists from six hospitals in the south west of England were invited to participate in the study. Five of the consultants were female and four of the centres were district general hospitals. Six research nurses were appointed with responsibilities to identify and recruit participants, conduct the interviews and coordinate data collection. The recruitment period lasted from October 1996 until February 1998. Ethical approval was granted by each of the six participating centres.

All women referred from primary to secondary care with uncomplicated menorrhagia, deemed non-urgent by their consultant, were considered for trial entry if their referral related to a new episode of menorrhagia. Patients were identified by the research nurse from an inspection of referral letters sent from GPs to the participating consultants.

All women identified from the referral letter inspection were registered with the trial management database held at the study administration centre. They were then sent a letter from their consultant inviting then to take part in the study 8 weeks prior to their scheduled outpatient appointment.

\section{Design}

For those consenting, random allocation to one of the three groups was then carried out using a form of random permuted blocks, with block size randomly set to three, six or nine to avoid any possibility of selection bias. ${ }^{28}$ The allocation sequence was generated by computer and stratified by consultant and the age at which the woman left full-time education. Secure randomisation was ensured by using a central telephone randomisation system based at the study administration centre. Patients were randomised to one of three arms:

- control: no intervention, standard practice control group

- information: the video and booklet were sent to women at their home 6 weeks before their consultation

- interview: in addition to receiving the information, women also attended a structured preference elicitation interview immediately before their consultation.

\section{Protocol}

Before randomisation, participants completed a baseline questionnaire (appendix 5), which collected data on clinical history, sociodemographic characteristics, treatment-related knowledge, generic and condition-specific health status measures and treatmentrelated preferences.

Included with the booklet and video in the pack sent to women in both of the intervention groups 6 weeks pre-consultation was a questionnaire that asked for patients' views on the information tools. Women were asked to complete this after they had read the booklet and watched the video.

Women in the structured interview group were asked to arrive 30 minutes before their scheduled outpatient appointment to attend the interview. In all three arms, doctors were asked to complete a short questionnaire after the consultation. Women were sent a questionnaire the following day, which asked about satisfaction with the consultation and treatment-related preferences. Women in the interview group also received a short questionnaire asking for their opinions on the preference elicitation interview.

Follow-up questionnaires were sent at 6, 12 and 24 months post-consultation. These focused on health status, treatment-related preferences, 
treatments undergone and satisfaction with the care they had received and the decision-making process. Women who did not respond to the 12or 24-month questionnaire after two reminder letters received a reminder telephone call. Those who said they did not wish to complete a follow-up questionnaire were asked to take part in a short telephone interview covering key items from the follow-up questionnaire. Those who said they would complete a final follow-up questionnaire at 24 months but did not return it were then asked to take part in a telephone interview.

A comprehensive resource use diary booklet was used to allow women to describe their contacts with health services. Three diary booklets were sent to women and covered the periods up to 6 months, 6-12 months and 12-24 months post-consultation. The first section of the follow-up questionnaires also asked for this data from women who had not completed their diary booklet.

\section{Data collection}

\section{General and condition-specific health status}

General health status was measured using the 36-item short-form general health survey $(\mathrm{SF}-36)^{29}$ and the EuroQol-5 dimensions (EQ-5D) instruments ('Outcomes', page 11).$^{30}$ A scale developed by Ruta and colleagues was used to measure the severity of menorrhagia. ${ }^{31}$ However, this scale is only relevant to women who menstruate, which limits its use as a measure of effectiveness to those women who did not undergo hysterectomy or reach the menopause during follow-up. A short-form of the State-Trait Anxiety Inventory was used to measure anxiety. ${ }^{32}$

\section{Preferences and treatments}

Many studies of decision aids have focused on a simple choice between undergoing one therapy or another (often no therapy). ${ }^{33}$ With menorrhagia, however, there are a number of different treatment options that women can choose from. Another feature of this clinical condition is that many women have a better idea of which treatment they do not want (often hysterectomy or drug therapy) than the treatment they do want. Therefore, preferences were collected using two separate open questions, which asked women whether they had any strong feelings about the type of treatment they would like (positive preference) and would not like (negative preference) like for their heavy periods. Women were able to list more than one treatment in each question.
These preferences were then coded in two ways. First, a binary variable was constructed, indicating whether or not the woman held any kind of preference. Secondly, ordinal variables were constructed for each of the following main treatments: hysterectomy, endometrial destruction, drug therapy, unspecified surgery, other (which included the levonorgestrel-releasing IUCD, fibroid removal and polyp removal) and no treatment. Responses were coded to indicate whether the woman held a positive preference, no preference or a negative preference towards each treatment. The unspecified surgery option was included because many women stated that they did or did not want surgery, without any firm indication of whether this meant hysterectomy or any form of surgery.

Change in preferences between baseline and post-consultation was defined in two ways. For those who had no preference at baseline a binary variable was used: no preference held post-consultation and preference formed postconsultation. For those who did hold a preference at baseline a nominal variable was produced with three categories: preference maintained (i.e. the same preferences were held at baseline and postconsultation), preference changed, no preference (the woman no longer held a preference postconsultation). In assessing change in preference, rather than the broad classification used above to define preferences, a more sensitive classification was used: hysterectomy, endometrial destruction, fibroid removal, polyp removal, drug therapy, hormonal drugs, non-hormonal drugs, levonorgestrelreleasing IUCD and unspecified surgery. Any other responses were coded on a case by case basis.

Women were asked to describe the treatments they had undergone as part of the resource use data collection. The question on drug therapy asked women for the name, dates started and finished, and reason for use of any tablets, pills, drops or injections that they had had. Data on surgical treatments and other procedures were collected from the resource use data, from questions looking at reasons for GP or outpatient visit or inpatient stay, and from a question asking about whether any surgical procedures had been undergone. Binary variables were used to describe whether a treatment had been undergone and the same variables as those used to describe preferences were employed.

\section{Agreement between post-consultation preferences and treatments undergone}

For those women specifying a preference postconsultation and undergoing a treatment during 
follow-up the extent to which their preferences matched the treatments they underwent was assessed. This relationship was defined as ordinal in nature and categorised as follows: treatment corresponded with a positive preference (they got what they wanted), no positive preference was held and the treatment undergone did not correspond with a negative preference (they didn't get what they didn't want), treatment did not correspond with either a positive or negative preference (they got something else), and treatment corresponded with a negative preference (they got what they didn't want). In the conduct of the analysis, however, this categorisation was found to be unstable and the first two categories were combined. The same categories of response used to assess change in preferences (above) were used to assess agreement.

In the analysis for the long-term follow-up, a further variable was produced taking into account any change in preferences between post-consultation and either 6- or 12-month follow-up to give a variable describing the laststated preference. Agreement between these preferences and treatments undergone was then assessed in the same way.

\section{Resource use}

The data collected covered the number of and reasons for GP and outpatient visits, the length of and reasons for inpatient stays, tests and treatments undergone.

\section{Clinical history}

Details of the women's menorrhagia-related clinical history were collected in terms of previous treatment undergone and the duration of this episode of the problem. Data on whether they had previously undergone surgery were also collected; research has shown that those who have undergone surgery are more likely to choose a surgical option if available. ${ }^{3}$

\section{Treatment-related knowledge}

Women's knowledge of the treatment options available was assessed by asking them whether they had heard of seven common treatments and whether they knew what they were. The options 'No, I have not heard of it', 'Yes, I've heard of it, but I don't know what it is', 'Yes, I've heard of it, and I know what it is' were scored as $0,1,2$ respectively and then rescaled to cover the range $0-100$.

\section{Satisfaction}

Satisfaction was assessed post-consultation and at follow-up. Post-consultation, a woman's perceived knowledge of the treatment options and her satisfaction with the consultation in terms of the extent to which she had been involved in the treatment decision and the importance of her opinion in reaching this decision were assessed.

At follow-up, women's experiences since their consultation were measured by their ratings of the extent to which they had opportunities to become involved in the treatment decision and their satisfaction with the care they had received.

The 6-month and 12-month data were merged together to form a short-term follow-up dataset. The 24-month data and subsequent interviews formed the long-term follow-up dataset. In the analysis of treatments undergone at 24 months, the data presented are cumulative and refer to any treatment undergone during the period of the study.

\section{Outcomes}

Patient outcomes were measured using standard validated scales where available. The primary outcome was general health status measured using the SF-36. ${ }^{29}$ It was acknowledged that not all the dimensions of the instrument were likely to show between-group differences, but it was considered important to use a generic measure to permit comparisons with other uses of healthcare resources.

\section{Secondary outcomes included the following:}

- Post-consultation treatment preferences and change in preferences between baseline and post-consultation. It was important to assess the effect of the interventions in helping women to form treatment preferences, and also to assess whether they could change previously held preferences.

- Treatments undergone during follow-up. If these types of intervention are to be introduced to routine care within the NHS their effect on patient management must be assessed.

- Agreement between women's preferences and treatments undergone. As an indication of the extent to which consultations fulfilled the principles of shared decision-making, ${ }^{34}$ the agreement between women's preferences and the treatments undergone were measured.

- Anxiety. ${ }^{32}$ A criticism of providing information to patients and involving them in decisions about their care is that it can increase anxiety. 
- The EQ-5D instrument. ${ }^{30}$ This was essential for the economic evaluation.

- Severity of menorrhagia. ${ }^{31}$ As noted in 'General and condition-specific health status' (page 8), this measure was limited to those women who had not undergone hysterectomy or reached the menopause.

- Patient satisfaction. Measured post-consultation and at follow-up.

\section{Covariates}

In addition to the effects of the interventions under evaluation, a number of other factors will affect the outcomes listed above and these covariates have therefore been included in the analyses. Covariate data collected at baseline covered clinical history, socio-demographics, symptom severity, treatment knowledge, treatment preference and baseline score for the health status measures. Other patient level covariates attempted to correct for any effects introduced by the study design. Length of follow-up was included where appropriate and the point in the recruitment period at which the women joined the trial was included in case there was a change in clinical practice, external to the study, during the conduct of the trial.

Characteristics of the women's consultant may also have an influence on the effectiveness of the interventions. Previous research has shown that hysterectomy rates differ when the sex of the consultant is compared. Year of qualification was also included among the possible covariates to account for any cohort effect of practice among consultants. In addition to these characteristics, there may also be a clustering effect attributed to the consultant. This effect occurs where patients referred to one consultant may be more similar than those referred to any other and the standard errors observed around estimates of effect at the patient level are then biased towards being too small. 'Consultant' has therefore been handled in a different manner to the other covariates in the analyses.

\section{Statistical methods}

The analyses were conducted on an intention-totreat basis. Non-response bias was assessed using $t$ tests, analysis of variance (ANOVA) and chisquared tests. Multiple regression methods were used to analyse health status. Logistic regression models were used to analyse whether a preference had been formed post-consultation and the treatments undergone during follow-up. Ordinal regression was used in the analysis of individual post-consultation preferences, the agreement between preferences and treatments undergone, and satisfaction. To allow for potential clustering, both consultant and (where methods were available) the consultant-intervention interaction were modelled as random effects. ${ }^{35}$ Change in preferences between baseline and post-consultation were analysed using multinomial logistic regression. Here robust standard error estimates were employed to account for clustering. ${ }^{35}$ A pool of covariates was defined for each model a priori (appendix 6) and a forward stepwise selection procedure was employed. The covariates included in the final models are shown in appendix 7 .

\section{Sample size}

The primary outcome of the study was the SF-36 instrument. A sample size of 900 was calculated to detect differences between study arms of five points with a power of $80 \%$ at the $5 \%$ significance level. This applied to all domains except the two role-related scales, which have standard deviations (SDs) more than a third greater than the other scales. ${ }^{36}$ 


\section{Chapter 4}

\section{Economic evaluation methods}

\section{Introduction}

The economic evaluation was conducted using cost-utility analysis. Costs were estimated from the perspective of the UK NHS and health benefits were expressed in terms of quality-adjusted lifeyears (QALYs) over a mean period of follow-up of 26 months.

\section{Cost analysis}

Resource use was measured prospectively in all women. The resources associated with the development and production of the interventions were recorded. For women in the interview group, the duration of time devoted by the nurse to the interview was recorded. So as not to interfere unduly with routine practice, clinicians were not asked to record the duration of their initial consultation with women in the study, so this element of care has not been costed under the assumption that they are the same in each of the three groups. This assumption is tested using sensitivity analysis.

During the follow-up period, women were asked to provide details of their use of health services as part of the questionnaires they were sent at 6, 12 and 24 months. This included details of therapeutic and diagnostic procedures and medications for menorrhagia; inpatient days in hospital for any reason; and outpatient and GP visits for any reason.

Health service resource use has been valued at 1999-2000 UK costs. The items costed and source of unit costs (prices) are summarised in Table $1 .^{37-41}$ The calculation of the intervention costs is shown in Table 2., ${ }^{3,42,43}$ Fixed costs, incurred through the expert input required for the content of the information pack and interview and the production of the booklet and video, are averaged over the total potential eligible population. Variable costs are calculated from the costs incurred during the study. The cost of the interview was included only for those patients in the interview arm who attended the interview.

\section{Outcomes}

Health-related outcomes were measured using QALYs. These were based on women's responses to the EQ-5D health status questionnaire at baseline, and 6, 12 and 24 months after the initial consultation. The EQ-5D is a generic measure of health status, where health is characterised on five dimensions (mobility, self care, ability to undertake usual activities, pain, anxiety/ depression). ${ }^{44}$ At each time-point, women were asked to indicate their level of health on each dimension using one of three levels: no problems, moderate problems and severe problems. Each response located a woman into one of 245 mutually exclusive health states, each of which had previously been valued on the 0 (equivalent to dead) to 1 (equivalent to good health) 'utility' scale based on interviews with a sample of 3395 members of the UK public. ${ }^{45}$ Hence, each woman in the trial had a health 'utility' at up to four time-points and, using area under the curve methods, ${ }^{46}$ these observations were translated into QALYs over each woman's period of follow-up.

\section{Analysis}

Given that the time horizon of the analysis was only 2 years, total costs and QALYs remain undiscounted. To account for the skewed nature of the data, $95 \%$ confidence intervals (CIs) for differential costs and QALYs have been calculated using bias corrected and accelerated (BCA) nonparametric bootstrapping (based on the 2.5th and 97.5 th percentiles). ${ }^{47}$

In some patients, resource use data and EQ-5D responses were wholly or partially missing. This was due to missing data within questionnaires, non-response and administrative censoring; for example, it was not possible to collect data on contacts with health services from women who took part in the telephone interview rather than complete a final follow-up questionnaire. For a large study of this type with a significant proportion of data being collected directly from women in the form of self-completed questionnaires, missing data is inevitable, despite the 
TABLE 1 Unit costs at 1999-2000 prices and sources of cost

\begin{tabular}{|c|c|c|}
\hline Item & Cost $(t)$ & Source \\
\hline \multicolumn{3}{|l|}{ Tests } \\
\hline $\mathrm{D} \& \mathrm{C}$ & 122.00 & NHS reference costs, $1999^{37}$ \\
\hline Endometrial biopsy & 75.00 & NHS reference costs, 1999 \\
\hline Laparoscopy & 246.50 & Sculpher et al., $2000^{*}, 38$ \\
\hline Hysteroscopy & 122.00 & NHS reference costs, 1999 \\
\hline Ultrasound scan & 75.00 & NHS reference costs, 1999 \\
\hline Blood test & 10.90 & $\begin{array}{l}\text { Specific NHS Trust } \\
\text { Netten \& Dennett, } 1999^{39}\end{array}$ \\
\hline Colposcopy & 105.00 & NHS reference costs, 1999 \\
\hline Examination under anaesthetic & 75.00 & NHS reference costs, 1999 \\
\hline $\begin{array}{l}\text { Treatments } \\
\text { Drugs }\end{array}$ & & British National Formulary, September $1999^{40}$ \\
\hline \multicolumn{3}{|l|}{ Surgery and procedures ${ }^{\dagger}$} \\
\hline Endometrial destruction & 646.00 & Sculpher et al., $1993^{*}, 41$ \\
\hline Polyp removal & 122.00 & NHS reference costs, 1999 \\
\hline Fibroid removal & 580.00 & Sculpher et al., $2000^{*}$ \\
\hline Levonorgestrel-releasing IUCD & 150.00 & $\begin{array}{l}\text { British National Formulary, September } 1999 \\
\text { Netten \& Dennett, } 1999 \\
\text { NHS reference costs, } 1999\end{array}$ \\
\hline Other & - & Costed on a case-by-case basis \\
\hline \multicolumn{3}{|l|}{ Inpatient stays (cost per day) } \\
\hline Gynaecology & 340.00 & NHS reference costs, 1999 \\
\hline Obstetrics & 335.00 & NHS reference costs, 1999 \\
\hline Surgery & 335.00 & NHS reference costs, 1999 \\
\hline Medical & 202.00 & NHS reference costs, 1999 \\
\hline \multicolumn{3}{|l|}{ Outpatient visits (cost per visit) } \\
\hline Related outpatient visit & 69.00 & NHS reference costs, 1999 \\
\hline Unrelated outpatient visit & 73.50 & NHS reference costs, 1999 \\
\hline \multicolumn{3}{|l|}{ GP visits (cost per visit) ${ }^{\ddagger}$} \\
\hline Related GP visits & 15.00 & Netten \& Dennett, 1999 \\
\hline Unrelated GP visits & 15.00 & Netten \& Dennett, 1999 \\
\hline \multicolumn{3}{|c|}{$\begin{array}{l}\text { * Updated for inflation } \\
\dagger \text { Including any inpatient stay, and outpatient or GP visit } \\
{ }^{\ddagger} \text { Excluding stay or visit associated with particular surgery or procedure }\end{array}$} \\
\hline
\end{tabular}

assiduous use of reminders. We have addressed the problem using multivariate multiple imputation (MI) methods that assume the data were missing at random; that is, cases with incomplete data differ from cases with complete data, but the missing data pattern is fully predictable from other variables in the dataset. ${ }^{48}$ Appendix 8 provides full details of the imputation methods.

Cost-effectiveness analysis was undertaken to relate differential mean cost to differential mean QALYs
Mean costs and QALYs are estimated with uncertainty. Therefore, to account for uncertainty due to sampling variation, we plotted costeffectiveness acceptability curves. ${ }^{49,50}$ Given the data collected within the trial, this curve shows the probability that any one management strategy is more cost-effective than the others for different maximum levels that the decision-maker may be willing to pay for an additional QALY. This is a Bayesian approach to the presentation of costeffectiveness data, ${ }^{51}$ although a full Bayesian analysis has not been undertaken. 
TABLE 2 Cost of interventions

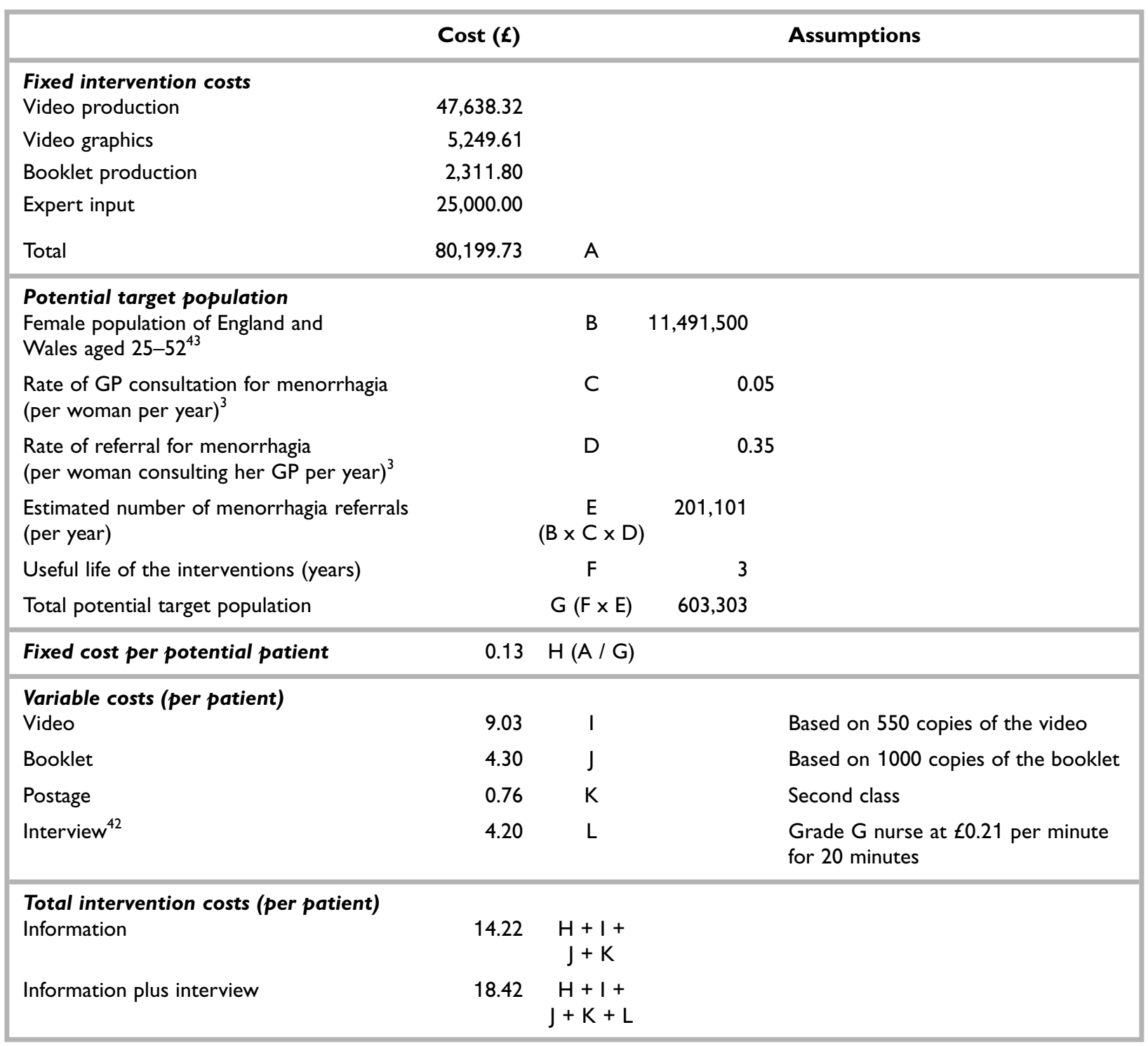





\section{Chapter 5}

\section{Results: baseline to post-consultation}

\section{Recruitment}

From the 1301 eligible women invited to take part in the study, $894(69 \%)$ gave their consent (Figure 1A) and there were no exclusions after randomisation. There was no difference in age between those granting (mean 40 years, SD 7.0) and refusing $(41,7.7)$ consent $(p=0.56)$. Response rates to the baseline and postconsultation questionnaires were $99 \%$ and $80 \%$, respectively.

\section{Baseline characteristics}

Table 3 gives baseline descriptive statistics for the three study arms. The sample was stratified by the women's age on leaving full-time education. This showed that $59 \%$ were aged 16 years or under and $16 \%$ were aged 19 years or over when they left full-time education. This distribution is similar to that of women from the general population, where $61 \%$ of women from this age group left full-time education aged 16 or under and $18 \%$ aged 19 or over. ${ }^{52}$ The consultant to whom women were referred was also used to stratify the sample so there were no between-group differences in the proportions seeing a female consultant or in the consultant's year of qualification. There may be small between-group differences in the duration of the problem and also in previous hormonal and non-hormonal drug treatment, but the other sample characteristics appear evenly distributed between the three study arms.

Women's treatment preferences at baseline, before randomisation, are also described in Table 3 and between-group differences were evident. The groups differed in the extent to which they held a preference and also in terms of their preferences for individual treatments, especially drug therapy. Few women expressed preferences for endometrial destruction, no treatment or other treatments.

\section{Use of interventions}

Information pack evaluation questionnaires were returned by $519(87 \%)$ women in the intervention groups. All but four women reported watching or reading at least some of the video or booklet. The structured interview, which lasted an average of 20 (SD 6.2) minutes, was conducted with $240(80 \%)$ of the 300 women randomised to that group.

\section{Satisfaction with the interventions}

Women's levels of satisfaction with the interventions were very high. Over $95 \%$ rated the information pack as interesting and understandable and would recommend it to women with a similar problem. Interview evaluation questionnaires were returned by $224(75 \%)$ women in this group and 207 (96\%) found it easy to participate in. Slightly fewer (177; $83 \%$ ) would recommend the interview to women with a similar problem.

In terms of the clinician's perceived duration of the consultations, there were between-group differences (chi-squared, $p=0.013$ ). Consultations with women in the interview group were more likely to be perceived as 'longer than average' than those with women in the other two groups (Table 4).

\section{Post-consultation preferences}

Table 5 shows women's treatment preferences post-consultation. In comparison with the control group, those in the intervention groups were much more likely to express a treatment preference after their consultation (information: $p=0.002$; interview: $p=0.0001)$.

In terms of the actual preferences held, the interview group was significantly less likely than controls to want either hysterectomy $(p=0.008)$ or drug therapy $(p=0.009)$, whereas the likelihood for the information group compared with controls was not significant $(p=0.41$ and $p=0.092)$. Compared with each other, there were no significant differences between the interventions. 


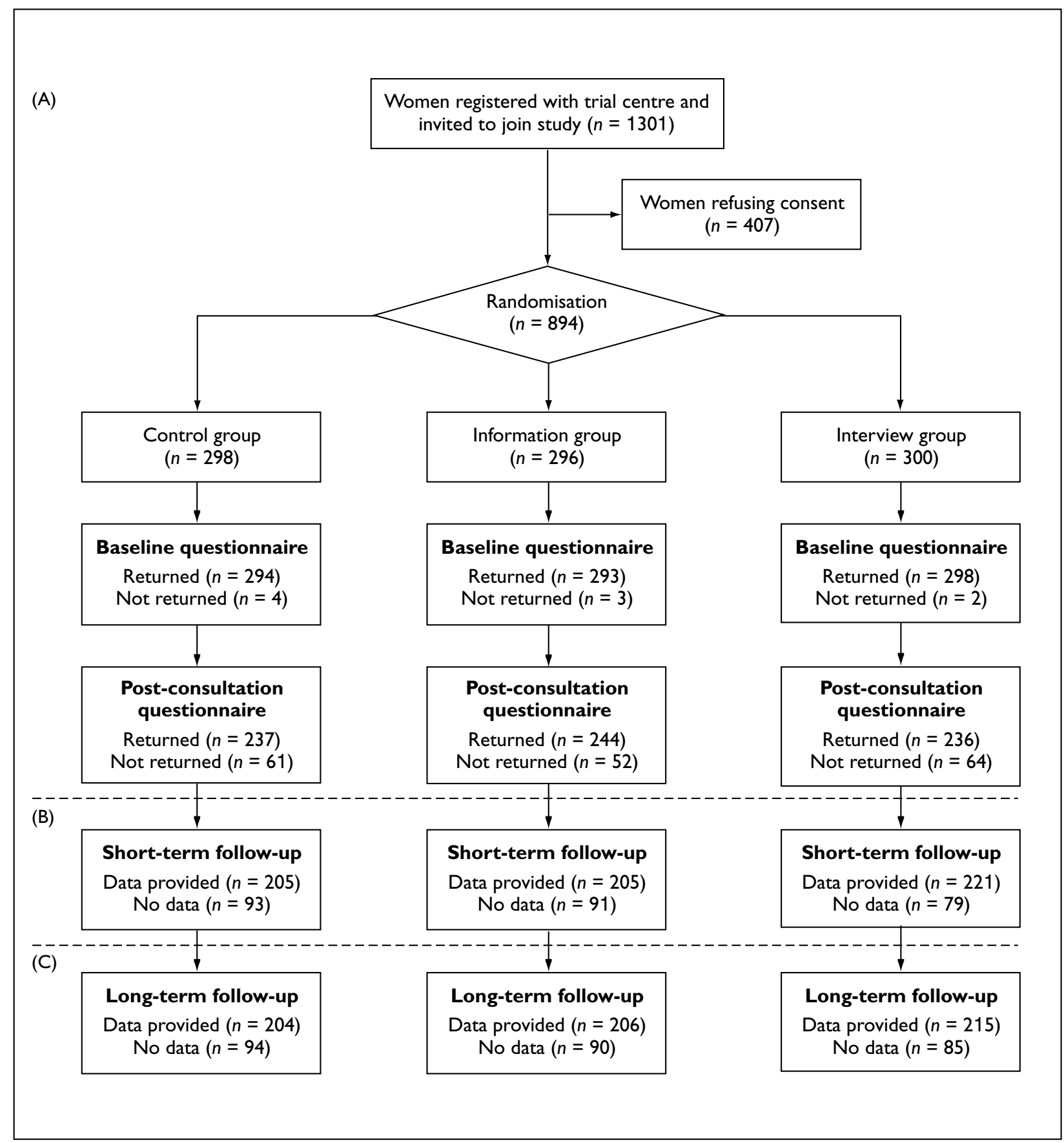

FIGURE I CONSORT diagram of recruitment and response to (A) follow-up post-consultation; (B) short-term follow-up; and (C) longterm follow-up (adapted from Kennedy, et al. (see 'Related publication' at front of this monograph), with permission from the American Medical Association)

\section{Change in preferences}

Changes in preferences held at baseline and those held post-consultation are shown in Table 6. Both interventions had a major effect on women who did not hold a preference at baseline, with highly significant increases in the likelihood of holding a treatment preference post-consultation (information: $p=0.0008$
For those who held a preference at baseline, women in both intervention groups were more likely to change their preferences (information pack: $p<0.0005$; interview: $p=0.008$ ) than to retain their baseline preference compared with women in the control group. Women in the information group were also more likely to no longer hold a preference, than to retain their preference, compared with women in both the control $(p=0.041)$ 
TABLE 3 Baseline characteristics of women and consultants by group

\begin{tabular}{|c|c|c|c|c|}
\hline & & $\begin{array}{l}\text { Control } \\
(n=298)\end{array}$ & $\begin{array}{l}\text { Information } \\
(n=296)\end{array}$ & $\begin{array}{c}\text { Interview } \\
(n=300)\end{array}$ \\
\hline \multicolumn{2}{|l|}{ Mean (SD) age in years } & $40(7.0)$ & $40(7.2)$ & $41(6.9)$ \\
\hline $\begin{array}{l}\text { Age at leaving } \\
\text { full-time education: }\end{array}$ & $\begin{array}{l}16 \text { or under } \\
17-18 \\
19 \text { or over } \\
\text { not given }\end{array}$ & $\begin{aligned} 172 & (57.7) \\
73 & (24.5) \\
44 & (14.8) \\
9 & (3.0)\end{aligned}$ & $\begin{aligned} & 171(57.8) \\
& 74(25.0) \\
& 44(14.9) \\
& 7(2.4)\end{aligned}$ & $\begin{aligned} 171 & (57.0) \\
69 & (23.0) \\
50 & (16.7) \\
10 & (3.3)\end{aligned}$ \\
\hline \multicolumn{2}{|l|}{ Female consultant seen } & $60(20.1)$ & $62(20.9)$ & $58(19.3)$ \\
\hline \multicolumn{2}{|c|}{ Median year of qualification for consultant } & 1974 & 1974 & 1974 \\
\hline & & $(n=293)$ & $(n=292)$ & $(n=297)$ \\
\hline \multirow[t]{2}{*}{ Duration of problem: } & $\begin{array}{l}3 \text { months or less } \\
4-7 \text { months } \\
8-11 \text { months } \\
1-2 \text { years } \\
2-3 \text { years } \\
\text { more than } 3 \text { years }\end{array}$ & $\begin{aligned} & 6(2.0) \\
& 28(9.6) \\
& 30(10.2) \\
& 67(22.9) \\
& 45(15.4) \\
& 117(39.9)\end{aligned}$ & $\begin{aligned} 6 & (2.1) \\
39 & (13.4) \\
28 & (9.6) \\
64 & (21.9) \\
40 & (13.7) \\
115 & (39.4)\end{aligned}$ & $\begin{aligned} & 7(2.4) \\
& 29(9.8) \\
& 27(9.1) \\
& 58(19.5) \\
& 48(16.2) \\
& 128(43.1)\end{aligned}$ \\
\hline & & $(n=247)$ & $(n=252)$ & $(n=257)$ \\
\hline \multirow[t]{2}{*}{ Previous treatment: } & $\begin{array}{l}\text { hormonal drugs } \\
\text { non-hormonal drugs } \\
\text { OCP } \\
\text { D\&C }\end{array}$ & $\begin{array}{r}99(40.1) \\
103(41.7) \\
58(23.5) \\
55(22.3)\end{array}$ & $\begin{array}{r}91(36.1) \\
108(42.9) \\
55(21.8) \\
64(25.4)\end{array}$ & $\begin{array}{l}84(32.7) \\
96(37.4) \\
61(23.7) \\
55(21.4)\end{array}$ \\
\hline & & $(n=286)$ & $(n=284)$ & $(n=292)$ \\
\hline \multicolumn{2}{|l|}{ Ever had any surgery } & $238(83.2)$ & $236(83.1)$ & $248(84.9)$ \\
\hline \multicolumn{2}{|c|}{ Mean (SD) knowledge of available treatments ${ }^{*}$} & $68(21.0)$ & $66(21.2)$ & $65(23.2)$ \\
\hline \multicolumn{2}{|c|}{ Mean (SD) menorrhagia severity } & $47(14.8)$ & 47 (13.8) & $48(14.8)$ \\
\hline & & $(n=285)$ & $(n=285)$ & $(n=292)$ \\
\hline Treatment preferences: & preference held & $130(45.6)$ & $117(41.1)$ & $139(47.6)$ \\
\hline Hysterectomy & $\begin{array}{l}\text { positive preference } \\
\text { no preference } \\
\text { negative preference }\end{array}$ & $\begin{array}{l}59(45.4) \\
44(33.8) \\
27(20.8)\end{array}$ & $\begin{array}{l}49(41.9) \\
38(32.5) \\
30(25.6)\end{array}$ & $\begin{array}{l}56(40.3) \\
53(38.1) \\
30(21.6)\end{array}$ \\
\hline Endometrial destruction & $\begin{array}{l}\text { positive preference } \\
\text { no preference } \\
\text { negative preference }\end{array}$ & $\begin{aligned} 6 & (4.6) \\
121 & (93.1) \\
3 & (2.3)\end{aligned}$ & $\begin{aligned} 9 & (7.7) \\
106 & (90.6) \\
2 & (1.7)\end{aligned}$ & $\begin{aligned} 6 & (4.3) \\
132 & (95.0) \\
1 & (0.7)\end{aligned}$ \\
\hline Unspecified surgery & $\begin{array}{l}\text { positive preference } \\
\text { no preference } \\
\text { negative preference }\end{array}$ & $\begin{aligned} 2(1.5) \\
115(88.5) \\
13(10.0)\end{aligned}$ & $\begin{array}{c}2(1.7) \\
98(83.8) \\
17(14.5)\end{array}$ & $\begin{aligned} 4 & (2.9) \\
122 & (87.8) \\
13 & (9.4)\end{aligned}$ \\
\hline Drug therapy & $\begin{array}{l}\text { positive preference } \\
\text { no preference } \\
\text { negative preference }\end{array}$ & $\begin{array}{l}13(10.0) \\
75(57.7) \\
42(32.3)\end{array}$ & $\begin{array}{c}6(5.1) \\
62(53.0) \\
49(41.9)\end{array}$ & $\begin{array}{c}5(3.6) \\
73(52.5) \\
61(43.9)\end{array}$ \\
\hline Other treatment & $\begin{array}{l}\text { positive preference } \\
\text { no preference } \\
\text { negative preference }\end{array}$ & $\begin{aligned} 7 & (5.4) \\
120 & (92.3) \\
3 & (2.3)\end{aligned}$ & $\begin{aligned} 5 & (4.3) \\
110 & (94.0) \\
2 & (1.7)\end{aligned}$ & $\begin{aligned} 6 & (4.3) \\
128 & (92.1) \\
5 & (3.6)\end{aligned}$ \\
\hline No treatment & $\begin{array}{l}\text { positive preference } \\
\text { no preference }\end{array}$ & $\begin{array}{c}2(1.5) \\
128(98.5)\end{array}$ & $\begin{aligned} 2(1.7) \\
115(98.3)\end{aligned}$ & $\begin{array}{c}1(0.7) \\
138(99.3)\end{array}$ \\
\hline $\begin{array}{l}\text { * Scored 0-2 for knowledge o } \\
\text { Data given as numbers (perce } \\
\text { (Adapted from Kennedy, et al. } \\
\text { Association.) }\end{array}$ & $\begin{array}{l}\text { en treatment options, the } \\
\text { es) unless stated otherw } \\
\text { 'Related publication' at }\end{array}$ & to a $0-100$ & rmission from $t$ & erican Medical \\
\hline
\end{tabular}


TABLE 4 Clinician's perception of the duration of the consultation by group

\begin{tabular}{|lccc|}
\hline & $\begin{array}{c}\text { Control } \\
(\mathbf{n}=\mathbf{2 5 9})\end{array}$ & $\begin{array}{c}\text { Information } \\
(\mathbf{n}=\mathbf{2 7 2})\end{array}$ & $\begin{array}{c}\text { Interview } \\
(\mathbf{n}=\mathbf{2 7 0})\end{array}$ \\
\hline Longer than average & $49(18.9)$ & $46(16.9)$ & $77(28.5)$ \\
Average & $189(73.0)$ & $200(73.5)$ & $170(63.0)$ \\
Shorter than average & $21(8.1)$ & $26(9.6)$ & $23(8.5)$ \\
\hline Data given as numbers (percentages) & & & \\
\hline
\end{tabular}

TABLE 5 Women's post-consultation treatment-related preferences by group

\begin{tabular}{|c|c|c|c|c|c|c|}
\hline & & \multirow{2}{*}{$\begin{array}{l}\text { Control } \\
(n=235)\end{array}$} & \multicolumn{2}{|c|}{ Information } & \multicolumn{2}{|c|}{ Interview } \\
\hline & & & $(n=240)$ & $\begin{array}{l}\text { Adjusted OR } \\
\qquad(95 \% \mathrm{Cl})\end{array}$ & $(n=233)$ & $\begin{array}{c}\text { Adjusted OR } \\
(95 \% \mathrm{CI})\end{array}$ \\
\hline \multicolumn{2}{|l|}{ Preference held ${ }^{*}$} & $113(48.1)$ & $145(60.4)$ & $\begin{array}{c}1.87 \\
(1.25 \text { to } 2.80)\end{array}$ & $160(68.7)$ & $\begin{array}{c}2.51 \\
\text { (1.66 to } 3.79)\end{array}$ \\
\hline \multicolumn{7}{|c|}{ Actual treatment preferences ${ }^{\dagger}:$} \\
\hline Hysterectomy: & $\begin{array}{l}\text { positive preference } \\
\text { no preference } \\
\text { negative preference }\end{array}$ & $\begin{array}{l}52(46.0) \\
37(32.7) \\
24(21.2)\end{array}$ & $\begin{array}{l}46(31.7) \\
58(40.0) \\
41(28.3)\end{array}$ & & $\begin{array}{l}50(31.3) \\
59(36.9) \\
51(31.9)\end{array}$ & \\
\hline \multicolumn{2}{|c|}{ Likelihood to want treatment } & & & $\begin{array}{c}0.78 \\
(0.44 \text { to } 1.41)\end{array}$ & & $\begin{array}{c}0.54 \\
(0.35 \text { to } 0.85)\end{array}$ \\
\hline $\begin{array}{l}\text { Endometrial } \\
\text { destruction: }\end{array}$ & $\begin{array}{l}\text { positive preference } \\
\text { no preference } \\
\text { negative preference }\end{array}$ & $\begin{aligned} 6 & (5.3) \\
106 & (93.8) \\
1 & (0.9)\end{aligned}$ & $\begin{aligned} 12 & (8.3) \\
127 & (87.6) \\
6 & (4.1)\end{aligned}$ & & $\begin{aligned} 22 & (13.8) \\
133 & (83.1) \\
5 & (3.1)\end{aligned}$ & \\
\hline \multicolumn{2}{|c|}{ Likelihood to want treatment } & & & $\begin{array}{c}0.93 \\
(0.42 \text { to } 2.03)\end{array}$ & & $\begin{array}{c}1.45 \\
\text { (0.77 to } 2.74)\end{array}$ \\
\hline Unspecified surgery & $\begin{array}{l}\text { positive preference } \\
\text { no preference } \\
\text { negative preference }\end{array}$ & $\begin{array}{c}1(0.9) \\
95(84.1) \\
17(15.0)\end{array}$ & $\begin{aligned} & 2(1.4) \\
& 117(80.7) \\
& 26(17.9)\end{aligned}$ & & $\begin{array}{r}3(1.9) \\
134(83.8) \\
23(14.4)\end{array}$ & \\
\hline \multicolumn{2}{|c|}{ Likelihood to want treatment } & & & $\begin{array}{c}0.79 \\
(0.32 \text { to } 1.90)\end{array}$ & & $\begin{array}{c}0.92 \\
(0.49 \text { to } 1.70)\end{array}$ \\
\hline Drug therapy: & $\begin{array}{l}\text { positive preference } \\
\text { no preference } \\
\text { negative preference }\end{array}$ & $\begin{array}{c}8(7.1) \\
72(63.7) \\
33(29.2)\end{array}$ & $\begin{array}{l}23(15.9) \\
71(49.0) \\
51(35.2)\end{array}$ & & $\begin{array}{l}19(11.9) \\
70(43.8) \\
71(44.4)\end{array}$ & \\
\hline \multicolumn{2}{|c|}{ Likelihood to want treatment } & & & $\begin{array}{c}0.59 \\
(0.31 \text { to } 1.09)\end{array}$ & & $\begin{array}{c}0.44 \\
(0.24 \text { to } 0.82)\end{array}$ \\
\hline Other treatment: & $\begin{array}{l}\text { positive preference } \\
\text { no preference } \\
\text { negative preference }\end{array}$ & $\begin{aligned} 7 & (6.2) \\
99 & (87.6) \\
7 & (6.2)\end{aligned}$ & $\begin{aligned} 10 & (6.9) \\
131 & (90.3) \\
4 & (2.8)\end{aligned}$ & & $\begin{aligned} 8 & (5.0) \\
151 & (94.4) \\
1 & (0.6)\end{aligned}$ & \\
\hline \multicolumn{2}{|c|}{ Likelihood to want treatment } & & & $\begin{array}{c}1.46 \\
(0.48 \text { to } 4.46)\end{array}$ & & $\begin{array}{l}1.57 \\
(0.66 \text { to } 3.76)\end{array}$ \\
\hline No treatment: & $\begin{array}{l}\text { positive preference } \\
\text { no preference }\end{array}$ & $\begin{array}{c}3(2.7) \\
110(97.3)\end{array}$ & $\begin{array}{c}4(2.8) \\
141(97.2)\end{array}$ & & $\begin{array}{c}5(3.1) \\
155(96.9)\end{array}$ & \\
\hline \multicolumn{7}{|c|}{$\begin{array}{l}\text { *OR calculated using logistic regression with a reference category of Control group } \\
+ \text { 'OR calculated using ordinal regression with a reference category of Control group and a referral level of 'negative preference' }\end{array}$} \\
\hline \multicolumn{7}{|c|}{ Data given as numbers (percentages) unless stated otherwise } \\
\hline
\end{tabular}


TABLE 6 Change in treatment-related preferences between baseline and post-consultation by group for women who completed both questionnaires

\begin{tabular}{|c|c|c|c|c|c|}
\hline & \multirow{2}{*}{$\begin{array}{l}\text { Control } \\
(n=225)\end{array}$} & \multicolumn{2}{|c|}{ Information } & \multicolumn{2}{|c|}{ Interview } \\
\hline & & $(n=234)$ & $\begin{array}{l}\text { Adjusted OR } \\
\quad(95 \% \mathrm{Cl})\end{array}$ & $(n=226)$ & $\begin{array}{l}\text { Adjusted OR } \\
\quad(95 \% \mathrm{Cl})\end{array}$ \\
\hline \multirow[t]{2}{*}{$\begin{array}{l}\text { Women with no preference at baseline: } \\
\text { preference formed post-consultation }\end{array}$} & $\begin{array}{r}122(54.2) \\
34(27.9)\end{array}$ & $\begin{array}{r}135(57.7) \\
67(49.6)\end{array}$ & $\begin{array}{c}- \\
2.48 \\
(1.46 \text { to } 4.20)\end{array}$ & $\begin{array}{r}114(50.4) \\
61(53.5)\end{array}$ & $\begin{array}{c}- \\
2.97 \\
(1.72 \text { to } 5.13)\end{array}$ \\
\hline & & & $\begin{array}{l}\text { Adjusted RRR } \\
\quad(95 \% \mathrm{Cl})\end{array}$ & & $\begin{array}{l}\text { Adjusted RRR } \\
\qquad(95 \% \mathrm{Cl})\end{array}$ \\
\hline $\begin{array}{l}\text { Women who stated a preference at baseline: } \\
\text { maintained preference post-consultation }\end{array}$ & $\begin{array}{r}103(45.7) \\
38(36.9)\end{array}$ & $\begin{array}{l}99(42.3) \\
20(20.2)\end{array}$ & $\begin{array}{l}- \\
-\end{array}$ & $\begin{array}{r}112(49.6) \\
34(30.4)\end{array}$ & $\begin{array}{l}- \\
-\end{array}$ \\
\hline $\begin{array}{l}\text { changed preference post-consultation }{ }^{\dagger} \\
\text { no preference post-consultation }{ }^{\dagger}\end{array}$ & $\begin{array}{l}36(35.0) \\
29(28.2)\end{array}$ & $\begin{array}{l}55(55.6) \\
24(24.2)\end{array}$ & $\begin{array}{c}3.56 \\
(1.86 \text { to } 6.84) \\
1.92 \\
(1.03 \text { to } 3.60)\end{array}$ & $\begin{array}{l}61(54.5) \\
17(15.2)\end{array}$ & $\begin{array}{c}2.08 \\
(1.21 \text { to } 3.57) \\
0.67 \\
(0.32 \text { to } 1.39)\end{array}$ \\
\hline \multicolumn{6}{|c|}{$\begin{array}{l}\text { * OR calculated using logistic regression with a reference category of Control group } \\
\text { 'RRR calculated using multinomial logistic regression with a reference category of 'women who maintained their preference post- } \\
\text { consultation' } \\
\text { Data given as numbers (percentages) unless stated otherwise }\end{array}$} \\
\hline
\end{tabular}

and interview groups (adjusted relative risk ratio (RRR) 2.88 (95\% CI, 1.45 to 5.72$)$, $p=0.002)$.

\section{Women's perceived knowledge and satisfaction}

After the gynaecological consultation, women in all three groups reported high rates of perceived knowledge for the available treatment options. However, women in the intervention groups were more likely to say that they understood what treatment options were available to them than those in the control group (Table 7). The effect was more variable in the interview group, which did not reach significance (information: $p=0.011$; interview: $p=0.072$ ). There were no significant differences between the groups in the extent to which women agreed that they had as much involvement in the treatment choice as they wanted. Compared with controls, both intervention groups were less likely to agree with the statement that their opinion was important in reaching the treatment decision, but these differences were not statistically significant (information: $p=0.053$; interview: $p=0.28$ ). 
TABLE 7 Women's perceived knowledge and satisfaction post-consultation by group

\begin{tabular}{|c|c|c|c|c|c|}
\hline & \multirow{2}{*}{$\begin{array}{l}\text { Control } \\
(n=237)\end{array}$} & \multicolumn{2}{|c|}{ Information } & \multicolumn{2}{|c|}{ Interview } \\
\hline & & $(n=244)$ & $\begin{array}{l}\text { Adjusted OR } \\
\quad(95 \% \mathrm{CI})\end{array}$ & $(n=236)$ & $\begin{array}{l}\text { Adjusted OR } \\
\quad(95 \% \mathrm{CI})\end{array}$ \\
\hline $\begin{array}{l}\text { I fully understood what treatment } \\
\text { options are available to me: }\end{array}$ & $(n=233)$ & $(n=241)$ & & $(n=231)$ & \\
\hline strongly agree & $56(24.0)$ & $86(35.7)$ & & $71(30.7)$ & \\
\hline agree & $120(51.5)$ & 101 (41.9) & & $120(51.9)$ & \\
\hline not sure & $29(12.4)$ & 27 (11.2) & & $20(8.7)$ & \\
\hline disagree & $26(11.2)$ & $23(9.5)$ & & $17(7.4)$ & \\
\hline strongly disagree & $2(0.9)$ & $4(1.7)$ & & $3(1.3)$ & \\
\hline Likelihood to agree $^{*}$ & & & $\begin{array}{c}1.41 \\
\text { (1.08 to } 1.84)\end{array}$ & & $\begin{array}{c}1.40 \\
(0.97 \text { to } 2.00)\end{array}$ \\
\hline $\begin{array}{l}\text { I had as much involvement as I wanted } \\
\text { in the choice of treatment I am to have: }\end{array}$ & $(n=229)$ & $(n=239)$ & & $(n=231)$ & \\
\hline strongly agree & $55(24.0)$ & $66(27.6)$ & & $63(27.3)$ & \\
\hline agree & $113(49.3)$ & $116(48.5)$ & & $110(47.6)$ & \\
\hline not sure & $36(15.7)$ & $28(11.7)$ & & $17(7.4)$ & \\
\hline disagree & $22(9.6)$ & $24(10.0)$ & & $29(12.6)$ & \\
\hline strongly disagree & $3(1.3)$ & $5(2.1)$ & & $12(5.2)$ & \\
\hline Likelihood to agree ${ }^{*}$ & & & $\begin{array}{c}1.12 \\
(0.87 \text { to } 1.45)\end{array}$ & & $\begin{array}{c}1.04 \\
(0.76 \text { to } 1.42)\end{array}$ \\
\hline $\begin{array}{l}\text { I am satisfied that my own opinion was } \\
\text { important in reaching a treatment decision: }\end{array}$ & $(n=231)$ & $(n=237)$ & & $(n=232)$ & \\
\hline strongly agree & $62(26.8)$ & $85(35.9)$ & & $71(30.6)$ & \\
\hline agree & $123(53.2)$ & $89(37.6)$ & & $107(46.1)$ & \\
\hline not sure & $27(11.7)$ & $27(11.4)$ & & $19(8.2)$ & \\
\hline disagree & $16(6.9)$ & $29(12.2)$ & & $24(10.3)$ & \\
\hline strongly disagree & $3(1.3)$ & $7(3.0)$ & & $11(4.7)$ & \\
\hline Likelihood to agree $^{\dagger}$ & & & $\begin{array}{c}0.65 \\
(0.42 \text { to } 1.01)\end{array}$ & & $\begin{array}{c}0.78 \\
(0.49 \text { to } 1.23)\end{array}$ \\
\hline \multicolumn{6}{|c|}{$\begin{array}{l}\text { * OR calculated using ordinal regression with a reference category of Control group and a referral level of 'strongly disagree' } \\
\text { † Item recoded as 'agree', 'unsure' and 'disagree'. OR calculated using ordinal regression with a reference category of Control group } \\
\text { and a referral level of 'disagree' }\end{array}$} \\
\hline
\end{tabular}




\section{Chapter 6}

\section{Results: short-term follow-up}

\section{Response to follow-up}

The response rate to short-term follow-up was $71 \%$ (Figure 1B, page 16), with a mean duration of follow-up of 12 months for each study arm. The rates of loss to follow-up varied between the groups, but these differences were not significant (chi-squared, $p=0.35$ ). Comparing baseline characteristics for responders and non-responders showed that nonresponders were significantly more likely to be younger (responders: mean (SD) 41 years (6.6), nonresponders: $39(7.7) ; p<0.0005)$, have more severe menorrhagia (46 (13.5), 51 (16.2); $p=0.0005)$, a lower level of knowledge of available treatments (68 (21.0), $63(21.5) ; p=0.002)$ and to be recruited in the first half of the study ( $n(\%) 295$ (46.8), 154 (58.6); $p=0.002)$. The between-group differences in these effects were only significant for treatment knowledge. Non-responders who had been randomised to the control group were more aware of available treatments than those in the intervention groups (control: mean (SD) 67 (19.4), information: 61 (21.5), interview: 59 (23.2); $p=0.045)$.

\section{Health status}

The observed differences between study arms in health status were small for all the measures used (Table 8 ) and the only difference that was statis-

TABLE 8 Adjusted mean between-group difference in health status at short-term follow-up (95\% Cl)

\begin{tabular}{|c|c|c|c|}
\hline & Interview - Control & Information - Control & Interview - Information \\
\hline & $\begin{array}{l}\text { Interview: } n=208 \text {, } \\
\text { Control: } n=189\end{array}$ & $\begin{array}{l}\text { Information: } n=198 \text {, } \\
\text { Control: } n=189\end{array}$ & $\begin{array}{l}\text { Interview: } n=208 \\
\text { Information: } n=198\end{array}$ \\
\hline$S F-36^{*}$ & & & \\
\hline Physical function & $1.2(-2.4$ to 4.7$)$ & $1.2(-2.4$ to 4.7$)$ & $0.0(-3.5$ to 3.5$)$ \\
\hline Social function & $0.0(-5.0$ to 5.0$)$ & $2.8(-2.3$ to 7.8$)$ & $-2.7(-7.7$ to 2.2$)$ \\
\hline Role physical & $0.5(-7.3$ to 8.3$)$ & $3.0(-4.9$ to 11.0$)$ & $-2.5(-10.3$ to 5.2$)$ \\
\hline Role emotional & $-0.5(-9.8$ to 8.9$)$ & $4.2(-5.3$ to 8.9$)$ & $-4.6(-13.9$ to 13.7$)$ \\
\hline Mental health & $0.8(-3.3$ to 4.9$)$ & $3.3(-0.9$ to 7.4$)$ & $-2.5(-6.6$ to 1.6$)$ \\
\hline Energy/vitality & 2.5 ( -2.0 to 7.0$)$ & $4.9(0.4$ to 9.5$)$ & $-2.5(-6.9$ to 2.0$)$ \\
\hline Pain & $-1.1(-6.3$ to 4.1$)$ & $0.2(-5.1$ to 5.5$)$ & $-1.3(-6.4$ to 3.9$)$ \\
\hline General health perception & $0.6(-3.8$ to 4.9$)$ & $1.4(-3.0$ to 5.8$)$ & $-0.8(-5.2$ to 3.5$)$ \\
\hline & $\begin{array}{l}\text { Interview: } n=202 \text {, } \\
\text { Control: } n=183\end{array}$ & $\begin{array}{l}\text { Information: } n=191 \text {, } \\
\text { Control: } n=183\end{array}$ & $\begin{array}{l}\text { Interview: } n=202 \\
\text { Information: } n=191\end{array}$ \\
\hline EQ-5D tariff & $-0.011(-0.053$ to 0.031$)$ & $-0.008(-0.051$ to 0.034$)$ & $0.003(-0.044$ to 0.039$)$ \\
\hline & $\begin{array}{l}\text { Interview: } n=203 \text {, } \\
\text { Control: } n=186\end{array}$ & $\begin{array}{l}\text { Information: } n=187 \text {, } \\
\text { Control: } n=186\end{array}$ & $\begin{array}{l}\text { Interview: } n=203 \\
\text { Information: } n=187\end{array}$ \\
\hline EQ-5D VAS & $-2.1(-5.7$ to 1.5$)$ & $1.3(-2.3$ to 5.0$)$ & $-3.5(-7.1$ to 0.1$)$ \\
\hline & $\begin{array}{l}\text { Interview: } n=143 \text {, } \\
\text { Control: } n=121\end{array}$ & $\begin{array}{l}\text { Information: } n=124 \text {, } \\
\text { Control: } n=121\end{array}$ & $\begin{array}{l}\text { Interview: } n=143 \\
\text { Information: } n=124\end{array}$ \\
\hline Anxiety & $-0.3(-1.6$ to 0.9$)$ & $-0.9(-2.2$ to 0.4$)$ & $0.6(-0.7$ to 1.9$)$ \\
\hline & $\begin{array}{l}\text { Interview: } n=128 \text {, } \\
\text { Control: } n=98\end{array}$ & $\begin{array}{l}\text { Information: } n=117 \text {, } \\
\text { Control: } n=98\end{array}$ & $\begin{array}{l}\text { Interview: } n=128 \\
\text { Information: } n=117\end{array}$ \\
\hline Menorrhagia outcome me & $-0.9(-5.3$ to 3.5$)$ & $1.1(-3.3$ to 5.6$)$ & $-2.1(-6.2$ to 2.1$)$ \\
\hline
\end{tabular}


tically significant was the energy dimension of the SF-36. Women in the information arm rated their energy levels and vitality significantly higher than those in the control group $(p=0.034)$. All three groups showed improvements from baseline in each of the health status measures (Figure 2).

\section{Treatment undergone}

Table 9 shows the treatments undergone during the follow-up period. Women in the interview group were significantly less likely to undergo hysterectomy than women in the control group $(p=0.034)$.

Women in the information group were also less likely to undergo hysterectomy, but this difference was smaller and not significant $(p=0.55)$. None of the other observed differences in treatments undergone was statistically significant.

\section{Agreement between preferences and treatments undergone}

Amongst women who expressed a treatment preference post-consultation and underwent treatment during follow-up, the likelihood that they would undergo treatments that corresponded with their preferences was assessed (Table 10). Women randomised to the information group were more likely to undergo a treatment that corresponded with their preferences than those in the control group $(p=0.006)$. In comparison with the interview group, the difference did not reach statistical significance (adjusted odds ratio (OR) 1.69 (95\% CI, 0.99 to 2.87$), p=0.053)$. There was no difference in the likelihood that the interview group would undergo treatments that corresponded with their preferences compared with controls $(p=0.71)$.

\section{Satisfaction}

Women in the intervention arms rated the opportunities they had been given to become involved in treatment decision-making more highly than those in the control group (Table 11). As observed with satisfaction post-consultation, the ratings by women in the interview group were more variable than those of the information group and did not achieve significance (information: $p=0.027$; interview: $p=0.057$ ). There were no differences between the groups in women's ratings of the results of treatment and whether they would make the same treatment choices again.

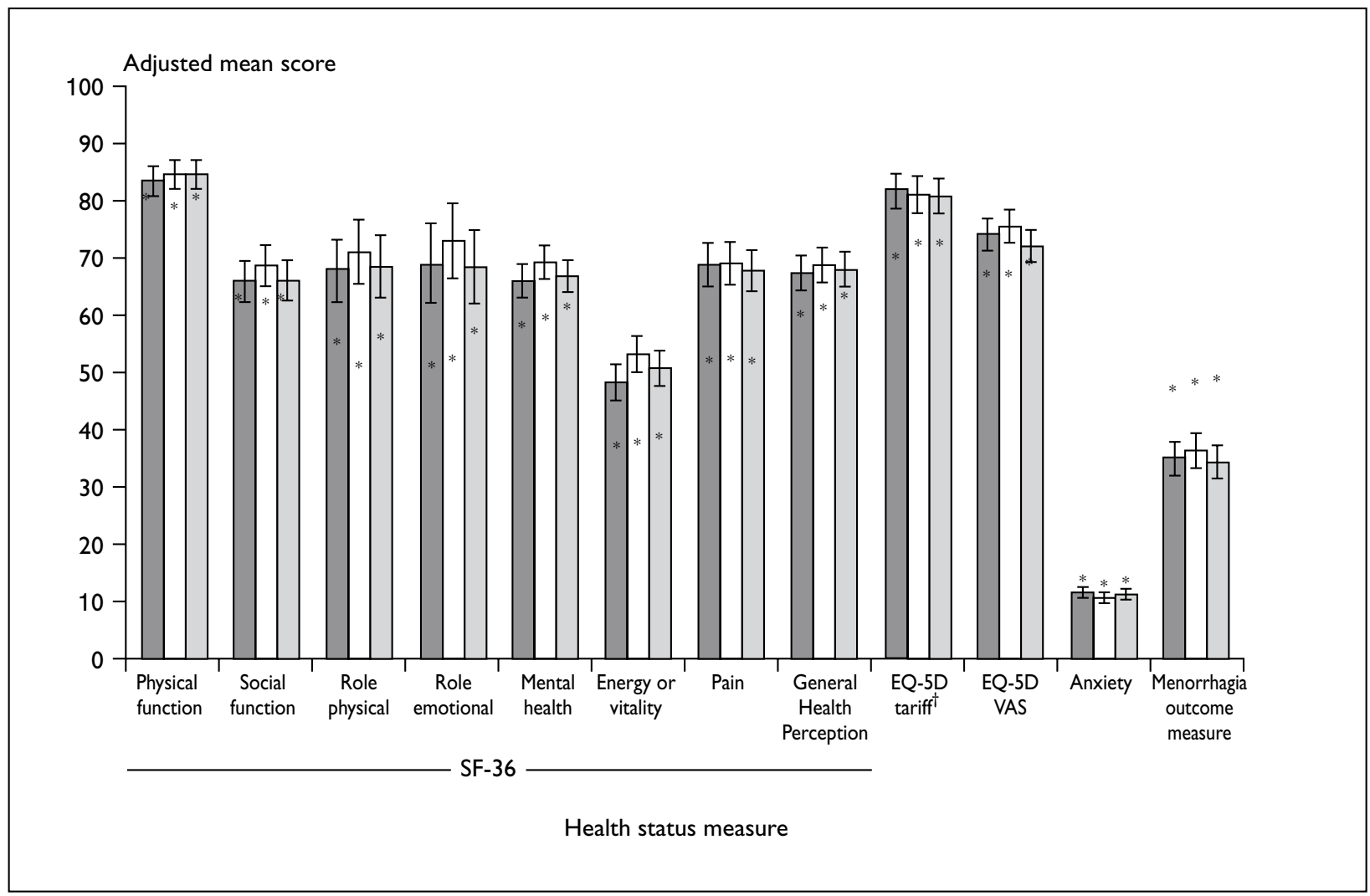

FIGURE 2 Health status at short-term follow-up by group (adjusted mean and 95\% Cl) ( $\square$, control; $\square$, information; $\square$, interview; * baseline score; ${ }^{\dagger} E Q-5 D$ tariff $\left.\times 100\right)$ 
TABLE 11 Women's satisfaction at short-term follow-up by group

\begin{tabular}{|c|c|c|c|c|c|}
\hline & \multirow{2}{*}{$\begin{array}{l}\text { Control } \\
(n=203)\end{array}$} & \multicolumn{2}{|c|}{ Information } & \multicolumn{2}{|c|}{ Interview } \\
\hline & & $(n=205)$ & $\begin{array}{l}\text { Adjusted OR } \\
(95 \% \mathrm{CI})^{*}\end{array}$ & $(n=218)$ & $\begin{array}{l}\text { Adjusted OR } \\
\qquad(95 \% \mathrm{Cl})^{*}\end{array}$ \\
\hline $\begin{array}{l}\text { How would you rate the opportunities } \\
\text { you have been given to become involved } \\
\text { in making decisions about your treatment: }\end{array}$ & $(n=182)$ & $(n=191)$ & & $(n=204)$ & \\
\hline excellent & $49(26.9)$ & $56(29.3)$ & & $66(32.4)$ & \\
\hline good & $63(34.6)$ & $81(42.4)$ & & $80(39.2)$ & \\
\hline fair & $49(26.9)$ & $36(18.8)$ & & $43(21.1)$ & \\
\hline poor & $21(11.5)$ & $18(9.4)$ & & $15(7.4)$ & \\
\hline Likelihood to be satisfied* & & & $\begin{array}{c}1.39 \\
(1.04 \text { to } 1.86)\end{array}$ & & $\begin{array}{c}1.49 \\
(0.99 \text { to } 2.25)\end{array}$ \\
\hline $\begin{array}{l}\text { Overall, how would you rate the } \\
\text { results of treatments for heavy periods: }\end{array}$ & $(n=173)$ & $(n=187)$ & & $(n=196)$ & \\
\hline excellent & $65(37.6)$ & $57(30.5)$ & & $69(35.2)$ & \\
\hline good & $41(23.7)$ & $71(38.0)$ & & $61(31.1)$ & \\
\hline fair & $46(26.6)$ & $35(18.7)$ & & $42(21.4)$ & \\
\hline poor & $21(12.1)$ & $24(12.8)$ & & $24(12.2)$ & \\
\hline Likelihood to be satisfied" & & & $\begin{array}{c}0.96 \\
(0.72 \text { to } 1.28)\end{array}$ & & $\begin{array}{c}1.05 \\
(0.72 \text { to } 1.55)\end{array}$ \\
\hline $\begin{array}{l}\text { Would make the same treatment } \\
\text { choices again? }{ }^{\dagger}\end{array}$ & $\begin{array}{r}(n=176) \\
142(80.7)\end{array}$ & $\begin{array}{l}(n=183) \\
153(83.6)\end{array}$ & $\begin{array}{c}1.34 \\
(0.71 \text { to } 2.53)\end{array}$ & $\begin{array}{l}(n=192) \\
166(86.5)\end{array}$ & $\begin{array}{c}1.58 \\
\text { (0.83 to } 2.99)\end{array}$ \\
\hline \multicolumn{6}{|c|}{$\begin{array}{l}\text { * OR calculated using ordinal regression with a reference category of Control group and a referral level of 'poor' } \\
\text { † OR calculated using logistic regression with a reference category of Control group }\end{array}$} \\
\hline Data given as numbers (percentages) unless st & ted otherwise & & & & \\
\hline
\end{tabular}




\section{Chapter 7}

\section{Results: long-term follow-up}

\section{Response to follow-up}

The response rate to the long-term follow-up was $70 \%$ (Figure 1C, page 16), with a mean duration of follow-up of 26 months for each study arm. The rates of loss to follow-up varied between the groups, but these differences were not significant (chi-squared, $p=0.69$ ). Comparing baseline characteristics for responders and non-responders showed that non-responders were significantly younger (responders: mean (SD) 41 years (6.5), non-responders: 39 (7.8); $p<0.0005)$, had more severe menorrhagia (46 (13.8), 50 (15.7); $p=0.001)$, a lower level of knowledge of available treatments $(68(21.0), 63(21.4) ; p=0.002)$ and were less likely to have had previous treatment with non-hormonal drugs (241 (38.8), 66 (25.0); $p<0.005)$. There were no between-group differences in these effects.

\section{Health status}

As with the results from the first year of follow-up, the effects of the interventions on health status were variable. Table 12 shows the between-group differences in SF-36 and menorrhagia severity. The role physical dimension, which measures the extent of any physical limitations to the women's lifestyle, with higher values indicating less limitation, was significantly higher in the interview group compared with the control group $(p=0.041)$. None of the other differences reached statistical significance. Figure 3 shows the adjusted mean health status scores for the three groups; again, improvements from baseline were evident.

\section{Treatments undergone}

The treatments reported by women at any point during the 2 years of follow-up are summarised in Table 13. Treatment data were reported by $81 \%$ of women during follow-up; this rate did not differ significantly between the groups (chi-squared, $p=0.17)$.

The interview group showed a significant reduction in hysterectomy rate in comparison with the control group $(p=0.039)$ and the information group (adjusted OR (95\% CI), 0.52 (0.33 to 0.82), $p=0.008)$. There was no difference between the

TABLE 12 Adjusted mean between-group difference in health status at long-term follow-up (95\% CI)

\begin{tabular}{|c|c|c|c|}
\hline & \multirow{2}{*}{$\begin{array}{l}\text { Interview - Control } \\
\text { Interview: } n=176, \\
\text { Control: } n=157\end{array}$} & \multirow{2}{*}{$\begin{array}{l}\text { Information - Control } \\
\text { Information: } n=164, \\
\text { Control: } n=157\end{array}$} & \multirow{2}{*}{$\begin{array}{l}\text { Interview - Information } \\
\text { Interview: } n=176 \\
\text { Information: } n=164\end{array}$} \\
\hline & & & \\
\hline \multicolumn{4}{|l|}{ SF-36* } \\
\hline Physical function & $1.1(-2.7$ to 4.8$)$ & $2.5(-1.3$ to 6.3$)$ & $-1.5(-5.2$ to 2.3$)$ \\
\hline Social function & $3.4(-1.5$ to 8.3$)$ & $0.2(-4.8$ to 5.2$)$ & $3.2(-1.6$ to 8.1$)$ \\
\hline Role physical & $8.3(0.4$ to 16.2$)$ & $2.5(-5.5$ to 10.6$)$ & $5.7(-2.1$ to 13.6$)$ \\
\hline Role emotional & $2.7(-6.5$ to 12.0$)$ & $-4.4(-13.8$ to 5.0$)$ & $7.1(-2.0$ to 16.4$)$ \\
\hline Mental health & $1.8(-2.0$ to 5.7$)$ & $0.8(-3.2$ to 4.7$)$ & $1.1(-2.8$ to 4.9$)$ \\
\hline Energy/vitality & $1.2(-4.1$ to 6.6$)$ & $0.9(-4.5$ to 6.3$)$ & $0.4(-5.0$ to 5.7$)$ \\
\hline Pain & $0.7(-4.8$ to 6.2$)$ & $0.4(-5.2$ to 6.0$)$ & $0.3(-5.2$ to 5.7$)$ \\
\hline \multirow[t]{2}{*}{ General health perception } & $1.2(-2.6$ to 5.1$)$ & $1.4(-2.6$ to 5.3$)$ & $-0.1(-4.0$ to 3.7$)$ \\
\hline & $\begin{array}{l}\text { Interview: } n=88 \text {, } \\
\text { Control: } n=81\end{array}$ & $\begin{array}{l}\text { Information: } n=74 \text {, } \\
\text { Control: } n=81\end{array}$ & $\begin{array}{l}\text { Interview: } n=88 \\
\text { Information: } n=81\end{array}$ \\
\hline \multicolumn{2}{|c|}{ Menorrhagia outcome measure -0.5 (-5.7 to 4.6$)$} & $-0.8(-6.0$ to 4.4$)$ & $0.3(-4.9$ to 5.4$)$ \\
\hline \multicolumn{4}{|c|}{$\begin{array}{l}\text { Numbers of responders vary across the dimensions of the SF-36 due to missing responses. Control: } \mathrm{n}=153-157 ; \text { Information: } \\
\mathrm{n}=159-164 ; \text { Interview: } \mathrm{n}=170-176\end{array}$} \\
\hline
\end{tabular}




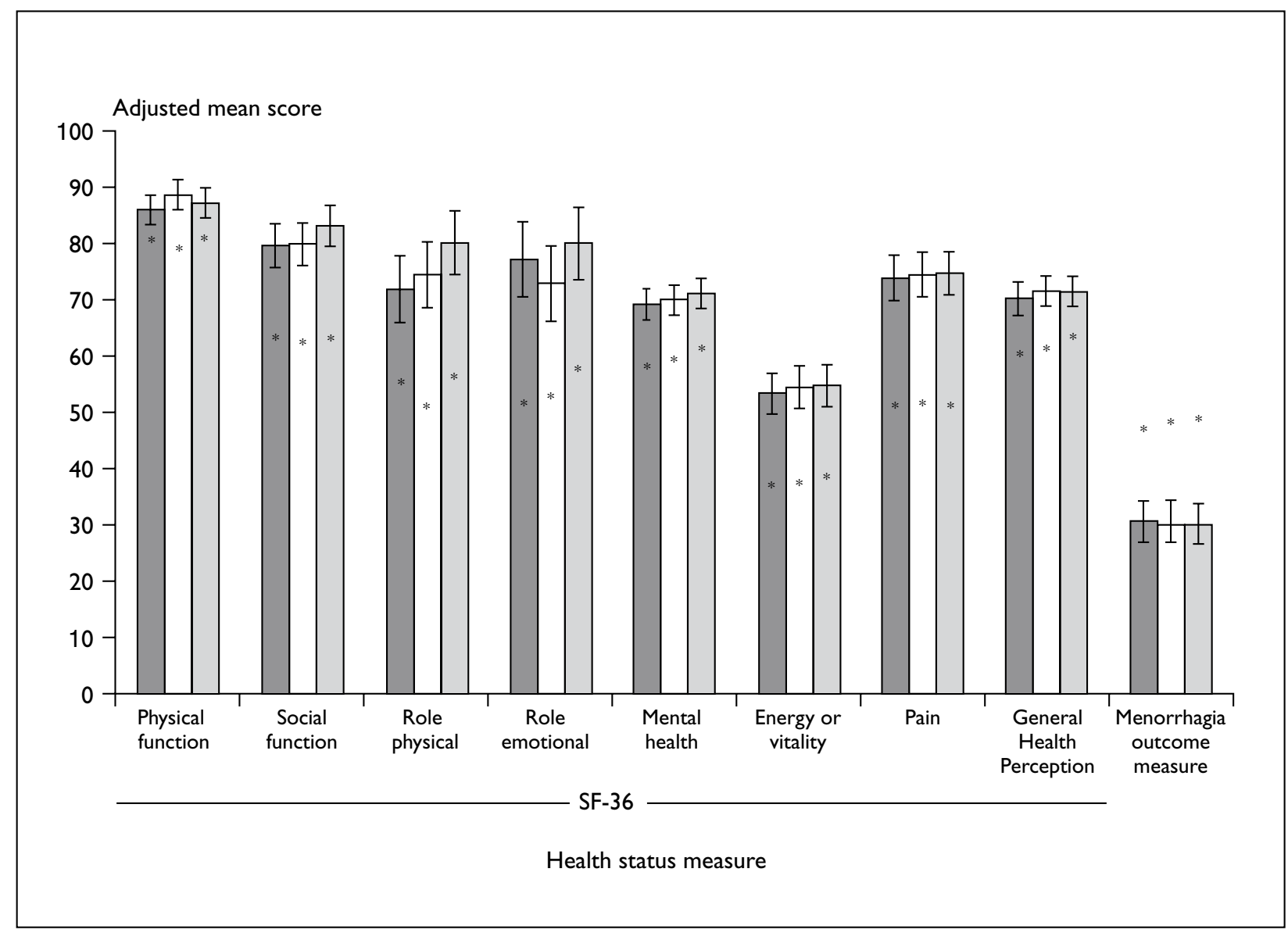

FIGURE 3 Health status at long-term follow-up by group (adjusted mean and $95 \% \mathrm{Cl}$ ) ( $\square$, control; $\square$, information; $\square$, interview; * baseline score)

TABLE 13 Treatments undergone during long-term follow-up by group

\begin{tabular}{|c|c|c|c|c|c|}
\hline & \multirow{2}{*}{$\begin{array}{l}\text { Control } \\
(n=244)\end{array}$} & \multicolumn{2}{|c|}{ Information } & \multicolumn{2}{|c|}{ Interview } \\
\hline & & $(n=232)$ & $\begin{array}{l}\text { Adjusted OR } \\
(95 \% \mathrm{CI})^{*}\end{array}$ & $(n=253)$ & $\begin{array}{l}\text { Adjusted OR } \\
\qquad(95 \% \mathrm{Cl})^{*}\end{array}$ \\
\hline Treatment undergone & $196(80.3)$ & $204(87.9)$ & & $212(83.8)$ & \\
\hline \multicolumn{5}{|l|}{ Reported treatment ${ }^{\dagger}:$} & 0.60 \\
\hline endometrial destruction & $16(8.2)$ & $15(7.4)$ & $\begin{array}{l}(0.73 \text { to } 1.85) \\
0.51 \\
(0.18 \text { to } 1.42)\end{array}$ & $25(11.8)$ & $\begin{array}{l}(0.38 \text { to } 0.96) \\
0.88 \\
(0.33 \text { to } 2.30)\end{array}$ \\
\hline drug therapy & $119(60.7)$ & $138(67.6)$ & $\begin{array}{c}1.40 \\
(0.87 \text { to } 2.25)\end{array}$ & $145(68.4)$ & $\begin{array}{c}1.48 \\
(0.93 \text { to } 2.36)\end{array}$ \\
\hline other treatment & $36(18.4)$ & $39(19.1)$ & $\begin{array}{l}0.99 \\
(0.59 \text { to } 1.67)\end{array}$ & $43(20.3)$ & $\begin{array}{c}1.14 \\
(0.68 \text { to } 1.89)\end{array}$ \\
\hline Hysterectomy undergone or waiting for ${ }^{\ddagger}$ & $101(51.5)$ & $101(49.3)$ & $\begin{array}{c}1.03 \\
(0.67 \text { to } 1.60)\end{array}$ & $82(38.7)$ & $\begin{array}{c}0.53 \\
(0.35 \text { to } 0.83)\end{array}$ \\
\hline \multicolumn{6}{|c|}{$\begin{array}{l}\text { * OR calculated using logistic regression with a reference category of Control group } \\
\text { † Women may have undergone more than one treatment } \\
\text { } \text { Denominator for Information group }=205 \text {; one woman in this group reported that they were waiting for a hysterectomy but had } \\
\text { undergone no other treatment }\end{array}$} \\
\hline \multicolumn{6}{|c|}{ Data given as numbers (percentages) unless stated otherwise } \\
\hline \multicolumn{6}{|c|}{$\begin{array}{l}\text { (Adapted from Kennedy, et al. (see 'Related publication' at front of this monograph), with permission from the American Medical } \\
\text { Association.) }\end{array}$} \\
\hline
\end{tabular}




\section{Chapter 8}

\section{Economic evaluation}

\section{Data availability}

The extent of missing data for the economic analyses is described in Table 17. The degree of missingness varies considerably between the categories and there are a number of reasons behind this pattern. All the variables suffer from questionnaire non-response; however, the effect on treatment and to a lesser extent test data is not as strong for two reasons. First, data for surgery and other procedures were collected cumulatively in that women were asked for treatments undergone since their first outpatient appointment. Secondly, in forming the economic dataset, we assumed that if women underwent a hysterectomy in one period then they could not undergo any further tests, surgery or other procedures in subsequent periods. This assumption does not apply to drug treatment, however, as some women who underwent hysterectomy will have been prescribed hormone replacement therapy. The proportion of data missing for NHS contacts has the additional cause of administrative censoring, where these data were not collected from women undergoing a telephone interview.

\section{Resource use}

Actual resource use reported by the three groups is described in Table 18. There are small differences between the groups in terms of tests undergone, and the difference in treatments described in the previous chapter are also evident, although the change in the denominator should be noted. The hysterectomy rate in the interview group is $7 \%$ lower than that of the control group and $10 \%$ lower than the information group. In terms of visits and stays, the main item that stands out is the high rate of inpatient stay for medical reasons in the control group. The majority of this effect comes from one woman who had an inpatient medical stay of 189 days.

\section{Costs}

Tables 19 and 20 report the mean costs and the mean between-group differences in costs from the imputed dataset. The main factors influencing costs are surgery and other procedures, and inpatient and outpatient costs. The driver for the lower surgery costs in the interview group comes from the reduction in hysterectomy rates, but this is partially offset by the greater number receiving endometrial destruction and the levonorgestrelreleasing IUCD. The higher rates of nongynaecology health service contacts have the greatest influence over the between-group differences in inpatient and outpatient costs.

In terms of overall costs, both intervention groups show major mean cost reductions in comparison with the control group. The interview group also shows a saving in comparison with the information group. The overall cost, however, is greatly influenced by hospital contacts. To assess the difference in costs without this influence, overall costs were calculated in two alternative ways. (1) Excluding all non-gynaecology health service contacts. The same effects were evident, but the sizes of the differences were reduced, especially for the comparison with the interview group. (2) We then looked at the overall costs excluding those associated with all inpatient stays and nongynaecology outpatient and GP visits. This reduced the between-group differences greatly. The difference between interview and control now shows just a small cost saving, and the information group shows a higher cost in comparison with controls.

TABLE 17 Summary of missing data pattern for health outcome and resource use data used in economic analyses

\begin{tabular}{|lllll|}
\hline & $\begin{array}{l}\text { EQ-5D } \\
(\mathbf{n = 8 9 4 )}\end{array}$ & $\begin{array}{l}\text { Treatments } \\
(\mathbf{n = 8 9 4 )}\end{array}$ & $\begin{array}{l}\text { Tests } \\
(\boldsymbol{n}=\mathbf{8 9 4})\end{array}$ & $\begin{array}{l}\text { NHS contacts } \\
(\boldsymbol{n}=\mathbf{8 9 4})\end{array}$ \\
\hline Data reported at one or more time points & $642(71.8)$ & $729(81.5)$ & $670(74.5)$ & $594(66.4)$ \\
Data reported at all time points & $365(40.8)$ & $666(74.5)$ & $475(53.1)$ & $185(20.7)$ \\
\hline Data given as numbers (percentages) & & & & \\
\hline
\end{tabular}


TABLE 18 Reported resource use by group

\begin{tabular}{|c|c|c|c|}
\hline \multirow[b]{2}{*}{ Tests } & \multirow{2}{*}{$\begin{array}{l}\text { Control } \\
n=222\end{array}$} & \multirow{2}{*}{$\begin{array}{l}\text { Information }^{*} \\
n=215\end{array}$} & \multirow{2}{*}{$\begin{array}{l}\text { Interview } \\
n=233\end{array}$} \\
\hline & & & \\
\hline $\mathrm{D \& C}$ & $36(16)$ & $39(18)$ & $46(20)$ \\
\hline Endometrial biopsy & $19(9)$ & $27(13)$ & $15(6)$ \\
\hline Laparoscopy & $11(5)$ & $13(6)$ & $12(5)$ \\
\hline Hysteroscopy & $19(9)$ & $32(15)$ & $21(9)$ \\
\hline Ultrasound scan & $29(13)$ & $35(16)$ & $40(17)$ \\
\hline Blood test & $32(14)$ & $40(19)$ & $39(17)$ \\
\hline Colposcopy & $0(0)$ & $3(1)$ & $1(0)$ \\
\hline Examination under anaesthetic & $1(0.5)$ & $0(0)$ & $2(1)$ \\
\hline Treatments & $n=244$ & $n=232$ & $n=253$ \\
\hline \multicolumn{4}{|c|}{ Drugs - number of women reporting use (per cent) } \\
\hline Hormonal & $69(28)$ & $81(35)$ & $83(33)$ \\
\hline Non-hormonal & $65(27)$ & $78(34)$ & $75(30)$ \\
\hline \multicolumn{4}{|l|}{ Surgery and procedures } \\
\hline Hysterectomy & $94(39)$ & $98(42)$ & $81(32)$ \\
\hline Endometrial destruction & $16(7)$ & $15(6)$ & $25(10)$ \\
\hline Polyp removal & $7(3)$ & $7(3)$ & $4(2)$ \\
\hline Fibroid removal & $3(1)$ & $3(1)$ & $3(1)$ \\
\hline Levonorgestrel-releasing IUCD & $26(11)$ & $27(12)$ & $34(13)$ \\
\hline Other & $5(2)$ & $5(2)$ & $6(2)$ \\
\hline NHS contacts & $n=190$ & $n=191$ & $n=213$ \\
\hline \multicolumn{4}{|c|}{$\begin{array}{l}\text { Inpatient days - } \\
\text { number of days in hospital } \\
\text { (number of days per patient) }\end{array}$} \\
\hline Gynaecology & $26(0.14)$ & $4(0.02)$ & $17(0.08)$ \\
\hline Obstetrics & $5(0.03)$ & $3(0.02)$ & $0(0.00)$ \\
\hline Surgery & $4(0.02)$ & $61(0.32)$ & $7(0.03)$ \\
\hline Medical & $217(1.14)$ & $37(0.19)$ & $7(0.03)$ \\
\hline $\begin{array}{l}\text { All outpatient visits - } \\
\text { number of visits } \\
\text { (number of visits per patient) }\end{array}$ & $291(1.53)$ & $286(1.50)$ & $265(1.24)$ \\
\hline $\begin{array}{l}\text { Outpatient visits } \\
\text { (menorrhagia-related) }\end{array}$ & $175(0.92)$ & $158(0.83)$ & $160(0.75)$ \\
\hline $\begin{array}{l}\text { Outpatient visits } \\
\text { (not menorrhagia-related) }\end{array}$ & $116(0.61)$ & $128(0.67)$ & $105(0.49)$ \\
\hline $\begin{array}{l}\text { All GP visits - } \\
\text { number of visits } \\
\text { (number of visits per patient) }\end{array}$ & $595(3.13)$ & $614(3.21)$ & $673(3.16)$ \\
\hline GP visits (menorrhagia-related) & $268(1.41)$ & $296(1.55)$ & $334(1.57)$ \\
\hline $\begin{array}{l}\text { GP visits } \\
\text { (not menorrhagia-related) }\end{array}$ & $327(1.72)$ & $318(1.66)$ & $339(1.59)$ \\
\hline \multicolumn{4}{|c|}{$\begin{array}{l}\text { Number of procedures performed (percentages) unless stated otherwise } \\
\text { (Adapted from Kennedy, et al. (see 'Related publication' at front of this monograph), with permission from the American Medical } \\
\text { Association.) }\end{array}$} \\
\hline
\end{tabular}


TABLE 19 Mean costs $(\boldsymbol{E})$ after 2 years of follow-up by group

\begin{tabular}{|lccc|}
\hline & $\begin{array}{c}\text { Control } \\
(\mathbf{n = 2 9 8 )}\end{array}$ & $\begin{array}{c}\text { Information } \\
(\mathbf{n = 2 9 6 )}\end{array}$ & $\begin{array}{c}\text { Interview } \\
(\mathbf{n}=\mathbf{3 0 0})\end{array}$ \\
\hline Test costs & 85 & 94 & 83 \\
Drug costs & 73 & 73 & 71 \\
Surgery/procedure costs & 634 & 697 & 567 \\
All inpatient and outpatient costs & 947 & 383 & 212 \\
All GP visit costs & 71 & 71 & 80 \\
Inpatient and outpatient costs (menorrhagia-related) & 196 & 92 & 34 \\
GP visit costs (menorrhagia-related) & 34 & 34 & 1030 \\
\hline Total cost & 1810 & 1333 & 907 \\
All costs & 1446 & 995 & 853 \\
\hline Sensitivity analysis & 887 & 946 & 34 \\
Excluding unrelated inpatient, outpatient and GP costs & & & \\
Excluding all inpatient and unrelated outpatient and GP costs & 84 & \\
\hline (Adapted from Kennedy, et al. (see 'Related publication' at front of this monograph), with permission from the American Medical \\
\hline Association.)
\end{tabular}

TABLE 20 Between-group difference in costs after 2 years of follow-up

\begin{tabular}{|c|c|c|c|}
\hline & $\begin{array}{l}\text { Interview - Control } \\
(n=298)\end{array}$ & $\begin{array}{l}\text { Information - Control } \\
(n=296)\end{array}$ & $\begin{array}{l}\text { Interview - Information } \\
(n=300)\end{array}$ \\
\hline Test costs & $-2 \quad(-22$ to 19$)$ & $10 \quad(-11$ to 32$)$ & $-12 \quad(-34$ to 10$)$ \\
\hline Drug costs & $-2 \quad(-18$ to 14$)$ & $0 \quad(-17$ to 17$)$ & $-2 \quad(-19$ to 14$)$ \\
\hline Surgery/procedure costs & $-67 \quad(-178$ to 34$)$ & $63(-50$ to 180$)$ & $-130 \quad(-245$ to -26$)$ \\
\hline All inpatient and outpatient costs & $-735 \quad(-1364$ to -423$)$ & $-563 \quad(-1198$ to -233$)$ & $-171 \quad(-336$ to -77$)$ \\
\hline All GP visit costs & 9 (0 to 18$)$ & $0 \quad(-10$ to 9$)$ & $9 \quad(-1$ to 20$)$ \\
\hline $\begin{array}{l}\text { Inpatient and outpatient costs } \\
\text { (menorrhagia-related) }\end{array}$ & $-81 \quad(-243$ to -8$)$ & $-104 \quad(-263$ to -32$)$ & $23 \quad(-14$ to 79$)$ \\
\hline $\begin{array}{l}\text { GP visit costs } \\
\text { (menorrhagia-related) }\end{array}$ & $0 \quad(-6$ to 6$)$ & $0 \quad(-5$ to 6$)$ & 0 (-6 to 7$)$ \\
\hline \multicolumn{4}{|l|}{ Total cost } \\
\hline $\begin{array}{l}\text { Sensitivity analysis } \\
\text { Excluding unrelated inpatient, } \\
\text { outpatient and GP costs }\end{array}$ & -539 ( -865 to -270$)$ & $-452 \quad(-783$ to -190$)$ & $-88 \quad(-195$ to 22$)$ \\
\hline $\begin{array}{l}\text { Excluding all inpatient and } \\
\text { unrelated outpatient and GP costs }\end{array}$ & $-35 \quad(-146$ to 70$)$ & 59 (-67 to 185$)$ & $-94 \quad(-206$ to 15$)$ \\
\hline $\begin{array}{l}\text { Data given as mean and bootstrappec } \\
\text { (Adapted from Kennedy, et al. (see 'Re } \\
\text { Association.) }\end{array}$ & $\begin{array}{l}\text { d bias corrected and adjuste } \\
\text { elated publication' at front of }\end{array}$ & $\begin{array}{l}95 \% \mathrm{Cls} \\
\text { this monograph), with permiss }\end{array}$ & om the American Medical \\
\hline
\end{tabular}


TABLE 21 Mean utilities and QALYs by group

\begin{tabular}{|llll|}
\hline & $\begin{array}{l}\text { Control } \\
(\boldsymbol{n}=\mathbf{2 9 8})\end{array}$ & $\begin{array}{l}\text { Information } \\
(\boldsymbol{n}=\mathbf{2 9 6})\end{array}$ & $\begin{array}{l}\text { Interview } \\
(\boldsymbol{n}=\mathbf{3 0 0})\end{array}$ \\
\hline $\begin{array}{l}\text { Health utilities } \\
\text { Baseline }\end{array}$ & 0.696 & 0.723 & 0.723 \\
6 months & 0.772 & 0.721 & 0.762 \\
12 months & 0.820 & 0.809 & 0.805 \\
24 months & 0.797 & 0.839 & 0.835 \\
\hline $\begin{array}{l}\text { QALYs } \\
\text { Over 24 months }\end{array}$ & 1.574 & 1.567 & 1.582 \\
\hline
\end{tabular}

TABLE 22 Between-group difference in utilities and QALYS

\begin{tabular}{|c|c|c|c|c|c|c|}
\hline Health utilities & \multicolumn{2}{|c|}{$\begin{array}{l}\text { Interview - Control } \\
(n=298)\end{array}$} & \multicolumn{2}{|c|}{$\begin{array}{l}\text { Information - Control } \\
(n=296)\end{array}$} & \multicolumn{2}{|c|}{$\begin{array}{l}\text { Interview - Information } \\
(n=300)\end{array}$} \\
\hline Baseline & 0.027 & -0.016 to 0.072 & 0.027 & -0.016 to 0.070 & -0.001 & -0.041 to 0.042 \\
\hline 6 months & -0.010 & -0.058 to 0.037 & -0.050 & -0.104 to 0.006 & 0.041 & -0.006 to 0.085 \\
\hline 12 months & -0.016 & -0.054 to 0.020 & -0.012 & -0.053 to 0.032 & -0.004 & -0.047 to 0.036 \\
\hline 24 months & 0.038 & -0.001 to 0.081 & 0.042 & 0.009 to 0.090 & -0.004 & -0.040 to 0.029 \\
\hline $\begin{array}{l}\text { QALYs } \\
\text { Over } 24 \text { months }\end{array}$ & 0.009 & -0.043 to 0.060 & -0.006 & -0.057 to 0.048 & 0.015 & -0.041 to 0.066 \\
\hline
\end{tabular}

\section{Health outcomes}

Health state values from the EQ-5D (utilities) increase for all three groups during the course of the study from baseline until the 24-month follow-up, except for the information group at 6 months and the control group at 24 months (Table 21). These effects also show up in the between-group differences in utility at these points (Table 22). In terms of QALYs, however, the effects across the three groups are similar and the between-group differences are very small.

\section{Cost-effectiveness}

On the basis of mean total costs and QALYs, information plus interview is a dominant intervention in that it has lower mean costs $(£ 1030)$ than information alone (£1333) and control (£1810), and has higher mean QALYs (1.582 versus 1.574 (control) and 1.567 (information)). This suggests that the addition of the interview to the information pack is unequivocally more cost-effective than the other forms of management. Using mean total costs per patient, information alone is less costly than control (£1333 versus £1810), but has modestly lower mean QALYs. Hence, compared with information, control has an incremental cost
Mean costs and QALYs are, however, measured with uncertainty. Figure 4 shows the cost-effectiveness acceptability curve under base-case assumptions. It shows the probability that any one form of management is more cost-effective than the others. Under the base case, where the decision-maker is unwilling to pay anything extra for an additional life-year, information plus interview is certain to be more cost-effective (i.e. less costly). If the decision-maker is willing to pay $£ 30,000$ per additional QALY, the probability of interview being more cost-effective than the other forms of management is $78 \%$.

\section{Sensitivity analysis}

As discussed above, overall costs are sensitive to the costs associated with health service contacts. Additional influences on the cost-effectiveness of the interventions are the costs of the interventions themselves, described in Table 2, and the perceived increase in consultation length by the clinicians (Table 4). A range of sensitivity analyses was therefore undertaken.

\section{Excluding unrelated costs}

Under this scenario, information plus interview remains the dominant intervention. There is no 


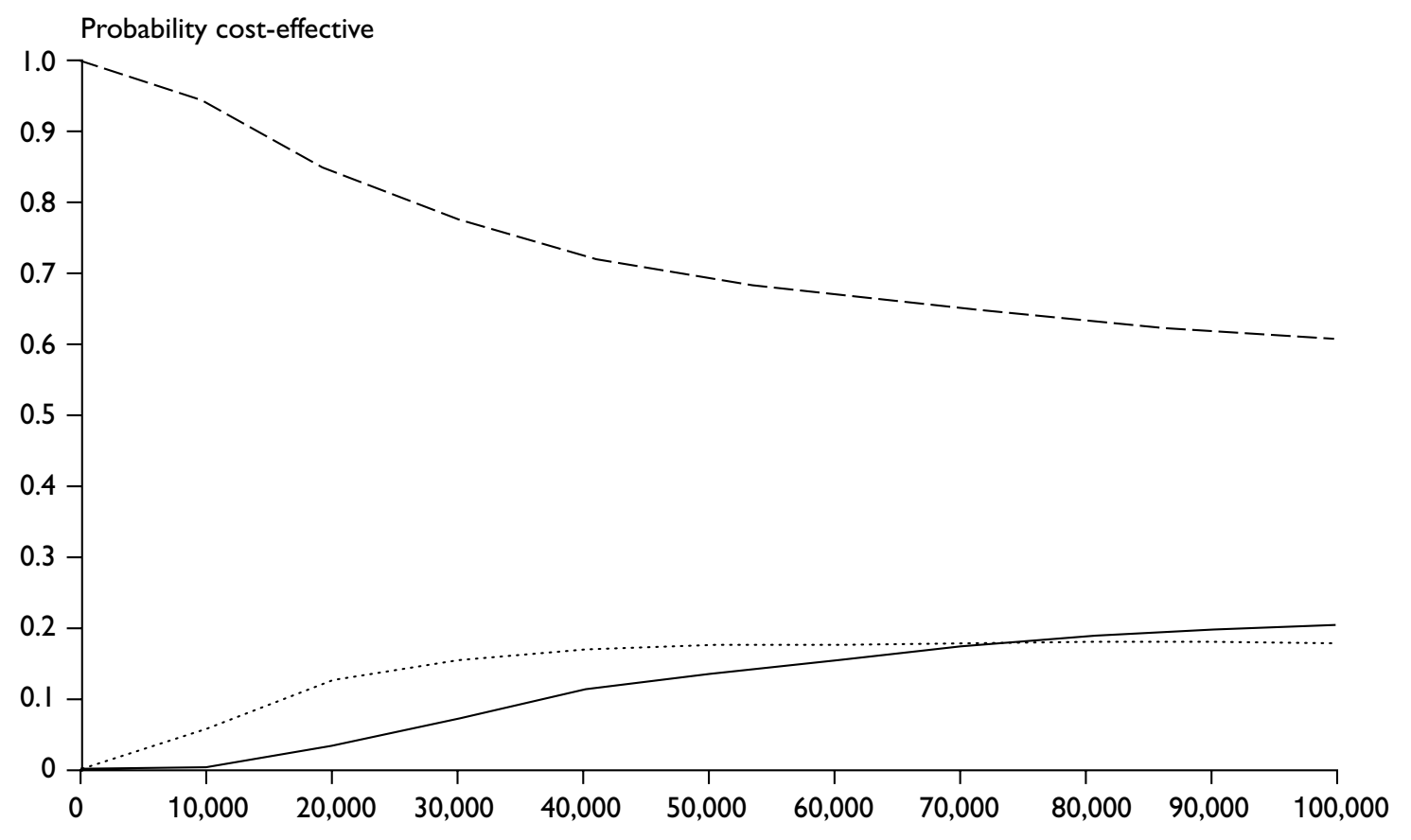

Maximum acceptable incremental cost per QALY $(€)$

FIGURE 4 Cost-effectiveness acceptability curves: base case (—, control; .........., information; - - -, interview)

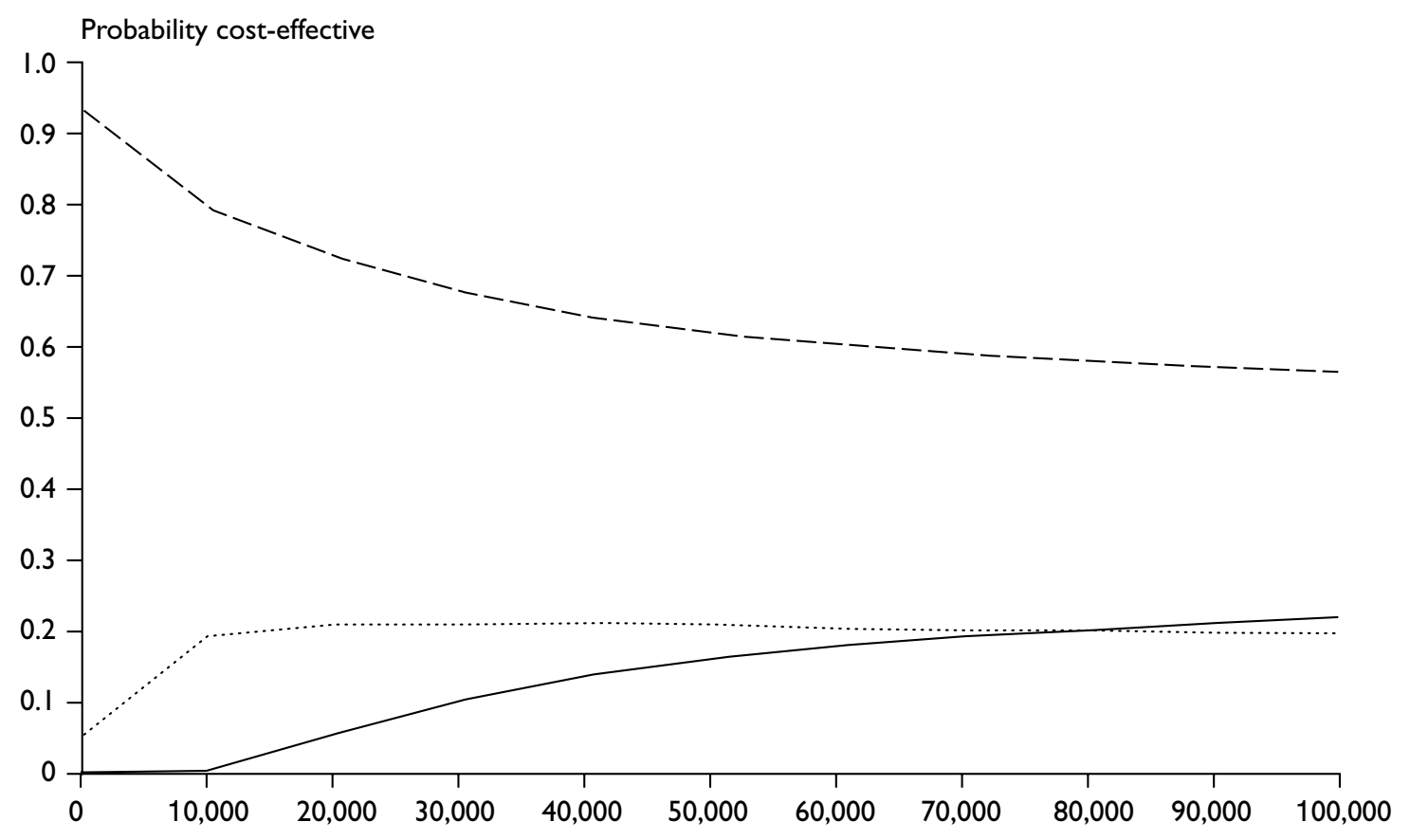

Maximum acceptable incremental cost per QALY $(t)$

FIGURE 5 Cost-effectiveness acceptability curves: unrelated inpatient, outpatient and GP costs excluded (—, control; .........., information;-- -, interview) 
change in QALYs but the interview group still has lower mean costs (£907) than the other two groups (information $£ 995$, control $£ 1446$ ) though the differences reduce compared with the basecase analysis. The effect on the control group in comparison with the information group changes little, with the incremental cost of control, relative to information, per additional QALY reducing very slightly to $£ 75,333$. Figure 5 shows the associated cost-effectiveness acceptability curves.

\section{Excluding inpatient and unrelated costs}

Even under this scenario, information plus interview dominates and remains unequivocally more cost-effective than the other two options. The savings in mean costs in the interview group reduce dramatically ( $£ 94$ versus information, £35 versus control), but it remains the management strategy with lower costs and higher mean QALYs. With the exclusion of inpatient and unrelated costs, the information group is now dominated by the control group: it has higher mean costs (information £946, control £887) and lower mean QALYs (1.567 versus 1.574). Figure 6 illustrates these points. The probability that information plus interview is less costly under the base case reduces to $71 \%$, and if the decision-maker is willing to pay $£ 30,000$ per additional QALY the probability that it is the most cost-effective strategy is $55 \%$.

\section{Intervention costs}

The variable costs of the information pack (Table 2) are based on the production of 550 copies of the video and 1000 copies of the booklet for use in this study. Were they to be introduced on a wider scale these costs would reduce. The fixed intervention costs are a good estimate of the costs of producing this type of intervention. However, the assumptions around the denominator for the calculation of fixed cost per patient (i.e. the potential eligible population and the effective life of the interventions) could be questioned. Under extreme assumptions, we might halve the number of menorrhagia referrals per year and cut the effective life of the interventions to 1 year. This would result in the fixed cost of the interventions per patient rising from $£ 0.13$ to $£ 0.80$, but would have no real impact on the incremental cost-effectiveness analysis presented here.

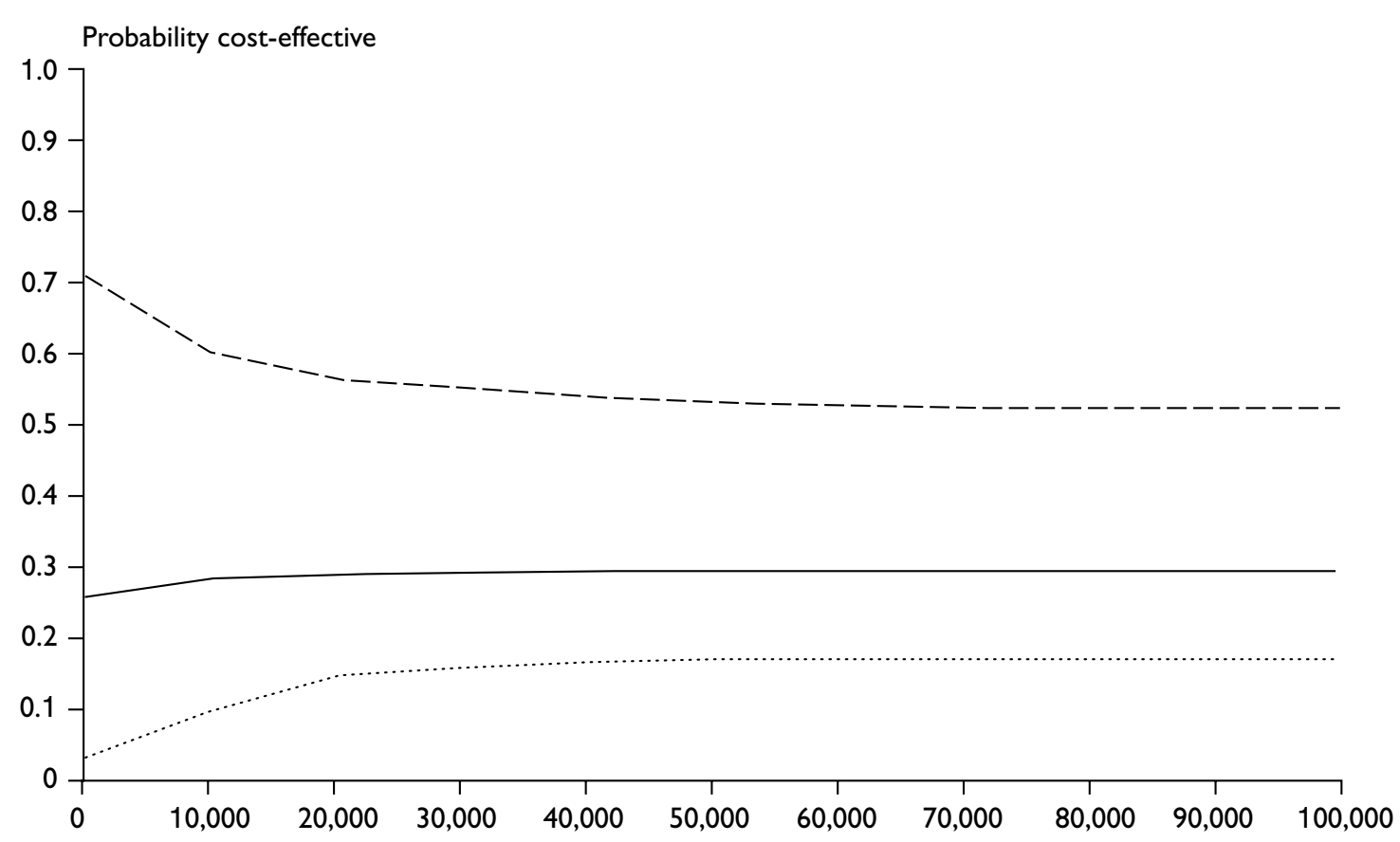




\section{Longer consultation times in the interview group}

Unfortunately, for practical reasons, we were unable to collect accurate data on the length of the initial consultations. However, clinicians' perceptions of the length of the consultations indicated that those with women from the interview group were more likely to be 'longer than average' consultations. Assuming that these consultations lasted 50\% longer and that they were all conducted by a consultant gynaecologist, this would result in an additional cost to the mean cost of the interview of $£ 6.20$ (assuming the cost per minute of a consultant's time is $£ 0.62^{53}$ and the average length of a consultation for a new gynaecology referral is 20 minute $^{54}$ ). Again, this will have little effect on the costeffectiveness of the interview. 



\section{Chapter 9 Discussion}

\begin{abstract}
A number of decision aids have been developed to help patients make specific deliberative decisions about treatment options. These have used a variety of media including leaflets, audiotapes, decision boards, computer programs, videos, websites, and structured interviews. ${ }^{33,55}$ They differ from traditional health education materials in that they do not recommend a particular course of action. Instead, they help patients decide on their most appropriate treatment by providing evidencebased information and quantified outcome probabilities to present the options in a balanced way, using interactive methods to help clarify values and preferences. Systematic reviews have shown that these aids increase patients' knowledge of the choices without increasing anxiety or decisional conflict. ${ }^{56}$ They reduce the number of patients who are uncertain about what to do and assist in promoting participative decision-making. ${ }^{56}$ Their effect on treatment choices and health outcomes is less well understood.
\end{abstract}

Among studies evaluating decision aids this is the largest of any yet undertaken and it also has the longest period of follow-up. This has enabled us to address a number of questions that previous studies have been unable to answer. These include the effects on health status, the relationship between preferences and treatments undergone, and the long-term effects on treatments undergone. It has also allowed the first comprehensive, economic evaluation of decision aids.

However, an important limitation of the study design used here is the possibility of contamination bias, where clinicians could have applied the experience gained from consultations with the intervention groups in their consultations with the control group. This bias would have the effect of reducing the differences between the intervention groups and the control group, so our conclusions could be considered conservative. Another bias could have been introduced if there was a clustering effect in terms of the consultation style of particular consultants or the types of patient referred to them. We have dealt with this by incorporating 'consultant' as a random effect in the statistical analysis. A further potential bias could result from the inability to ensure that clinicians were blind to the allocation group. They were not told which patients were randomised to the information only group, but we could not be certain that patients did not mention this fact in the subsequent consultation. Patients in the interview group were given a summary sheet to take into the consultation, so clinicians would have been aware of the allocation in this case.

The rates of follow-up, $71 \%$ for the short-term dataset and $70 \%$ for the long-term dataset, are in line with those of other studies in the field. Four, much smaller, studies have also used postal questionnaires and followed-up patients for 12 months: Barry and colleagues and Deyo and colleagues achieved higher rates of follow-up $(92 \%$ and $88 \%),{ }^{57,58}$ and Holmes-Rovner and colleagues and Rothert and colleagues lower rates $(67 \%$ and $53 \%))^{59,60}$ There are no studies with which to compare the rates at 24 months. There were differences in baseline characteristics between responders and non-responders for the short- and long-term follow-up datasets. Any effect of the between-group difference in baseline treatment knowledge for non-responders will be countered by its inclusion in the pool of covariates for the multiple regression analyses. The other observed differences will not affect the internal validity of the trial, but they should be noted when attempting to generalise the findings. The results of the non-response analysis differ slightly for the short- and long-term datasets, and these differences should be noted when making comparisons between the short- and longer-term effects of the interventions.

Neither intervention had a major impact on health status. There were no consistent differential effects between groups and this finding is consistent with previous studies. ${ }^{56,61}$ The impact of decision aids on health may be as much influenced by the conditions on which they focus as the decision aids themselves.

The information pack helped women form preferences and change previously held preferences. Women with strong treatment preferences who received the pack were, however, less likely to hold a preference after their consultation than women in the other two groups. The information also increased the extent to which women underwent 
treatments that corresponded with their postconsultation preferences within the first 12 months of follow-up. However, at 24 months this effect was not evident. Even where the information group was significantly more likely to undergo a treatment that corresponded with their preferences there was a considerable degree of discordance between patients' preferences and treatments undergone. This suggests that, for a significant proportion of women, management decisions did not adopt the principles of shared decision-making. ${ }^{34}$

Information and interview together gave major additional benefits to the information pack on its own. In addition to helping women form and change their overall preferences, the interview also led to changes in preferences for specific treatments, with women who underwent the interview much less likely to want hysterectomy or drug therapy. This negative attitude to hysterectomy was also carried through to the treatments they underwent, with a major reduction in the hysterectomy rate compared with controls at 12 months. This effect was maintained at 24 months and also when women on the waiting list for hysterectomy were taken into account. Women who received the interview were also more satisfied both with the opportunities they had been given to be involved in making treatment decisions as well as with the results of the care they received.

In terms of the effects of the interview on treatments undergone, this study adds weight to the non-significant trend observed in the latest update of the O'Connor and colleagues review. ${ }^{56}$ Five studies showed reduced rates of surgery (ranging from $21 \%$ to $42 \%$ ) where decision aids were compared with standard practice or a simple decision aid. However, the effect of the interview on satisfaction contradicts that observed in the literature, where no effect was detected in four out of five studies measuring satisfaction with the decision-making process and five out of six studies looking at satisfaction with the decision. It should be noted that, as with our study, these trials had relatively high levels of satisfaction in both intervention and control groups.

The results of the economic evaluation suggest that the use of information plus interview is costeffective in secondary care. The study indicates important reductions in hysterectomy and inpatient and outpatient costs. Even if the cost impact of lower inpatient days and outpatient and GP visits unrelated to menorrhagia (which high-cost women) is excluded from the analysis, interview remains a dominant intervention compared with both control and information. If decision-makers are willing to pay $£ 30,000$ per additional QALY, the probability that information plus interview is the most cost-effective form of management is $55 \%$, even when these costs are excluded.

The limitations of the study have been described above and these should be taken into account when assessing the generalisability of the results. We would argue that the findings, in terms of the effects on preferences, management and costeffectiveness, can be generalised in two ways: first, in terms of setting and secondly, in terms of the underlying clinical condition.

Information alone is not sufficient, patients require help in using the information to clarify their preferences and these preferences must then be effectively communicated to their clinician. The model of information provision plus interview used in this study could easily be adapted for use in primary care, where the observed effects would be almost equally applicable. Women who opt for a drug treatment or the levonorgestrel-releasing IUCD could be adequately treated without recourse to secondary care referral. Those opting for a surgical treatment could be referred with a good understanding of the potential options available to them, and a summary of their treatment preferences could be included with their referral letter.

In terms of the effect of the interview on hysterectomy rates, the results of this study are consistent with those observed elsewhere ${ }^{56}$ Similar trends in effect have been observed for decisions relating to treatment for benign prostatic hyperplasia, ${ }^{57}$ ischaemic heart disease, ${ }^{61,62}$ low back pain ${ }^{58}$ and breast cancer. ${ }^{63}$ All these decisions relate to conditions with conservative and radical surgical options.

There does not appear to be any reason why the effect of the interview on satisfaction cannot be generalised to primary care. However, generalising to other clinical conditions may be more problematical given the inconsistent effects observed in other studies. ${ }^{56}$

\section{Conclusions}

\section{Implications for healthcare}

The clinical setting of this study was treatment in secondary care for uncomplicated menorrhagia. 
Providing women with evidence-based information was found to be neither effective nor cost-effective. However, the addition of a structured interview helped women to use the information to clarify their values and preferences, which were summarised on a proforma and given to them to give to their clinician. This process had a significant effect on women's treatment preferences, their subsequent management and long-term satisfaction. It also had a high probability of being cost-effective.

Neither intervention had a consistent effect on health status or a long-term impact on the agreement between preferences and treatments undergone relative to control.

The findings of this study could equally be applied to the treatment of menorrhagia in primary care. The effects on hysterectomy rate are also consistent with other studies where decision aids for conditions with conservative and radical surgical treatments have been compared.

\section{Recommendations for future research}

Our decision aids were aimed at patients and not their doctors. Future decision aids should incorporate training for clinicians in the principles and practice of involving patients in treatment decision-making, alongside evidence-based information, value clarification and preference elicitation for patients.

This study was pragmatic in design, with aims to assess the effectiveness and cost-effectiveness of the interventions rather than explain how they worked. The information plus interview intervention is a complex decision aid, which includes information provision, preference clarification and elicitation, and the presentation of these preferences to doctors for discussion and inclusion in the patient's medical record. Research into the dynamics of the intervention would prove valuable for the future development of decision aids. In particular, the effects on the strength of women's preferences and their abilities to articulate and discuss their problem with their doctor in a decisionfocused manner.

This would also inform further research into other methods of preference elicitation and value clarification, and the presentation of patient's preferences to their clinician. Research into the clinical settings in which these methods would prove most effective and cost-effective would also be valuable to decision-makers, to enable them to form a long-term strategy for the development and implementation of new decision aids. 



\section{Acknowledgements}

$\mathrm{W}$

e would like to thank all the women who took part in this study for their time and goodwill. Thanks are extended to the clinicians and other hospital staff who aided in the conduct of the study. We would also like to thank Dr Lelia Duley for her helpful comments during the conduct of the study, Pit Rink for her advice on interview skills and Natalie Moore, Karen Arnold, Nicky Dunne and Pauline Sorzano for clerical and administrative support.
This study was commissioned by the NHS R\&D HTA Programme.

The help and advice of the NCCHTA was greatly appreciated and the considered and constructive comments of the referees were extremely useful.

The views and opinions expressed in this report are those of the authors alone. 



\section{References}

1. Corrado M. Women's health in 1990. London: MORI; 1990.

2. Royal College of General Practitioners. Office of Population Censuses and Surveys. Morbidity statistics from general practice 1981-2. London: HMSO; 1986.

3. Coulter A, Peto V, Doll H. Patients' preferences and general practitioners' decisions in the treatment of menstrual disorders. Fam Pract 1994;11:67-74.

4. Sculpher M. A cost-utility analysis of abdominal hysterectomy versus transcervical endometrial resection for the surgical treatment of menorrhagia. Int J Technol Assess Health Care 1998;14:302-19.

5. Effective Health Care. The management of menorrhagia. Leeds: University of Leeds; 1995. Effective Health Care Bulletin No. 9.

6. Vessey M, Villard-Mackintosh L, McPherson K, Coulter A, Yeates D. The epidemiology of hysterectomy: findings in a large cohort study. Br J Obstet Gynaecol 1992;99:402-7.

7. Grant JM, Hussein IY. An audit of abdominal hysterectomy over a decade in a district hospital. Br J Obstet Gynaecol 1984;91:73-7.

8. Coulter A, Bradlow J, Agass M, Martin-Bates C, Tulloch A. Outcomes of referrals to gynaecology outpatient clinics for menstrual problems: an audit of general practice records. Br J Obstet Gynaecol 1991;98:789-96.

9. Coulter A, Kelland J, Peto V, Rees M. Treating menorrhagia in primary care. Int J Technol Assess Health Care 1995;11:456-71.

10. Bonnar J, Sheppard BL. Treatment of menorrhagia during menstruation: randomised controlled trial of ethamsylate, mefenamic acid, and tranexamic acid. BMJ 1996;313:579-82.

11. Hirsch NA. Technologies for the treatment of menorrhagia and uterine myomas. Canberra: Australian Government Publishing Service; 1993. Australian Institute of Health and Welfare Health Care Technology Series number 10

12. Sculpher MJ, Dwyer N, Browning J, Horsley S, Cullimore J. A survey of women's preferences regarding alternative surgical treatments for menorrhagia. Health Expect 1998;1:96-105.

13. Kassirer JP. Incorporating patients' preferences into medical decisions. N Engl J Med 1994;330:1895-6.
14. Prentice A. Medical management of menorrhagia. BMJ 1999;319:1343-5.

15. Coulter A. Paternalism or partnership? Patients have grown up - and there's no going back. BMJ 1999;319:719-20.

16. Domenighetti G, Luraschi P, Casabianca A. Effect of information campaign by the mass media on hysterectomy rates. Lancet 1988;ii:1470-3.

17. Mazur DJ, Hickam DH. The effect of physicians' explanations on patients' treatment preferences: five-year survival data. Med Decis Making 1994;14:255-8.

18. Hall JA, Roter DL, Katz NR. Meta-analysis of correlates of provider behavior in medical encounters. Med Care 1988;26:657-75.

19. Slevin ML, Stubbs L, Plant HJ, Wilson P, Gregory WM, Armes PJ, et al. Attitudes to chemotherapy: comparing views of patients with cancer with those of doctors, nurses, and general public. $B M J$ 1990;300:1458-60.

20. Wilson RG, Hart A, Dawes P. Mastectomy or conservation: the patient's choice. $B M J$ 1988;297:1167-9.

21. Greenfield S, Kaplan S, Ware JE. Expanding patient involvement in care. Effects on patient outcomes. Ann Intern Med 1985;102:520-8.

22. Brody DS, Miller SM, Lerman CE, Smith DG. Patient perception of involvement in medical care: relationship to illness attitudes and outcomes. J Gen Intern Med 1989;4:506-11.

23. Finch H. Shared decision-making programmes for hormone replacement therapy and treatment of benign conditions of the uterus. London: Social \& Community Planning Research; 1993.

24. Gath D, Osborn M, Bungay G, Iles S, Day A, Bond A, et al. Psychiatric disorder and gynaecological symptoms in middle aged women: a community survey. BMJ 1987;294:213-18.

25. Barry MJ, Fowler FJ, Mulley AG, Henderson JV, Wennberg JE. Patient reactions to a program designed to facilitate patient participation in treatment decisions for benign prostatic hyperplasia. Med Care 1995;33:771-82.

26. Kempson E. Informing health consumers. A review of consumer health information needs and services. London: College of Health; 1987.

27. Buckland S. Unmet needs for health information: a literature review. Health Libr Rev 1994;11:82-95. 
28. Pocock SJ. Clinical trials: a practical approach. Chichester: Wiley; 1983.

29. Brazier JE, Harper R, Jones NM, O'Cathain A, Thomas KJ, Usherwood T, et al. Validating the SF-36 health survey questionnaire: new outcome measure for primary care. BMJ 1992;305:160-4.

30. Brooks R. EuroQol: the current state of play. Health Policy 1996;37:53-72.

31. Ruta DA, Garratt AM, Chadha YC, Flett GM, Hall MH, Russell IT. Assessment of patients with menorrhagia: how valid is a structured clinical history as a measure of health status? Qual Life Res 1995;4:33-40.

32. Marteau TM, Bekker H. The development of a sixitem short-form of the state scale of the Spielberger State-Trait Anxiety Inventory (STAI). Br J Clin Psychol 1992;31:301-6.

33. O'Connor AM, Rostom A, Fiset V, Tetroe J, Entwistle V, Llewellyn-Thomas $\mathrm{H}$, et al. Decision aids for patients facing health treatment or screening decisions: systematic review. BMJ 1999;319:731-4.

34. Charles C, Gafni A, Whelan T. Shared decisionmaking in the medical encounter: what does it mean? (or it takes at least two to tango). Soc Sci Med 1997;44:681-92.

35. Brown H, Prescott R. Applied mixed models in medicine. Chichester: Wiley; 1999.

36. Jenkinson C, Layte R, Wright L, Coulter A. The UK SF-36: an analysis and interpretation manual: a guide to health status measurement with particular reference to the short form 36 health survey. Oxford: Health Services Research Unit; 1996.

37. Department of Health. The new NHS 1999 reference costs. Wetherby: DoH, 1999.

38. Sculpher M, Thompson E, Brown J, Garry R. A cost effectiveness analysis of goserelin compared with danazol as endometrial thinning agents. BrJ Obstet Gynaecol 2000;107:340-6.

39. Netten A, Dennett J. Unit costs of health and social care. Canterbury: Personal Social Sciences Research Unit (PSSRU), University of Kent, 1999.

40. British National Formulary. London: British Medical Association and the Royal Pharmaceutical Society of Great Britain, 1999. Number 38.

41. Sculpher MJ, Bryan S, Dwyer N, Hutton J, Stirrat GM. An economic evaluation of transcervical endometrial resection versus abdominal hysterectomy for the treatment of menorrhagia. Br J Obstet Gynaecol 1993;100:244-52.

42. NHS Executive. Nurses' and midwives' pay for 1999/00. Leeds: NHS Executive (advanced letter); 1999.

43. National Statistics. Health statistics (quarterly). London: HMSO; 2001.
44. Kind P. The EuroQoL instrument: an index of health-related quality of life. In: Spilker B, editor. Quality of life and pharmacoeconomics in clinical trials. 2nd ed. Philadelphia (PA): Lippincott-Raven, 1996.

45. Kind P, Hardman G, Macran S. UK population norms for EQ-5D. York: Centre for Health Economics, University of York, 1999. Centre for Health Economics Discussion Paper 172.

46. Matthews JNS, Altman D, Campbell MJ. Analysis of serial measurements in medical research. BMJ 1990;300:230-5.

47. Efron B, Tibshirani R. An introduction to the bootstrap. New York: Chapman and Hall; 1993.

48. Rubin DB. Multiple imputation for nonresponse in surveys. New York: John Wiley \& Sons; 1987.

49. Van Hout BA, Al MJ, Gordon GS, Rutten FFH. Costs, effects and c/e-ratios alongside a clinical trial. Health Econ 1994;3:309-19.

50. Fenwick E, Claxton K, Sculpher M. Representing uncertainty: the role of cost-effectiveness acceptability curves. Health Econ 2001;10:779-87.

51. Briggs AH. A Bayesian approach to stochastic costeffectiveness analysis. Health Econ 1999;8:257-62.

52. Office for National Statistics. Labour force survey. London: The Stationary Office; 2000.

53. Review body on doctors and dentists' remuneration. Report 2000. London: HMSO; 2000.

54. Royal College of Obstetricians and Gynaecologists. A blue print for the future (a working party report on the future structure of the medical workforce and service delivery in obstetrics and gynaecology). London: RCOG Press; 2000.

55. Molenaar S, Sprangers MAG, Postma-Schuit FCE, Rutgers EJT, Noorlander J, Hendriks J, et al. Feasibility and effects of decision aids. Med Decis Making 2000;20:112-27.

56. O'Connor AM, Stacey D, Rovner D, HolmesRovner M, Tetroe J, Llewellyn-Thomas $\mathrm{H}$, et al. Decision aids for people facing health treatment or screening decisions (Cochrane Review). In: The Cochrane Library. Issue 3. Oxford: Update Software; 2001.

57. Barry MJ, Cherkin DC, Chang Y, Fowler FJ, Skates $\mathrm{S}$. A randomized trial of a multimedia shared decision-making program for men facing a treatment decision for benign prostatic hyperplasia. Dis Manag Clin Outcomes 1997;1:5-14. 
58. Deyo RA, Cherkin DC, Weinstein J, Howe J, Ciol M, Mulley AG Jr. Involving patients in clinical decisions: impact of an interactive video program on use of back surgery. Med Care 2000;38:959-69.

59. Holmes-Rovner M, Kroll J, Rovner DR, Schmitt N, Rothert M, Padonu G, et al. Patient decision support intervention: increased consistency with decision analytic models. Med Care 1999;37:270-84.

60. Rothert ML, Holmes-Rovner M, Rovner D, Kroll J, Breer L, Talarczyk G, et al. An educational intervention as decision support for menopausal women. Res Nurs Health 1997;20:377-87.
61. Bernstein SJ, Skarupski KA, Grayson CE, Starling MR, Bates ER, Eagle KA. A randomized controlled trial of information-giving to patients referred for coronary angiography: effects on outcomes of care. Health Expect 1998;1:50-61.

62. Morgan MW, Deber RB, Llewellyn-Thomas HA, Gladstone P, Cusimano RJ, O'Rourke K, et al. Randomized controlled trial of an interactive videodisc decision aid for patients with ischemic heart disease. J Gen Intern Med 2000;15:685-93.

63. Street RL, Voigt B, Geyer C, Manning T, Swanson GP. Increasing patient involvement in choosing treatment for early breast cancer. Cancer 1995;76:2275-85. 



\section{Appendix 1}

\section{Expert advisory group for phase I}

Ken Bidgood

Taunton and Somerset Hospital

Taunton, UK

Angela Coulter

The King's Fund

London, UK

John Cullimore

Princess Margaret Hospital

Swindon, UK

Nuala Dwyer

Weston General Hospital

Weston-super-Mare, UK

Sue Horsley

Princess Margaret Hospital

Swindon, UK
Richard Kerr-Wilson

St Paul's Hospital

Cheltenham, UK

Margaret Rees

John Radcliffe Hospital

Oxford, UK

Mark Sculpher

Health Economics Research Group

Brunel University

Uxbridge, UK

Gordon Stirrat

St Michael's Hospital

Bristol, UK 



\section{Appendix 2}

\section{The Bleeding Nuisance booklet and video}

Copies of the Bleeding Nuisance booklet and video are available from:

Angela Coulter

Picker Institute Europe

King's Mead House

Oxpens Road

Oxford OX1 1RX

UK
Tel: $+44(0) 1865208100$

Fax: $+44(0) 1865208101$

Website: www.pickereurope.org

Charity reg. no. 1081688 



\title{
Appendix 3
}

\author{
Interview schedule
}



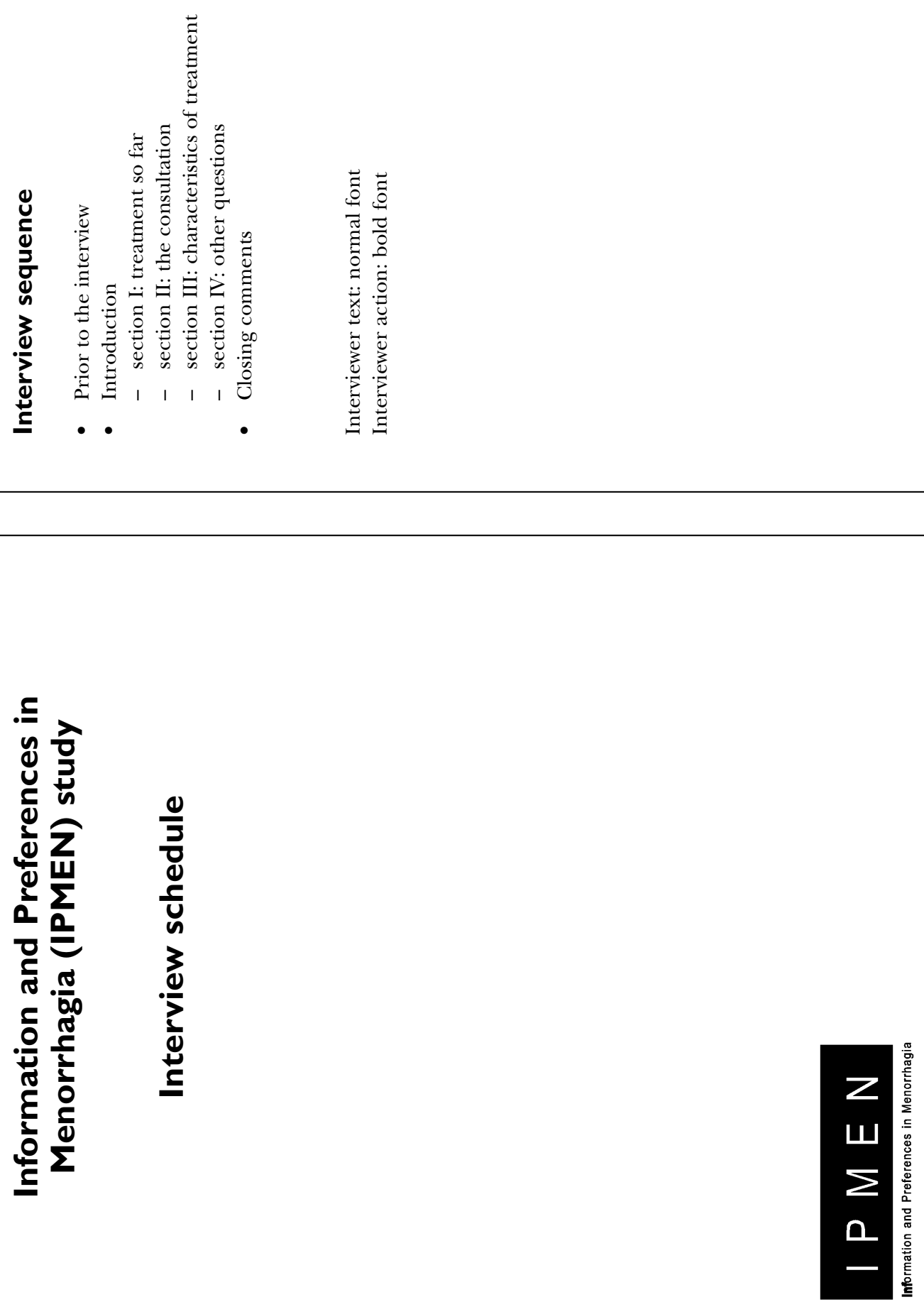

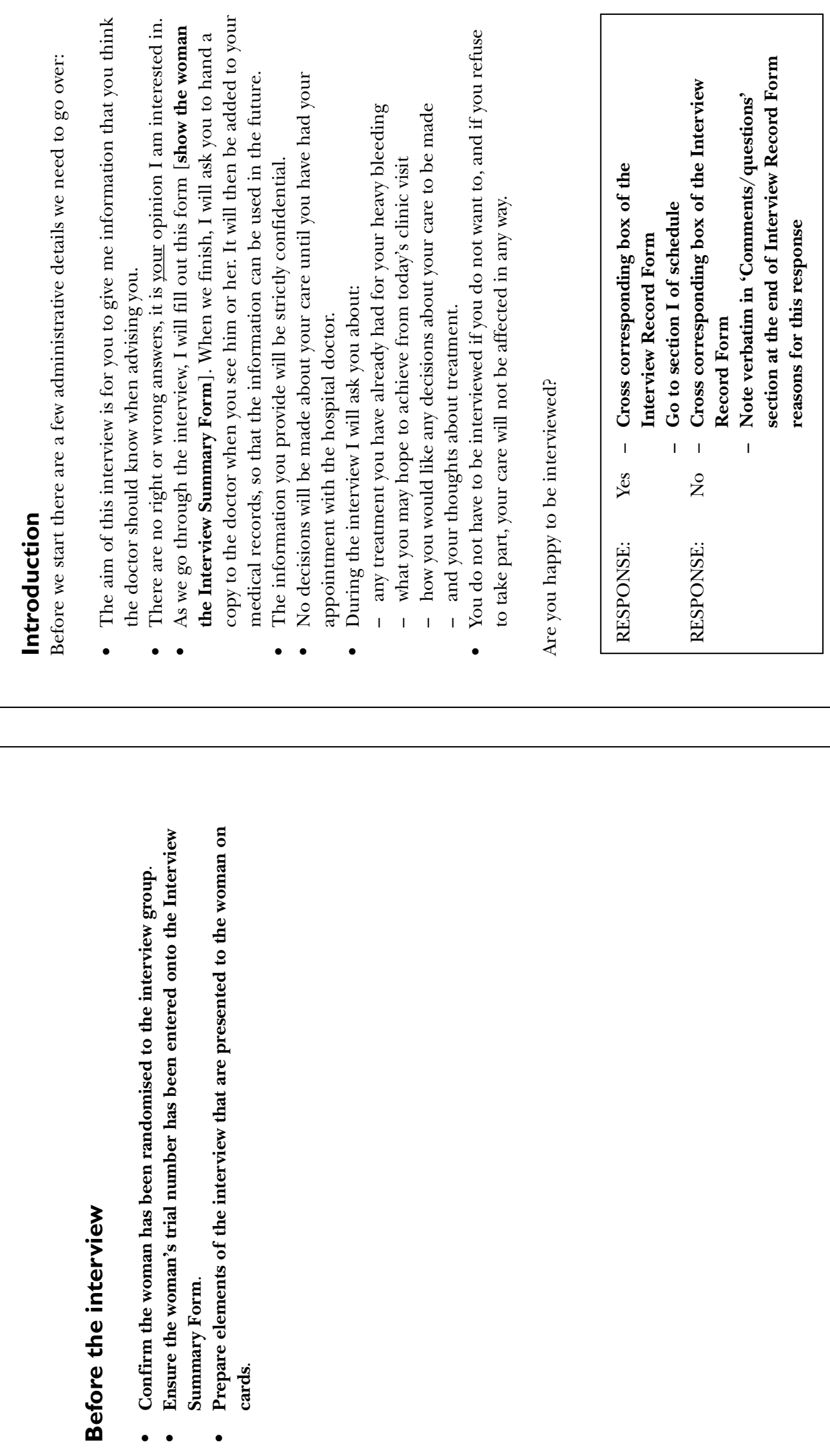

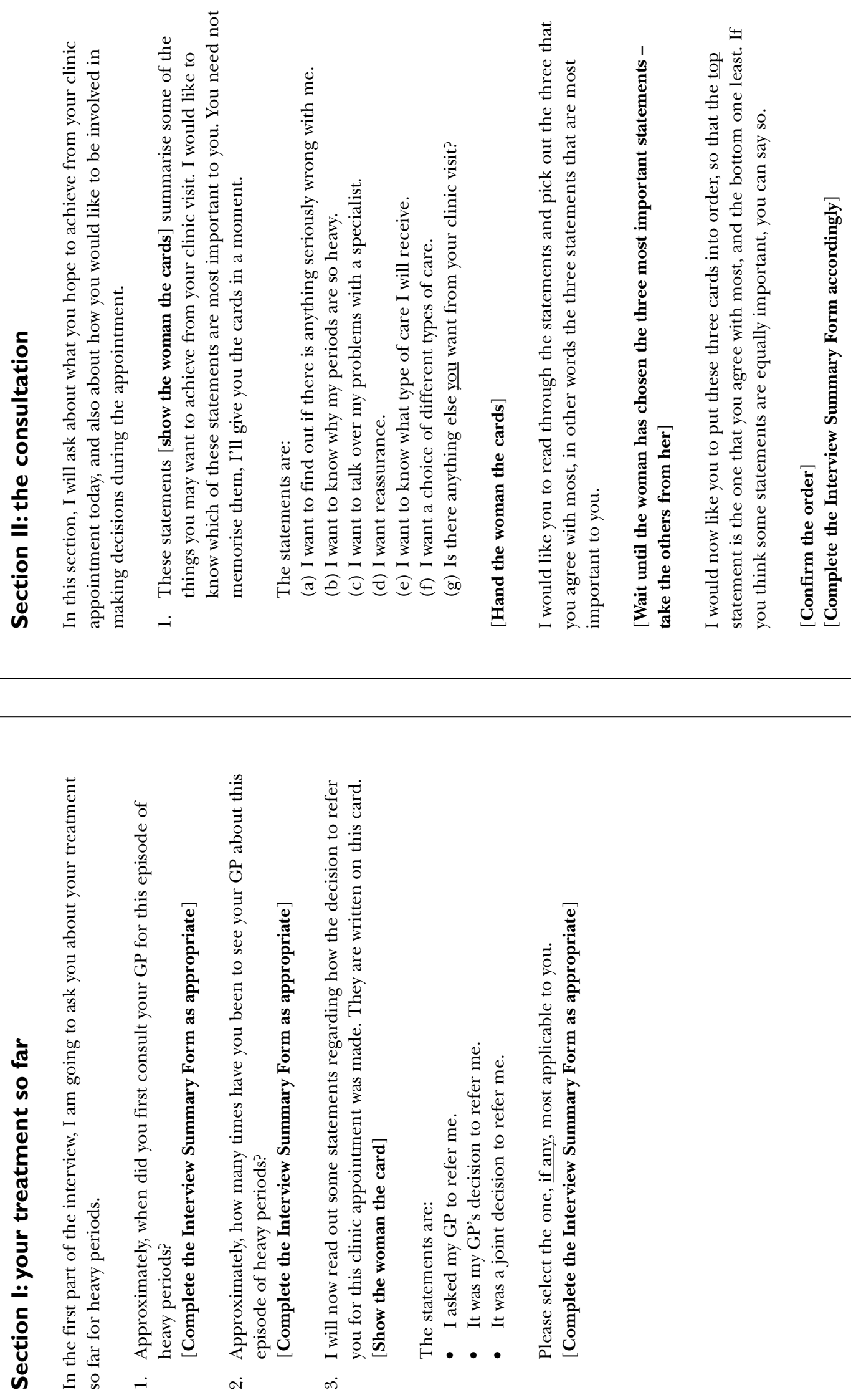

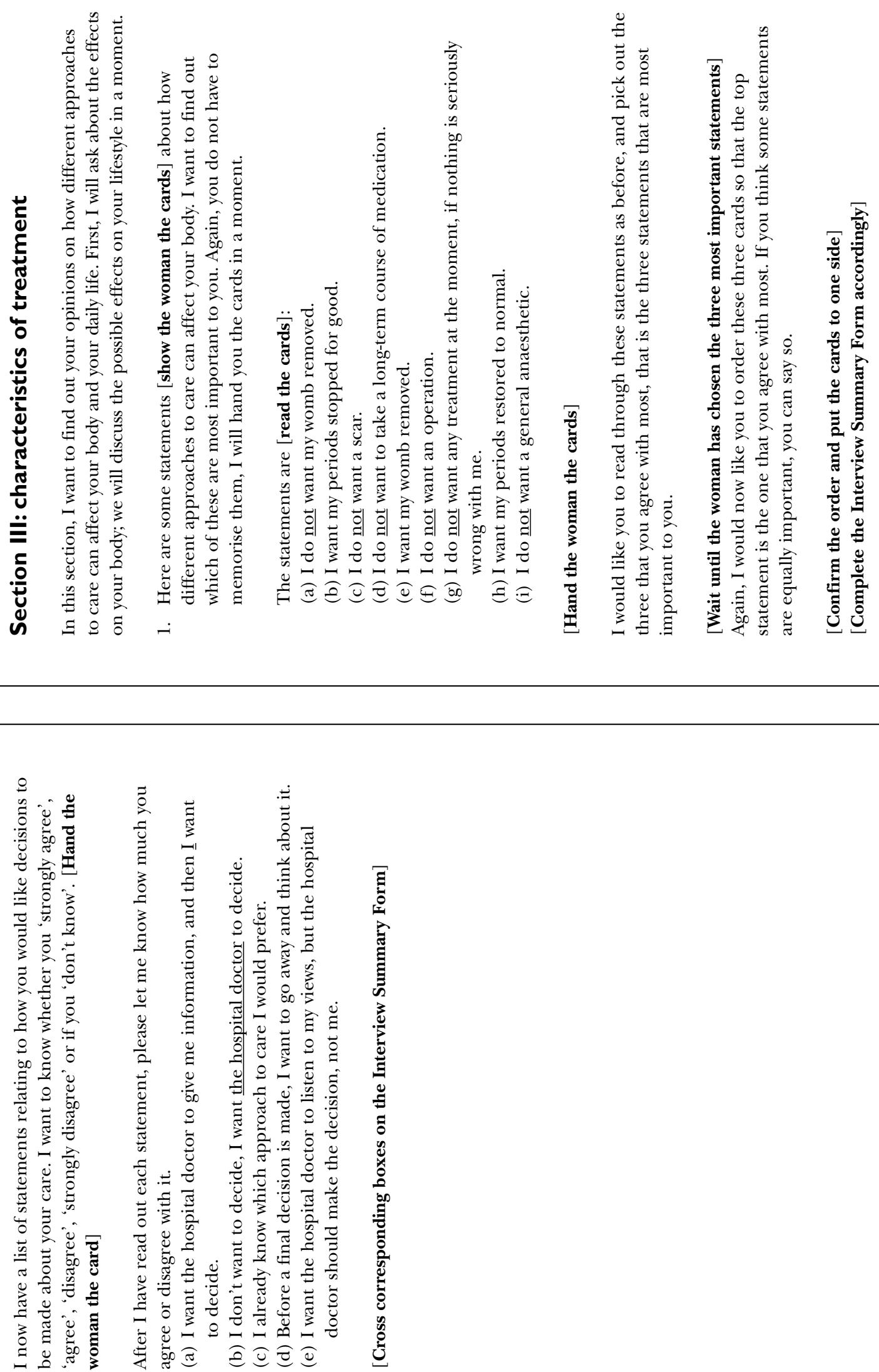

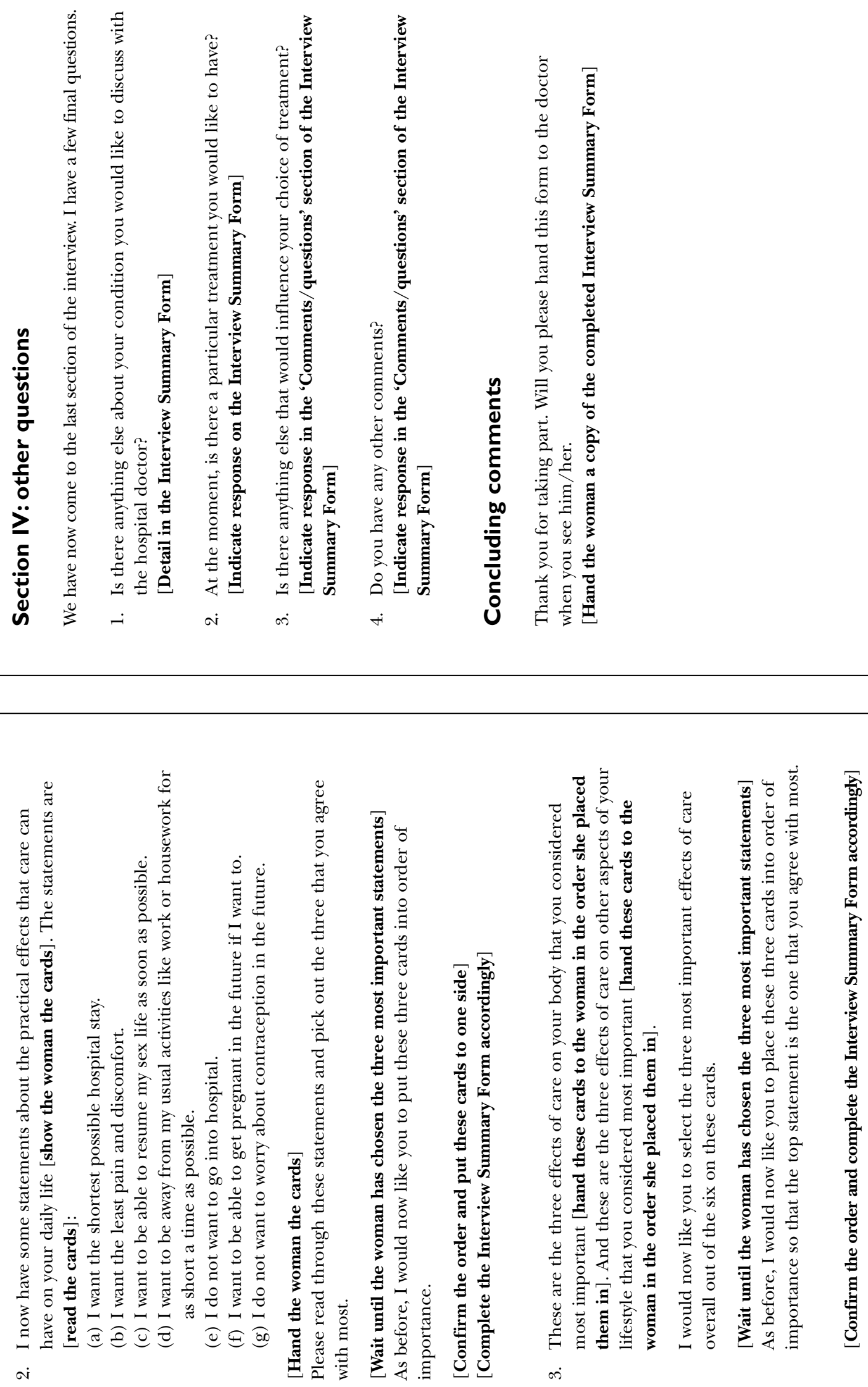


\section{Appendix 4}

\section{Interview Summary Form}


Trial no.

\section{Information and Preferences in Menorrhagia (IPMEN) study Interview Summary Form}

First visit to GP for this episode of heavy periods:

4 months ago $\square$

4-7 months ago

8-11 months ago

1 year or more ago

Approximate no. of visits to GP for this episode of menorrhagia:

How was the decision to refer made: Woman asked for referral

GP made decision

Joint decision

NA

These statements cover what the woman wants from the consultation:

Rank

I want to find out if there is anything seriously wrong with me I want to know why my periods are so heavy I want to talk over my problems with a specialist I want reassurance I want to know what type of care I will receive I want a choice of different types of care

Other issue wanted by woman:

$\bar{\square} \bar{\square}$

These statements concern how the woman thinks decisions about her care should be made:

I want the doctor to give me information, and then I want to decide I don't want to decide, I want the doctor to decide I already know which approach to care I would prefer Before a final decision is made, I want to go away and think about it I want the doctor to listen to my views, but the doctor should make the decision, not me

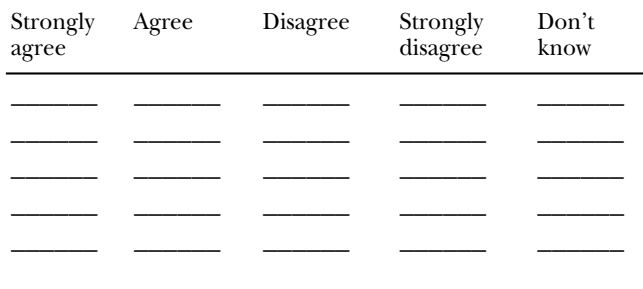

Women were asked to choose the three most important clinical and non-clinical characteristics of treatment and rank them 1-3. They were then asked to pick the top three from the six chosen.

Following is a list of clinical characteristics relating to care:

I do not want my womb removed I want my periods stopped for good I do not want a scar I do not want to take a long-term course of medication I want my womb removed I do not want an operation I do not want any treatment at the moment, if nothing is seriously wrong with me I want my periods restored to normal I do not want a general anaesthetic

Following is a list of non-clinical characteristics relating to care:

I want the shortest possible hospital stay I want the least pain and discomfort I want to be able to resume my sex life as soon as possible I want to be away from my usual activities like work or housework for as short a time as possible

I do not want to go into hospital I want to be able to get pregnant in the future if I want to I do not want to worry about contraception in the future
Rank

Overall rank

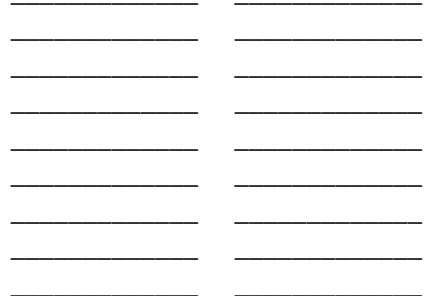

Rank

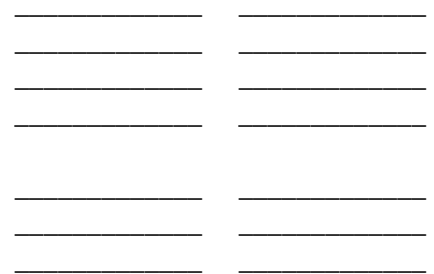

Other issues the woman wants to discuss:

Preferred care: 


\section{Appendix 5}

\section{Baseline questionnaire}



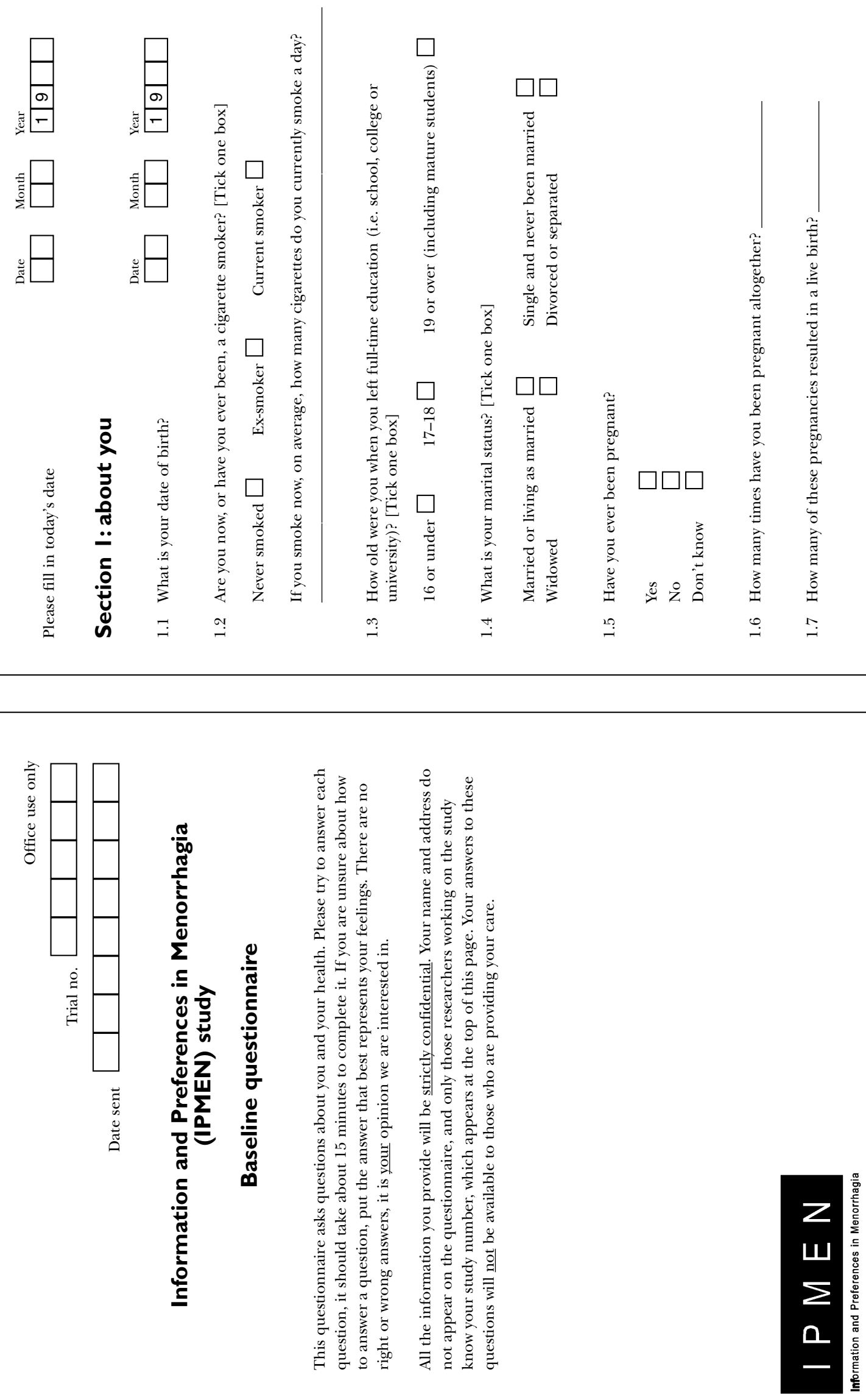

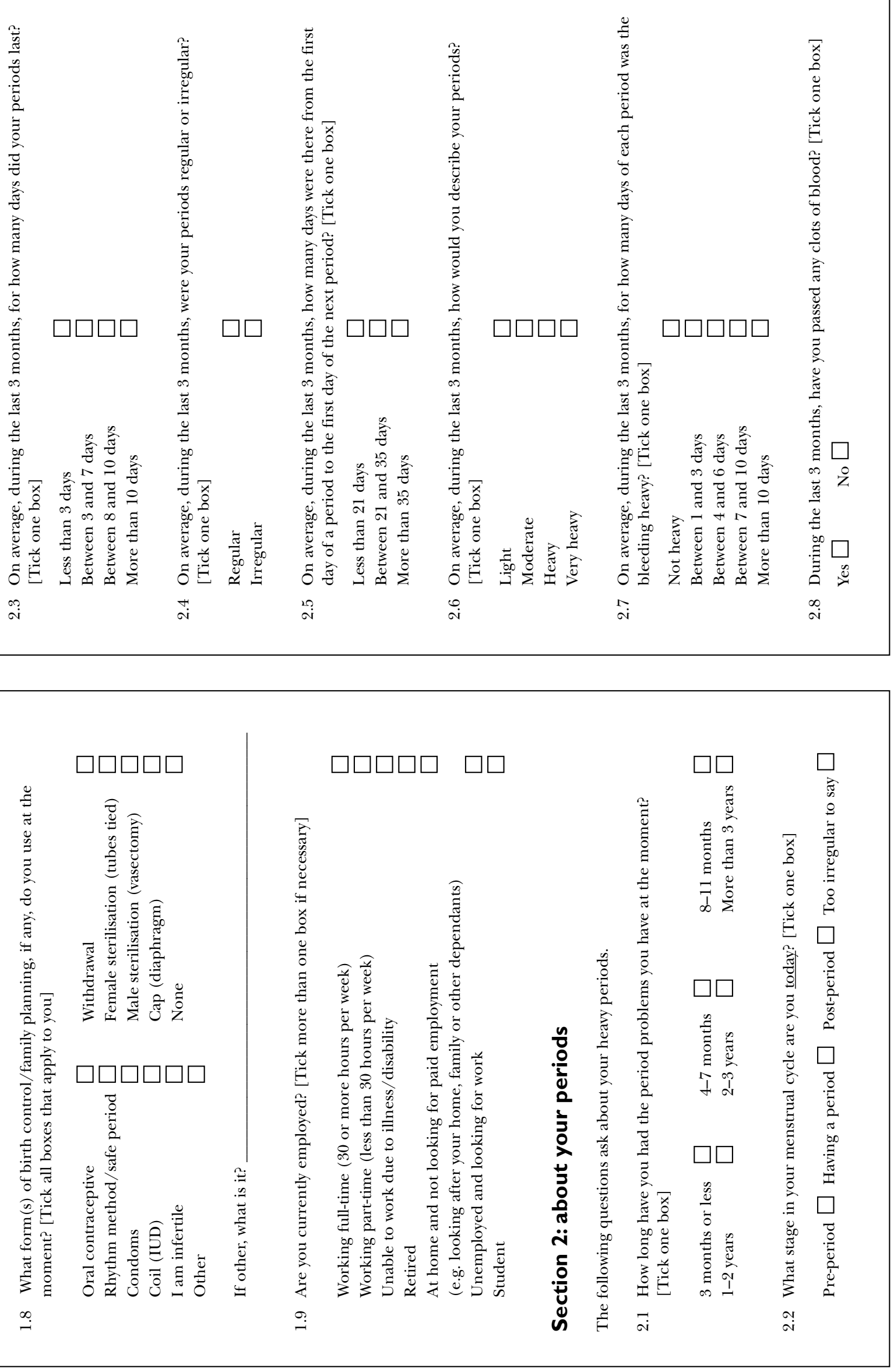

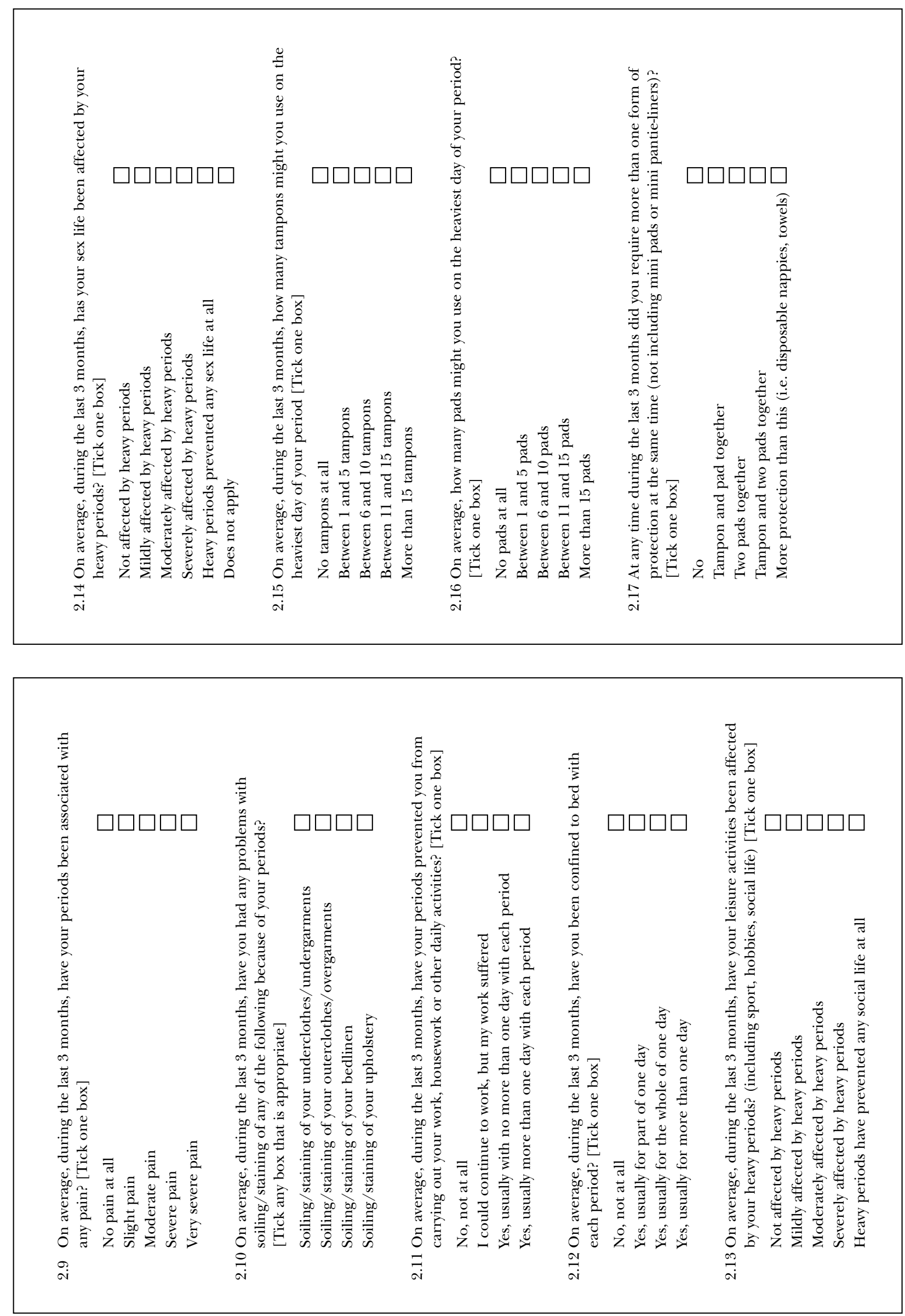

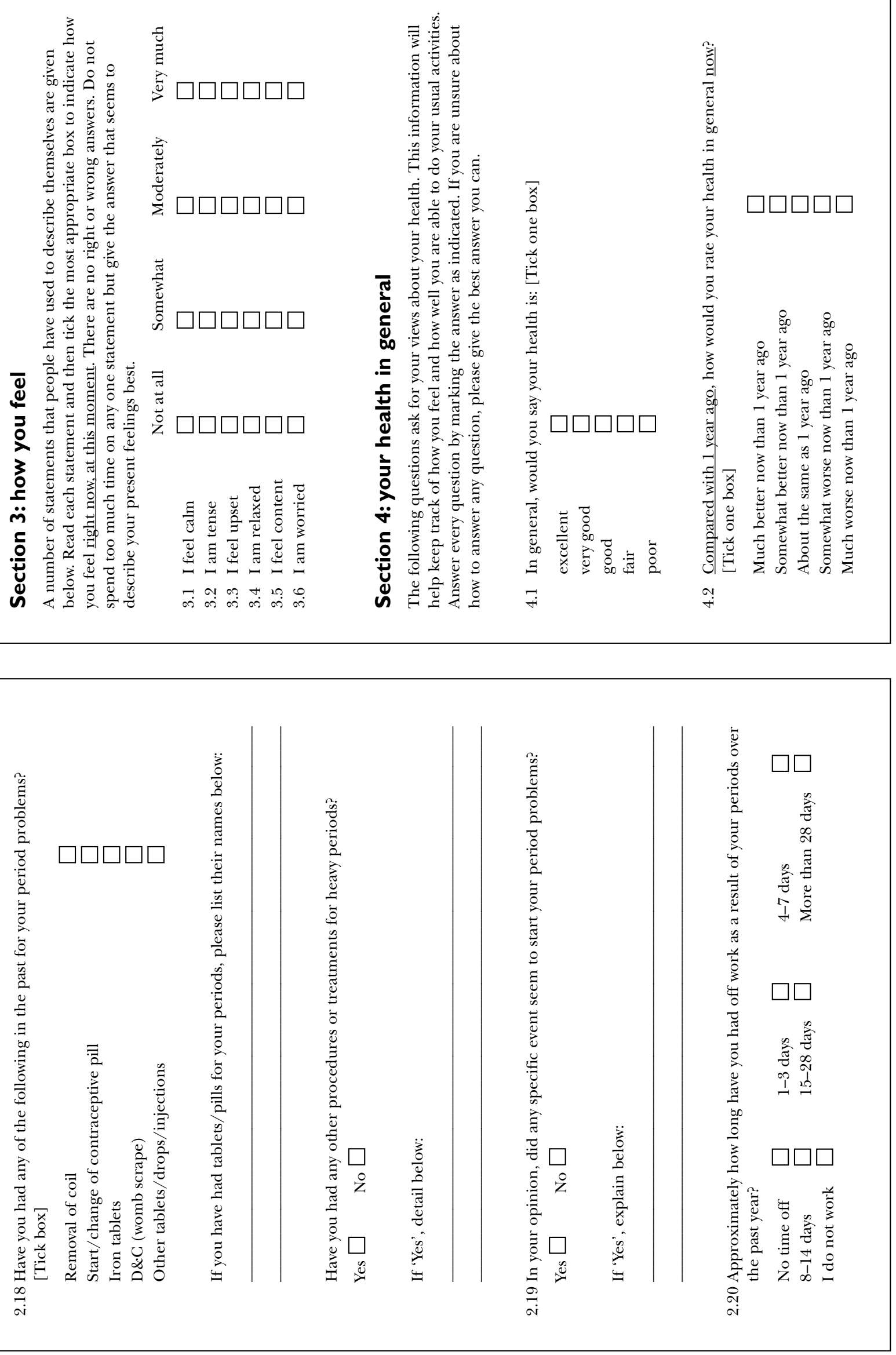

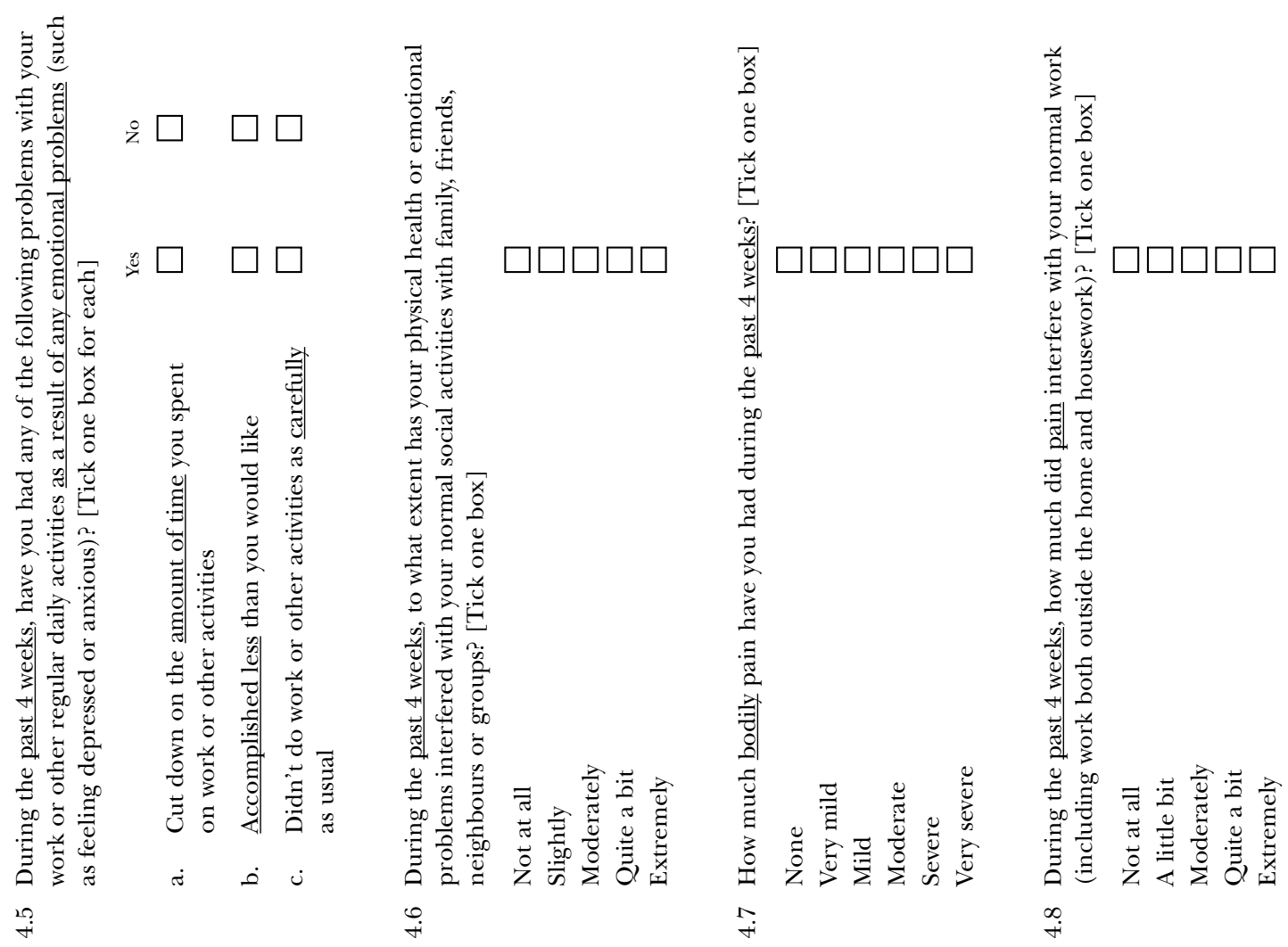

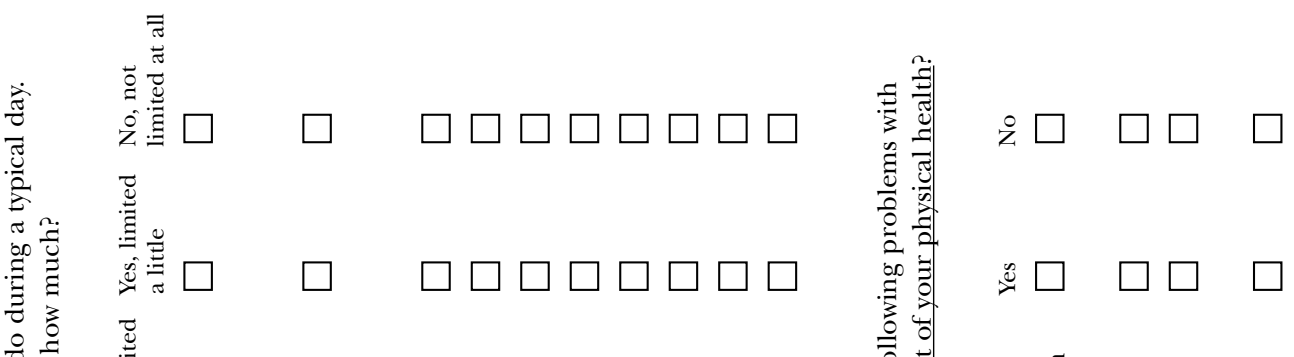

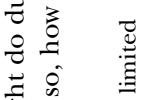

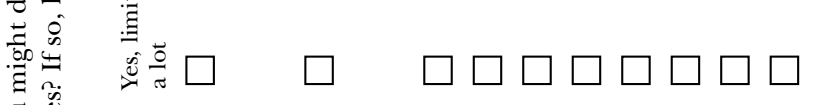

范

芴

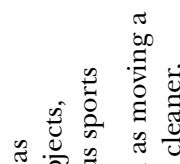

気

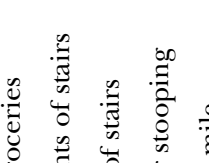

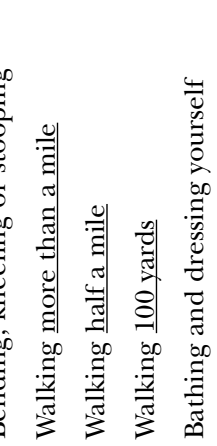

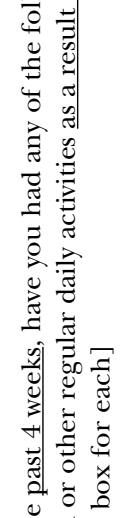

के

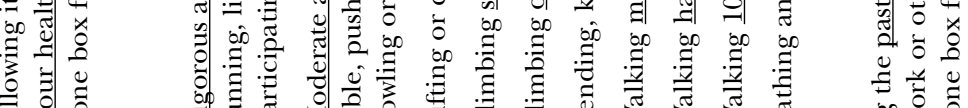

흥 항

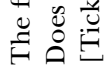

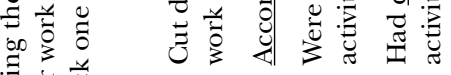

$\stackrel{\infty}{+}$

言总

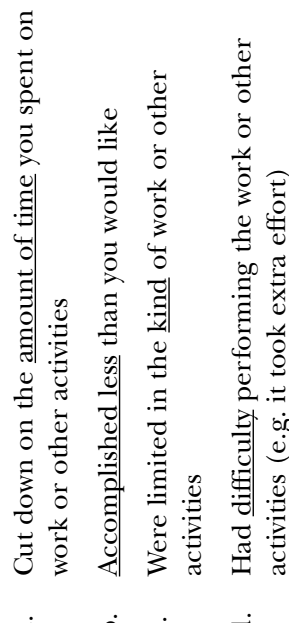



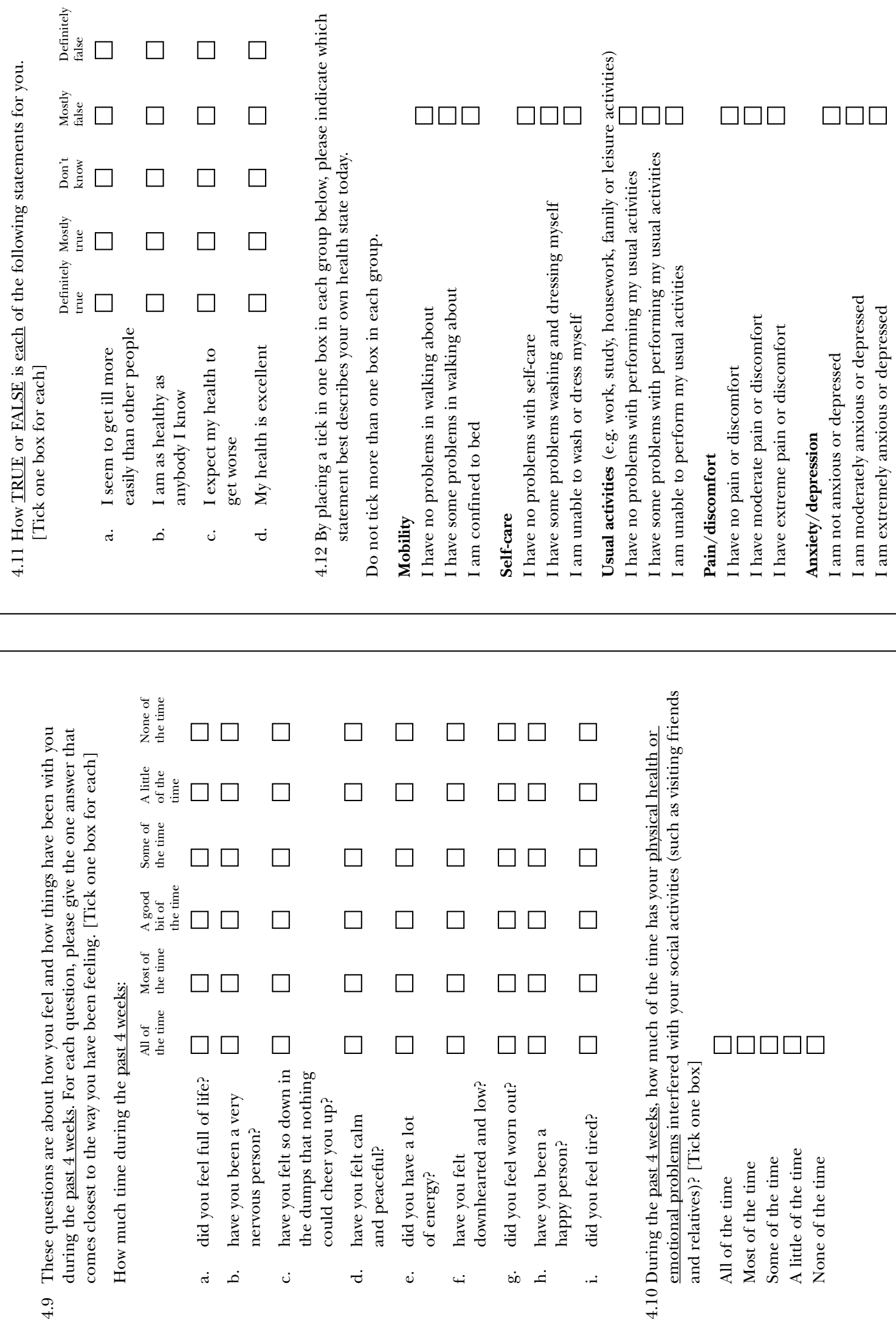


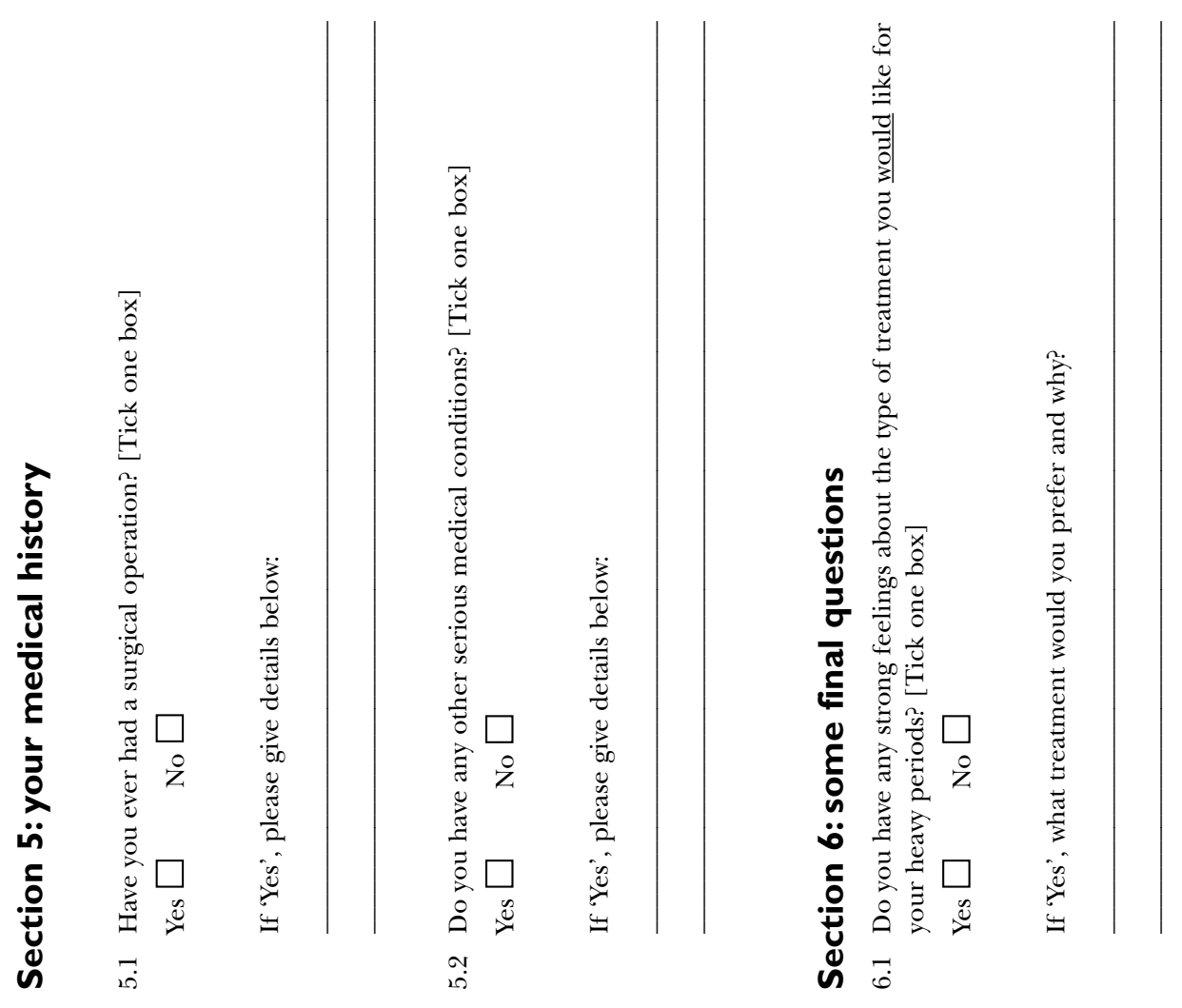

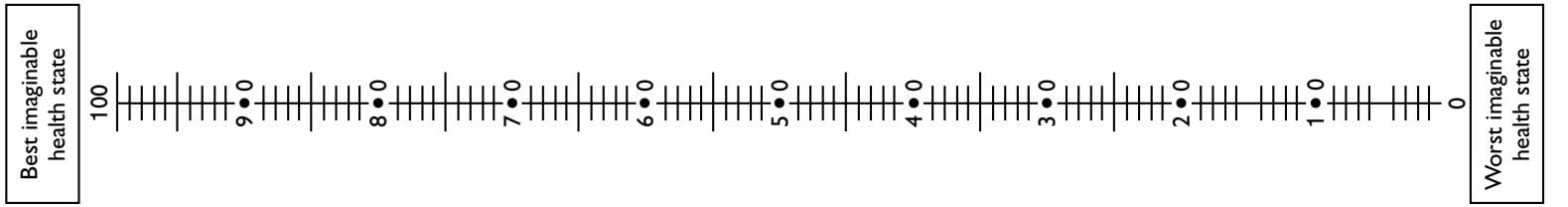
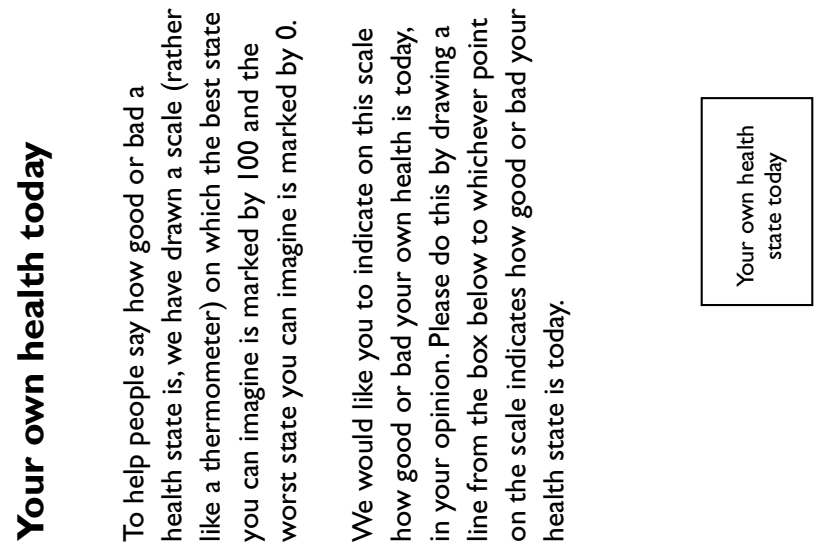

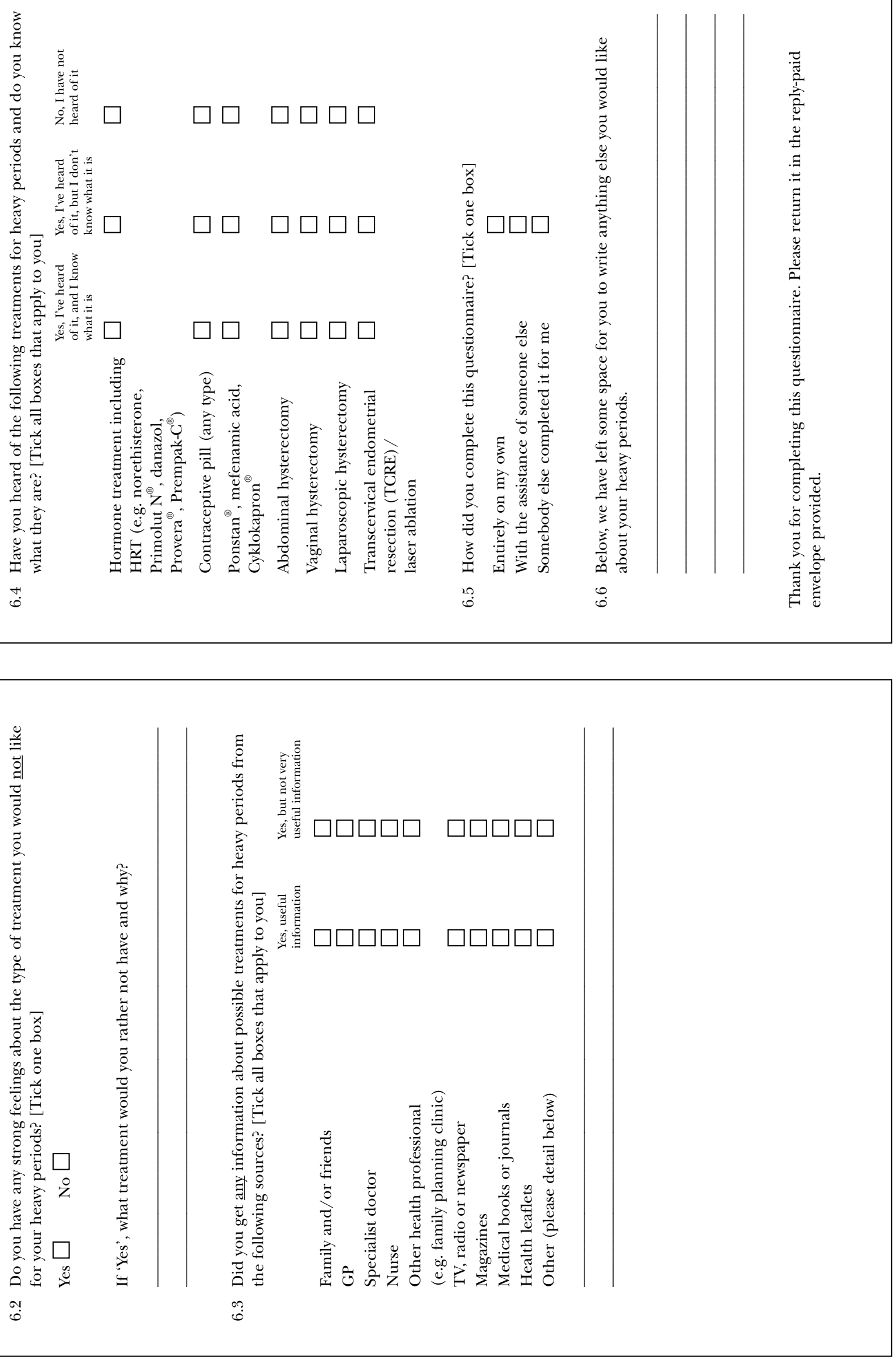



\section{Appendix 6}

\section{Fixed effect covariate pool for each analysis}

\begin{tabular}{|c|c|}
\hline Analysis & Covariate pool \\
\hline Post-consultation preferences & $\begin{array}{l}\text { Consultant sex } \\
\text { Consultant year of qualification } \\
\text { Age } \\
\text { Baseline menorrhagia severity } \\
\text { Baseline knowledge } \\
\text { Previous treatment - D\&C } \\
\text { Previous treatment - OCP } \\
\text { Previous treatment - hormonal drugs } \\
\text { Previous treatment - non-hormonal drugs } \\
\text { Duration of problem } \\
\text { Any previous surgery } \\
\text { Baseline preferences } \\
\text { Recruitment period }\end{array}$ \\
\hline Change in preferences between baseline and post-consultation & $\begin{array}{l}\text { Consultant sex } \\
\text { Consultant year of qualification } \\
\text { Age } \\
\text { Baseline menorrhagia severity } \\
\text { Baseline knowledge } \\
\text { Previous treatment - D\&C } \\
\text { Previous treatment - OCP } \\
\text { Previous treatment - hormonal drugs } \\
\text { Previous treatment - non-hormonal drugs } \\
\text { Duration of problem } \\
\text { Any previous surgery } \\
\text { Baseline preferences (where preference held at baseline) } \\
\text { Recruitment period }\end{array}$ \\
\hline Health status & $\begin{array}{l}\text { Consultant sex } \\
\text { Consultant year of qualification } \\
\text { Age } \\
\text { Baseline health status score } \\
\text { Baseline menorrhagia severity } \\
\text { Baseline knowledge } \\
\text { Duration of problem } \\
\text { Length of follow-up }\end{array}$ \\
\hline Treatments undergone & $\begin{array}{l}\text { Consultant sex } \\
\text { Consultant year of qualification } \\
\text { Age } \\
\text { Baseline menorrhagia severity } \\
\text { Baseline knowledge } \\
\text { Previous treatment - D\&C } \\
\text { Previous treatment - OCP } \\
\text { Previous treatment - hormonal drugs } \\
\text { Previous treatment - non-hormonal drugs } \\
\text { Duration of problem } \\
\text { Any previous surgery } \\
\text { Baseline preferences } \\
\text { Recruitment period } \\
\text { Length of follow-up }\end{array}$ \\
\hline
\end{tabular}


contd

\section{Analysis}

Agreement between preferences and treatments undergone

\section{Covariate pool}

\section{Consultant sex}

Consultant year of qualification

Age

Baseline menorrhagia severity

Baseline knowledge

Previous treatment - D\&C

Previous treatment - OCP

Previous treatment - hormonal drugs

Previous treatment - non-hormonal drugs

Duration of problem

Any previous surgery

Baseline preferences

Recruitment period

Length of follow-up (agreement between last-stated preference and treatment undergone only)

Consultant sex

Consultant year of qualification

Age

Baseline menorrhagia severity

Baseline knowledge

Baseline anxiety (post-consultation satisfaction only)

Previous treatment - D\&C

Previous treatment - OCP

Previous treatment - hormonal drugs

Previous treatment - non-hormonal drugs

Duration of problem

Any previous surgery

Baseline preferences

Recruitment period

Length of follow-up (follow-up satisfaction only) 


\section{Appendix 7}

\section{Fixed effect covariates included in each analysis}

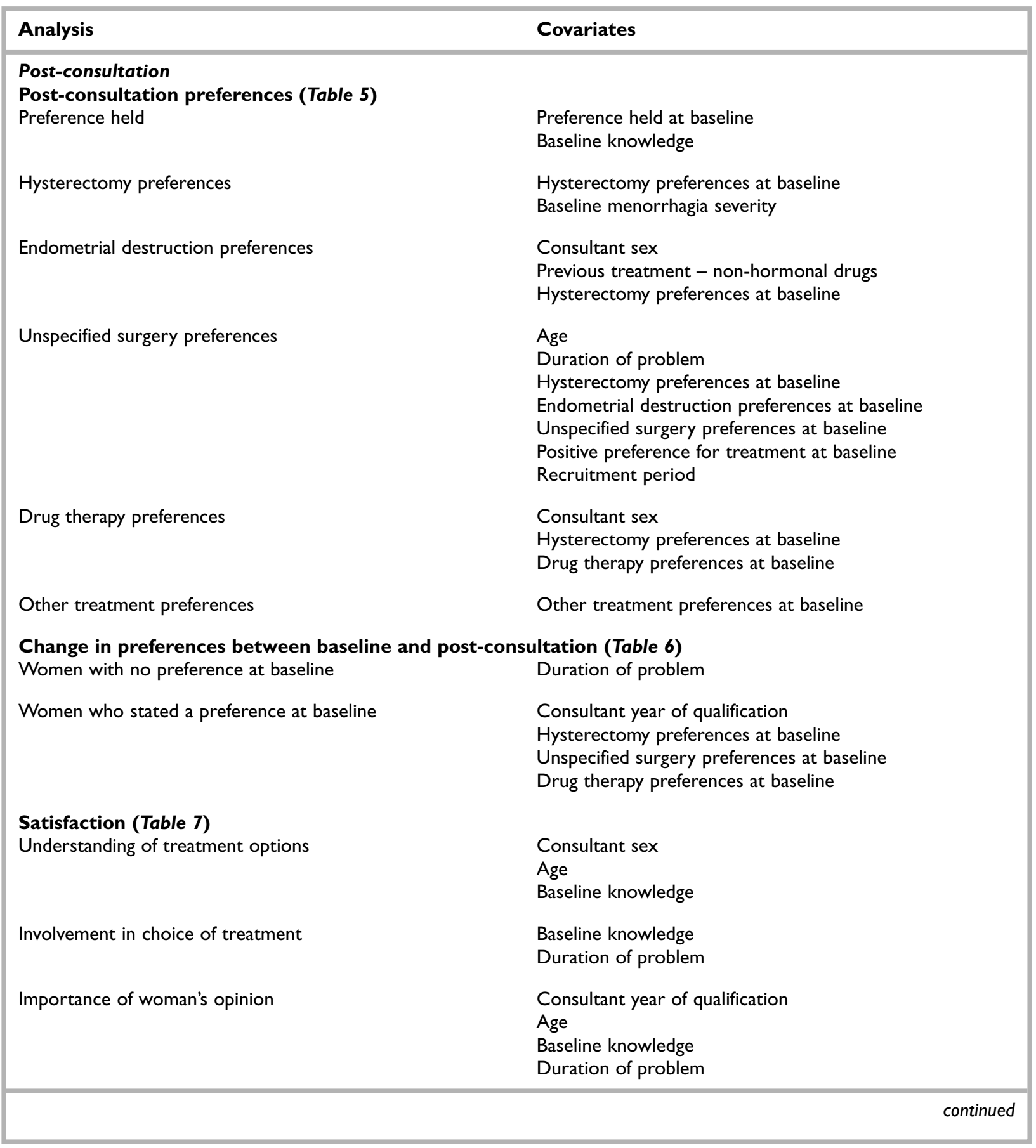


contd

\section{Analysis}

Short-term follow-up

Health status (Table 8 and Figure 2)

SF-36

Physical function

Social function

Role physical

Role emotional

Mental health

Energy/vitality

Pain

General health perception

EQ-5D

VAS

Tariff

Anxiety

Menorrhagia severity

Treatments undergone (Table 9)

Hysterectomy

Endometrial destruction

Drug therapy

Other treatment

\section{Covariates}

Consultant sex

Age

Baseline physical function

Length of follow-up

Baseline social function

Length of follow-up

Baseline role physical

Duration of problem

Length of follow-up

Baseline role emotional

Baseline mental health Length of follow-up

Baseline energy/vitality Length of follow-up

Baseline pain

Baseline menorrhagia severity

Length of follow-up

Baseline general health perception

Baseline EQ-5D VAS

Baseline EQ-5D tariff

Baseline anxiety

Baseline menorrhagia severity

Age

Baseline menorrhagia severity

Hysterectomy preferences at baseline

Unspecified surgery preferences at baseline

Previous treatment - OCP

Any previous surgery

Endometrial destruction preferences at baseline

Previous treatment - non-hormonal drugs

Hysterectomy preferences at baseline

Unspecified surgery preferences at baseline

Recruitment period

Agreement between preferences and treatments undergone (Table 10)

Baseline menorrhagia severity

Positive preference held at baseline

Satisfaction (Table II)

Involvement in choice of treatment

Consultant sex

Age

Baseline knowledge

Results of treatment

Consultant sex

None 
contd

\begin{tabular}{|c|c|}
\hline Analysis & Covariates \\
\hline $\begin{array}{l}\text { Long-term follow-up } \\
\text { Health status (Table I } 2 \text { and Figure 3) } \\
\text { SF-36 } \\
\text { Physical function }\end{array}$ & Baseline physical function \\
\hline Social function & $\begin{array}{l}\text { Baseline social function } \\
\text { Duration of problem }\end{array}$ \\
\hline Role physical & Baseline role physical \\
\hline Role emotional & Baseline role emotional \\
\hline Mental health & Baseline mental health \\
\hline Energy/vitality & Baseline energy/vitality \\
\hline Pain & Baseline pain \\
\hline General health perception & Baseline general health perception \\
\hline Menorrhagia severity & $\begin{array}{l}\text { Consultant year of qualification } \\
\text { Baseline menorrhagia severity }\end{array}$ \\
\hline $\begin{array}{l}\text { Treatments undergone (Table I3) } \\
\text { Hysterectomy }\end{array}$ & $\begin{array}{l}\text { Age } \\
\text { Baseline menorrhagia severity } \\
\text { Hysterectomy preferences at baseline } \\
\text { Unspecified surgery preferences at baseline } \\
\text { Positive preference held at baseline }\end{array}$ \\
\hline Endometrial destruction & $\begin{array}{l}\text { Baseline menorrhagia severity } \\
\text { Previous treatment - OCP } \\
\text { Endometrial destruction preferences at baseline } \\
\text { Unspecified surgery preferences at baseline } \\
\text { Negative preference held at baseline } \\
\text { Length of follow-up }\end{array}$ \\
\hline Drug therapy & $\begin{array}{l}\text { Hysterectomy preferences at baseline } \\
\text { Unspecified surgery preferences at baseline }\end{array}$ \\
\hline Other treatment & $\begin{array}{l}\text { Endometrial destruction preferences at baseline } \\
\text { Drug therapy preferences at baseline } \\
\text { Length of follow-up }\end{array}$ \\
\hline Hysterectomy undergone or waiting for & $\begin{array}{l}\text { Baseline menorrhagia severity } \\
\text { Hysterectomy preferences at baseline } \\
\text { Positive preference held at baseline }\end{array}$ \\
\hline $\begin{array}{l}\text { Agreement between preferences and treatments } \\
\text { Post-consultation preferences and treatments undergone } \\
\text { (Table 14) }\end{array}$ & $\begin{array}{l}\text { rgone } \\
\text { Baseline menorrhagia severity } \\
\text { Positive preference held at baseline } \\
\text { Length of follow-up }\end{array}$ \\
\hline $\begin{array}{l}\text { Last-stated preference and treatments undergone } \\
\text { (Table 15) }\end{array}$ & $\begin{array}{l}\text { Baseline menorrhagia severity } \\
\text { Hysterectomy preferences at baseline }\end{array}$ \\
\hline $\begin{array}{l}\text { Satisfaction (Table 16) } \\
\text { Involvement in choice of treatment }\end{array}$ & $\begin{array}{l}\text { Consultant sex } \\
\text { Age }\end{array}$ \\
\hline Results of treatment & $\begin{array}{l}\text { Consultant sex } \\
\text { Age }\end{array}$ \\
\hline Choices made & Duration of problem \\
\hline
\end{tabular}





\section{Appendix 8}

\section{Details of the multiple imputation procedures used to handle missing data in the economic evaluation}

$\mathrm{N}$ on-response and missing data are common problems in many evaluations of health technologies, especially those that rely on postal questionnaires to collect data. This problem is often simply ignored and analyses are conducted on cases with complete data. This approach assumes that data are missing completely at random, that there is no difference in effect between responders and non-responders. This assumption is seldom entirely valid and a more plausible assumption is that data are missing at random. This assumes that once observed differences between responders and nonresponders are adjusted for then there is no further difference in effect. ${ }^{48}$

This is the approach that we have taken to replace missing values for the utility measurement and resource use items in the economic analyses. However, simply adjusting for known differences and then replacing each missing value with an imputed estimate has the danger of adding spurious precision to the analysis conducted. This approach does not allow for extra uncertainty around the estimated missing value. To counter this we have employed MI, where each missing value is replaced by a number of different estimates; we have used five estimates for each missing value.

To impute these five estimates we have used a propensity scoring method of imputation ${ }^{48}$ as this allows for the non-normally distributed data. This method estimates the propensity score, or probability that an item of data is missing, for all cases conditional on a specified set of covariates. Cases with missing data are matched with non-missing cases that have a similar propensity score, and a value from these cases is randomly selected to replace the missing value.

The covariates specified for the MI process were chosen such that they were related to nonresponse, were related to the variable being imputed or were design variables. These covariates must have complete data. During the imputation process each variable with missing values is imputed in turn according to the degree of missingness (i.e. those with least missing values are imputed first) and then added to the list of covariates.

The imputation process was conducted for utility and resource use separately. For utility imputation, age, when in the study the woman was recruited, baseline menorrhagia severity, baseline knowledge, baseline utility, study arm, centre and age leaving full-time education were specified as covariates. Centre was used in place of the variable indicating consultant, as models with this variable produced problems with the propensity scoring technique. Age, recruitment period, study arm, centre and age leaving full-time education had complete data. For the other covariates, due to the small number of missing responses, single imputation was employed to impute missing values. Mean imputation was used to replace the nine missing values in knowledge and severity. For the 27 missing values in the utility measure, each dimension of the EQ-5D was imputed using modal imputation and then the tariff applied to give baseline utility. Missing values for 6-, 12- and 24-month EQ-5D dimensions were imputed from these covariates using the propensity scoring methods and then the tariff applied to give utility.

In the imputation of resource use, the specified covariates were age, when recruited, baseline menorrhagia severity, baseline knowledge, study arm, centre and age leaving full-time education. Baseline hysterectomy preference was also specified as a covariate due to its strong relation to treatments undergone; however, due to the level of missingness for this variable it was included with the resource use variables in the imputation process, but due to having fewer missing values than the other variables it was the first variable imputed and added to the covariate list. The resource use variables imputed were: hysterectomy, other surgery costs, drug therapy costs, test costs, number of gynaecology and other GP visits, and hospital gynaecology and other costs. It was 
not possible to impute inpatient stays accurately due to the sparse nature of the data; therefore the costs of inpatient stays and outpatient visits were combined to give variables for hospital gynaecology and other costs.

Rubin advises that when conducting analyses on multiply-imputed datasets the analysis be conducted on each imputation in turn and then combined. ${ }^{48}$ In constructing the BCA CIs used in the economic analyses, ${ }^{47} 1000$ bootstrap replications of the mean between-group differences were calculated and BCA CIs produced for each of the five imputed datasets. The 1000 mean between-group differences were then combined for each imputation to give a set of 5000 mean differences. The mean bias and acceleration parameter across the five imputed datasets was then applied to this combined dataset to give the BCA CIs reported in the analysis. 


\section{Health Technology Assessment Programme}

\section{Prioritisation Strategy Group}

\section{Members}

\section{Chair,}

Professor Kent Woods,

Director,

NHS HTA Programme, \&

Professor of Therapeutics

University of Leicester

Professor Bruce Campbell,

Consultant Vascular

\& General Surgeon,

Royal Devon \& Exeter Hospital
Professor Shah Ebrahim,

Professor in Epidemiology

of Ageing,

University of Bristol

Dr John Reynolds,

Clinical Director,

Acute General Medicine SDU,

Oxford Radcliffe Hospital
Dr Ron Zimmern,

Director, Public Health

Genetics Unit,

Strangeways Research

Laboratories, Cambridge

\section{HTA Commissioning Board}

\section{Members}

\section{Programme Director,} Professor Kent Woods, Director,

NHS HTA Programme, \& Professor of Therapeutics University of Leicester

\section{Chair,}

Professor Shah Ebrahim,

Professor in Epidemiology

of Ageing,

University of Bristol

\section{Deputy Chair,}

Professor Jon Nicholl, Director, Medical Care Research Unit,

University of Sheffield

Professor Douglas Altman, Director, ICRF Medical Statistics Group,

University of Oxford

Professor John Bond, Director, Centre for Health Services Research, University of Newcastle-upon-Tyne
Professor John Brazier, Director of Health Economics, University of Sheffield

Dr Andrew Briggs,

Research Fellow,

Institute of Health Sciences,

University of Oxford

Ms Christine Clark,

Freelance Medical Writer, Bury, Lancs

Professor Martin Eccles, Professor of

Clinical Effectiveness,

University of Newcastleupon-Tyne

Dr Andrew Farmer,

General Practitioner \&

NHS R\&D Clinical Scientist,

Institute of Health Sciences,

University of Oxford

Professor Adrian Grant,

Director, Health Services

Research Unit,

University of Aberdeen
Dr Alastair Gray,

Director, Health Economics

Research Centre,

Institute of Health Sciences,

University of Oxford

Professor Mark Haggard, Director, MRC Institute

of Hearing Research,

University of Nottingham

Professor Jenny Hewison, Academic Unit of Psychiatry

\& Behavioural Sciences,

University of Leeds

Professor Peter Jones,

University Department of Psychiatry,

University of Cambridge

Professor Alison Kitson, Director, Royal College of Nursing Institute, London

Professor Sarah Lamb,

Research Professor

in Physiotherapy,

University of Coventry
Dr Donna Lamping,

Head, Health Services

Research Unit,

London School of Hygiene

\& Tropical Medicine

Professor David Neal, Department of Surgery, University of Newcastleupon-Tyne

Professor Tim Peters,

Social Medicine,

University of Bristol

Professor Martin Severs, Professor in Elderly

Health Care,

University of Portsmouth

Dr Jonathan Shapiro, Senior Fellow, Health Services Management Centre, Birmingham

Dr Sarah Stewart-Brown, Director, Health Services Research Unit, University of Oxford

Dr Gillian Vivian, Consultant in Nuclear Medicine \& Radiology, Royal Cornwall Hospitals Trust, Truro 
continued

\begin{tabular}{|c|c|c|c|}
\hline $\begin{array}{l}\text { Chair, } \\
\text { Dr Ron Zimmern, } \\
\text { Director, Public Health } \\
\text { Genetics Unit, Strangeways } \\
\text { Research Laboratories, } \\
\text { Cambridge }\end{array}$ & $\begin{array}{l}\text { Dr Andrew Farmer, } \\
\text { General Practitioner \& NHS } \\
\text { R\&D Clinical Scientist, } \\
\text { Institute of Health Sciences, } \\
\text { University of Oxford }\end{array}$ & $\begin{array}{l}\text { Professor Jennie Popay, } \\
\text { Professor of Sociology } \\
\text { \& Public Health, } \\
\text { Institute for Health Research, } \\
\text { University of Lancaster }\end{array}$ & $\begin{array}{l}\text { Mrs Kathlyn Slack, } \\
\text { Professional Support, } \\
\text { Diagnostic Imaging \& } \\
\text { Radiation Protection Team, } \\
\text { Department of Health, } \\
\text { London }\end{array}$ \\
\hline
\end{tabular}

Members

Chair,

Dr John Reynolds,

Clinical Director,

Acute General Medicine SDU,

Oxford Radcliffe Hospital

Professor Tony Avery

Professor of Primary

Health Care,

University of Nottingham

Professor Iain T Cameron, Professor of Obstetrics

\& Gynaecology,

University of Southampton

Mr Peter Cardy,

Chief Executive,

Macmillan Cancer Relief,

London

\section{Diagnostic Technologies \& Screening Panel}

Epidemiology

Cambridge

David Elliman,

St. George's Hospital, London

Dr Tom Fahey,

Dr Andrew Farmer,

University of Oxford

Professor of Medicine,

University of Birmingham
Reproductive \& Child Health,
University of Birmingham

\section{Pharmaceuticals Panel}

Dr Christopher Cates,

GP \& Cochrane Editor,

Bushey Health Centre,

Bushey, Herts

Dr Karen A Fitzgerald,

Pharmaceutical Adviser,

Bro Taf Health Authority, Cardiff

Dr Felicity J Gabbay,

Managing Director,

Transcrip Ltd,

Milford-on-Sea, Hants

Mr Peter Golightly,

Director, Trent Medicines

Information Services,

Leicester Royal Infirmary

Dr Alastair Gray,

Director, Health Economics

Research Centre,

Institute of Health Sciences,

University of Oxford
Mrs Sharon Hart,

Managing Editor, Drug $\mathcal{E}$

Therapeutics Bulletin,

London

Dr Christine Hine,

Consultant in Public

Health Medicine,

Bristol South \& West

Primary Care Trust

Mrs Jeannette Howe, Deputy Chief Pharmacist,

Department of Health, London

Professor Robert Peveler Professor of Liaison Psychiatry, Royal South Hants Hospital, Southampton

Dr Frances Rotblat,

CPMP Delegate,

Medicines Control Agency, London
Dr Eamonn Sheridan, Consultant in Clinical

Genetics, St James's University Hospital, Leeds

Mrs Katrina Simister, New Products Manager, National Prescribing Centre, Liverpool

Professor Terence Stephenson, Professor of Child Health,

University of Nottingham

Dr Richard Tiner,

Medical Director,

Association of the British

Pharmaceutical Industry,

London

Professor Jenifer Wilson-

Barnett, Head of Florence

Nightingale School of Nursing

\& Midwifery, King's College,

London 
Members

Chair,
Professor Bruce Campbell,

Consultant Vascular \& General Surgeon, Royal Devon

\& Exeter Hospital

Professor John Bond,

Professor of Health

Services Research, Centre for

Health Services Research,

University of Newcastle-

upon-Tyne

Ms Judith Brodie,

Head of Cancer

Support Service,

Cancer BACUP, London

Ms Tracy Bury,

Head of

Research \& Development,

Chartered Society

of Physiotherapy, London

Mr Michael Clancy,

Consultant in A \& E Medicine,

Southampton General Hospital

Professor Collette Clifford, Professor of Nursing \&

Head of Research,

School of Health Sciences,

University of Birmingham

\section{Therapeutic Procedures Panel}

\begin{tabular}{|c|c|c|}
\hline $\begin{array}{l}\text { Dr Carl E Counsell, } \\
\text { Senior Lecturer in Neurology, } \\
\text { University of Aberdeen }\end{array}$ & $\begin{array}{l}\text { Dr Duncan Keeley, } \\
\text { General Practitioner, } \\
\text { Thame, Oxon }\end{array}$ & $\begin{array}{l}\text { Dr John C Pounsford, } \\
\text { Consultant Physician, } \\
\text { Frenchay Healthcare Trust, } \\
\text { Bristol }\end{array}$ \\
\hline $\begin{array}{l}\text { Dr Keith Dodd, } \\
\text { Consultant Paediatrician, } \\
\text { Derbyshire Children's Hospital, } \\
\text { Derby }\end{array}$ & $\begin{array}{l}\text { Dr Phillip Leech, } \\
\text { Principal Medical Officer } \\
\text { for Primary Care, } \\
\text { Department of Health, } \\
\text { London }\end{array}$ & $\begin{array}{l}\text { Professor Mark Sculpher, } \\
\text { Professor of } \\
\text { Health Economics, } \\
\text { Institute for Research } \\
\text { in the Social Services, }\end{array}$ \\
\hline $\begin{array}{l}\text { Mr John Dunning, } \\
\text { Consultant Cardiothoracic }\end{array}$ & $\begin{array}{l}\text { Mr George Levvy, } \\
\text { Chief Executive, }\end{array}$ & University of York \\
\hline $\begin{array}{l}\text { Surgeon, Papworth Hospital } \\
\text { NHS Trust, Cambridge }\end{array}$ & $\begin{array}{l}\text { Motor Neurone } \\
\text { Disease Association, } \\
\text { Northampton }\end{array}$ & $\begin{array}{l}\text { Dr Ken Stein, } \\
\text { Senior Lecturer in } \\
\text { Public Health, }\end{array}$ \\
\hline $\begin{array}{l}\text { Mr Jonothan Earnshaw, } \\
\text { Consultant Vascular Surgeon, } \\
\text { Gloucestershire Royal Hospital, } \\
\text { Gloucester }\end{array}$ & $\begin{array}{l}\text { Professor James Lindesay, } \\
\text { Professor of Psychiatry } \\
\text { for the Elderly, } \\
\text { University of Leicester }\end{array}$ & $\begin{array}{l}\text { Peninsular Technology } \\
\text { Assessment Group, } \\
\text { University of Exeter }\end{array}$ \\
\hline $\begin{array}{l}\text { Professor Gene Feder, } \\
\text { Professor of Primary } \\
\text { Care R\&D, St Bartholomew's } \\
\text { \& the London, } \\
\text { Queen Mary's School of } \\
\text { Medicine \& Dentistry, } \\
\text { University of London }\end{array}$ & $\begin{array}{l}\text { Professor Rajan Madhok, } \\
\text { Medical Director \& } \\
\text { Director of Public Health, } \\
\text { North \& East Yorkshire } \\
\text { \& Northern Lincolnshire } \\
\text { Strategic Health Authority, } \\
\text { York }\end{array}$ & \\
\hline $\begin{array}{l}\text { Professor Richard Johanson, } \\
\text { Consultant \& Senior Lecturer, } \\
\text { North Staffordshire Infirmary } \\
\text { NHS Trust, Stoke-on-Trent } \\
\text { (deceased Feb 2002) }\end{array}$ & $\begin{array}{l}\text { Dr Mike McGovern, } \\
\text { Senior Medical Officer, } \\
\text { Heart Team, } \\
\text { Department of Health, } \\
\text { London }\end{array}$ & \\
\hline
\end{tabular}


continued

Members

\section{Expert Advisory Network}

Mr Gordon Aylward,

Chief Executive,

Association of British

Health-Care Industries,

London

Mr Shaun Brogan,

Chief Executive,

Ridgeway Primary Care Group,

Aylesbury, Bucks

Mr John A Cairns,

Reader in Health Economics,

Health Economics

Research Unit,

University of Aberdeen

Professor Nicky Cullum,

Director of Centre for

Evidence-Based Nursing,

University of York

Dr Katherine Darton,

Information Unit,

MIND - The Mental

Health Charity, London

Professor Carol Dezateux,

Professor of

Paediatric Epidemiology,

Institute of Child Health,

London

Professor Pam Enderby, Dean of Faculty of Medicine Institute of General Practice \& Primary Care,

University of Sheffield

Mr Leonard R Fenwick,

Chief Executive,

Freeman Hospital,

Newcastle-upon-Tyne
Professor David Field, Professor of

Neonatal Medicine,

The Leicester Royal Infirmary NHS Trust

Mrs Gillian Fletcher, Antenatal Teacher \&

Tutor \& President,

National Childbirth

Trust, Henfield,

West Sussex

Ms Grace Gibbs,

Deputy Chief Executive

Director for Nursing,

Midwifery \& Clinical

Support Services,

West Middlesex

University Hospital,

Isleworth, Middlesex

Dr Neville Goodman,

Consultant Anaesthetist,

Southmead Hospital, Bristol

Professor Robert E Hawkins,

CRC Professor \& Director

of Medical Oncology,

Christie Hospital NHS Trust,

Manchester

Professor F D Richard Hobbs,

Professor of Primary Care

\& General Practice,

University of Birmingham

Professor Allen Hutchinson,

Director of Public Health \&

Deputy Dean of ScHARR,

University of Sheffield
Professor David Mant,

Professor of General Practice,

Institute of Health Sciences,

University of Oxford

Professor Chris Price,

Director of Clinical Research,

Bayer Diagnostics Europe,

Stoke Poges, Berks

Professor Alexander Markham,

Director,

Director, College of Health,

St James's University Hospital, London

Leeds

Dr Chris McCall,

General Practitioner,

The Hadleigh Practice,

Corfe Mullen, Dorset

Professor Alistair McGuire,

Professor of Health Economics, Professor Ala Szczepura,

London School of Economics,

University of London

Director, Centre for

Health Services Studies,

University of Warwick

Dr Peter Moore,

Freelance Science Writer,

Ashtead, Surrey

Dr Andrew Mortimore,

Consultant in Public

Health Medicine,

Southampton City Primary

Care Trust

Dr Sue Moss,

Associate Director,

Cancer Screening

Evaluation Unit,

Institute of Cancer Research,

Sutton, Surrey

Mrs Julietta Patnick,

National Coordinator

NHS Cancer

Screening Programmes,

Sheffield
Dr Ross Taylor,

Senior Lecturer,

Department of General

Practice \& Primary Care.

University of Aberdeen

Mrs Joan Webster,

Consumer member,

HTA - Expert

Advisory Network 



\section{Feedback}

The HTA Programme and the authors would like to know your views about this report.

The Correspondence Page on the HTA website (http://www.ncchta.org) is a convenient way to publish your comments. If you prefer, you can send your comments to the address below, telling us whether you would like us to transfer them to the website.

We look forward to hearing from you.

Copies of this report can be obtained from:

The National Coordinating Centre for Health Technology Assessment,

Mailpoint 728, Boldrewood,

University of Southampton,

Southampton, SOI6 7PX, UK.

Fax: +44 (0) 2380595639 Email: hta@soton.ac.uk

http://www.ncchta.org 